\title{
Effects of structure on
}

\section{hydrogel microbead function}

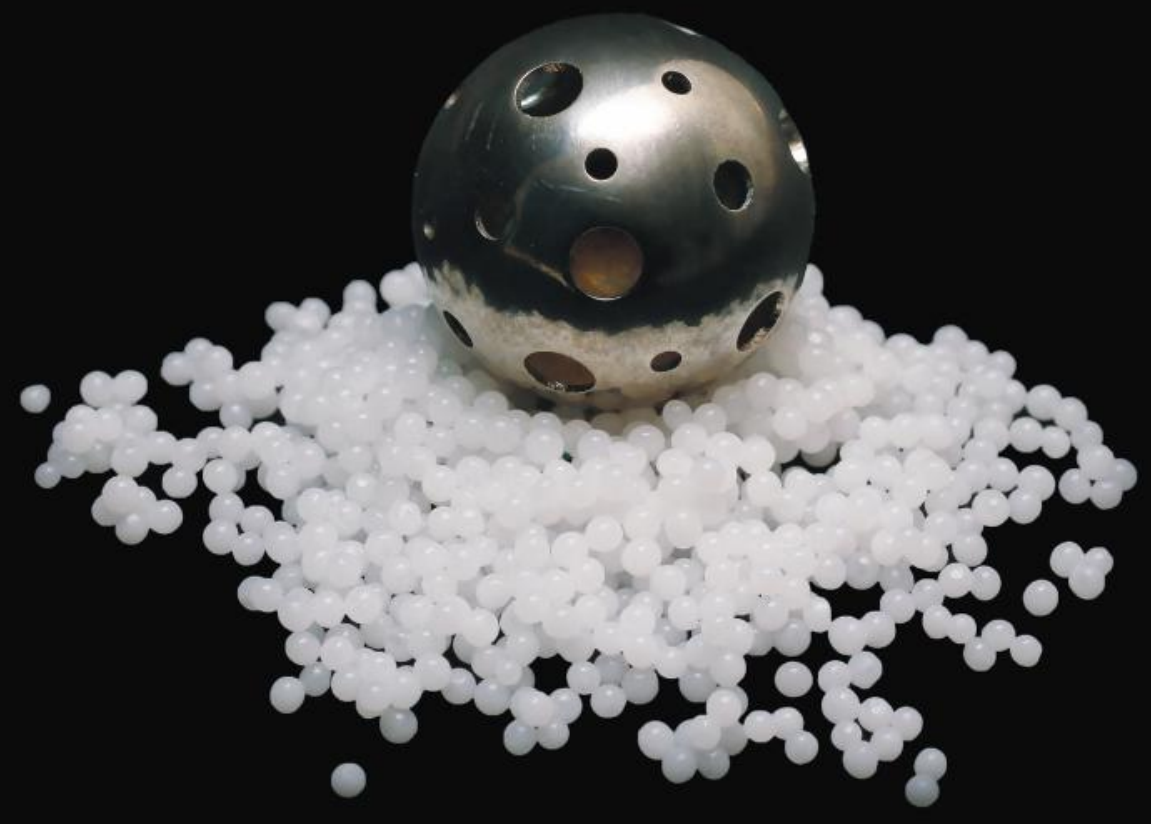

Pauline van Leusden 


\section{Propositions}

1. The method of gelation is more important to microbead strength than the hydrocolloid they are made from.

(this thesis)

2. Diffusion of lipase into an oil-loaded alginate microbead should be described by the Maxwell-Cattaneo equation.

(this thesis)

3. The information in the article of Dönmez et al. does not sufficiently substantiate their conclusion that polyphenols significantly modify syneresis of set yogurts. (Dönmez, Ö.; Mogol, B.A.; Gökmen, V., Syneresis and rheological behaviors of set yogurt containing green tea and green coffee powders. Journal of Dairy Science 2017, 100(2), 901-907)

4. The work of Werthmann et al. should be known to all parents of young children. (Werthmann, J.; Jansen, A.; Havermans, R.; Nederkoorn, C.; Kremers, S.; Roefs, A., Bits and pieces. Food texture influences food acceptance in young children. Appetite 2015, 84, 181-187)

5. Producing a PhD thesis is like producing a piece of silver jewellery.

6. Bands should discourage mosh pits during their concerts.

Propositions belonging to the $\mathrm{PhD}$ thesis, entitled "Effects of structure on hydrogel microbead function"

Pauline van Leusden, Wageningen, 4 July 2018 



\title{
Effects of structure on hydrogel microbead function
}

\author{
Pauline van Leusden
}




\section{Thesis committee}

\section{Promotors}

Prof. Dr E. van der Linden

Professor of Physics and Physical Chemistry of Foods

Wageningen University \& Research

Dr L.M.C. Sagis

Associate professor, Physics and Physical Chemistry of Foods

Wageningen University \& Research

\section{Co-promotors}

Prof. Dr habil. M.A.B. Postema

Distinguished Professor of Biomedical Engineering

University of the Witwatersrand, Johannesburg, South Africa

Dr G.J.M. den Hartog

Assistant Professor Pharmacology and Toxicology

Maastricht University

\section{Other members}

Prof. Dr C.G.P.H. Schroën, Wageningen University \& Research

Prof. Dr F.A.M. Leermakers, Wageningen University \& Research

Dr A.T. Poortinga, Eindhoven University of Technology

Dr N.J. Zuidam, Unilever R\&D, Vlaardingen

This research was conducted under the auspices of the Graduate School VLAG (Advanced studies in Food Technology, Agrobiotechnology, Nutrition and Health Sciences). 


\title{
Effects of structure on hydrogel microbead function
}

\author{
Pauline van Leusden
}

\section{Thesis}

submitted in fulfilment of the requirements for the degree of doctor at Wageningen University

by the authority of the Rector Magnificus,

Prof. Dr A.P.J. Mol,

in the presence of the

Thesis Committee appointed by the Academic Board

to be defended in public

on Wednesday 4 July 2018

at 1.30 p.m. in the Aula. 
Pauline van Leusden

Effects of structure on hydrogel microbead function, 137 pages.

$\mathrm{PhD}$ thesis, Wageningen University, Wageningen, the Netherlands (2018)

With references, with summary in English

ISBN: 978-94-6343-856-8

DOI: https://doi.org/10.18174/446239 


\section{Contents:}

Chapter 1: Introduction

Chapter 2: Strength of microbeads for the encapsulation of heat sensitive, hydrophobic components

Chapter 3: Structure engineering of filled protein microbeads to tailor release of oil droplets in gastric digestion

Chapter 4: Permeation of probe molecules into alginate microbeads: Effect of salt and processing

Chapter 5: Lipase diffusion in oil-filled, alginate micro- and 85 macrobeads

Chapter 6: General discussion

Summary

Acknowledgements 



\title{
Chapter 1
}

\author{
Introduction
}


In this thesis, we investigate how different production parameters influence the microstructure of protein and polysaccharide hydrogel microbeads, and how that in turn influences their functional properties as encapsulation devices in various systems.

Hydrogel microbeads can be used to trap, protect and deliver components such as living cells and chemicals. How well these beads function as encapsulation devices is dependent on the bead strength, breakdown profile and rate at which external components diffuse in. Hydrogel microbeads can be made in different sizes from a variety of food-grade biopolymers, with a variety of gelling mechanisms and gelling agents. Most current research focuses on building hydrogel microbeads for a particular function in a particular system, where only one of the factors is varied. We create a better understanding of how the different production processes influence the characteristics of hydrogel beads as encapsulation devices.

In this introduction the building blocks and production methods of microbeads are described, and different uses and release methods of microbeads are discussed. At the end of this introduction the outline of this thesis is given.

\subsection{Delivery systems}

Encapsulation is a process in which one or more components are enclosed in a matrix, to protect them from the outside environment. Encapsulation systems can improve efficacy and reduce toxicity of the encapsulated components [1-3]. The most common example of encapsulation is a soft shell enclosing medication to be taken orally. In this case the capsule is a delivery system, it protects its content until it arrives in the stomach, where the capsule disintegrates, and the content is released. Sometimes it is required that the encapsulation systems are small, with dimensions on the microscale. There are many types of matrices which can be used to protect components in microsystems [4]. One of these is the hydrogel microbead.

Products which can be encapsulated in a hydrogel matrix are very diverse and include living cells and chemicals. Cells which have been encapsulated include: Islet cells [5, 6], Stem cells [7, 8], Bacteria [9-11] and Chondrocytes 
[12]. Chemicals which have been encapsulated include: oil droplets [13, 14], proteins $[15,16]$ and drugs $[17,18]$.

Encapsulation systems can have various modes to release of their load. The load can be released by diffusion, fracturing, dissolution, and biodegradation [19]. In diffusive systems, the load slowly diffuses out of a semi-permeable system. This generally allows for a sustained and long-term release of the load. In fracturing the load is released by forcibly breaking the system, for example, by chewing. Dissolution is when the coating material is dissolved or melted, as happens in the drug capsule described above. Biodegradation is when biological systems, such as bacteria or the digestive tract, break down the capsule so the load is released. The mechanical strength, matrix stability, and porosity are thus very important factors for the eventual application of the microsystems. The polymer from which the gels are made and how they are gelled is very important for these characteristics. In this thesis we investigated two polymers in specific: whey protein isolate (WPI) and alginate.

\subsection{Polymers}

\section{Whey protein isolate (WPI)}

Proteins are well suited for the encapsulation of compounds because they are safe for consumption, have a high nutritional value and are able to form gels and emulsions [20, 21]. Proteins can however induce allergic reactions and are thus not suited for some consumers. Proteins are a polyionic compound build of individual amino acids bound by peptide bonds. The side groups of the amino acid can be charged and reactive, and they therefore determine the fold of the protein and its isoelectric point (IEP or pI). The isoelectric point is the $\mathrm{pH}$ where the overall charge of the protein is neutral. WPI is a leftover product of the cheese making industry, and is a mixture of proteins (Table 1.1). The main constituent of WPI is $\beta$-lactoglobulin, which is a globular protein with 2 disulphide bridges and one free thiol group. $\alpha$-Lactalbumin is the second most prevalent protein, and contains four disulphide bonds [22]. In addition, a small fraction of bovine serum albumin and immunoglobulins is present. Each protein has its own IEP, however the overall IEP is generally regarded to be 5.1 [23]. 
Table 1.1: Physical characteristics of whey proteins, taken from [23]

\begin{tabular}{l|cccc}
\multicolumn{1}{l}{ Protein } & $\%$ & IEP & $\begin{array}{l}\text { Molecular } \\
\text { weight }(\mathrm{Da})\end{array}$ & $\begin{array}{l}\text { Denaturation } \\
\text { Temperature }\left({ }^{\circ} \mathrm{C}\right)\end{array}$ \\
\hline B-lactoglobulin & 60 & 5.2 & 18400 & 78 \\
$\alpha$-lactalbumin & 22 & $4.8-5.1$ & 14200 & 62 \\
immunoglobins & 9.1 & $5.5-6.8$ & $15-96 \cdot 10^{4}$ & 72 \\
bovine serum albumin & 5.5 & $4.8-5.1$ & 66000 & 64
\end{tabular}

Several methods can be used to gel WPI. Heat-set gelation of WPI is an irreversible two-step aggregation process where the protein is first unfolded at elevated temperatures, where it subsequently aggregates [24]. Most proteins start unfolding around a temperature of $80^{\circ} \mathrm{C}$ [25]. After unfolding, the reactive groups of the amino acids are free to rearrange and make new bonds. These bonds are most prominently sulphur bridges and electrostatic interactions, but also hydrophobic, van der Waals, and hydrogen interactions $[26,27]$. A gel is formed when the proteins are present above a certain critical concentration, and rearranged in such a way that a space spanning network is created.

During heat-set gelation, the processes of unfolding, aggregation and gelation occur in one step (Figure 1.1). Cold-set gelation is a two-step process. In the first step a protein solution, below the critical concentration, is heated so that small aggregates are created. In the second step the chilled aggregate solution is gelled, which can be achieved by the addition of acid, salt, protein crossing enzymes, or additional processing steps [28-32]. Cold-set gelation may be advantageous when components are present which are sensitive to heat, such as living cells or vitamins, because they can be added after the first gelation step. In this thesis we have used heat-, acid- and salt-induced gelation. 


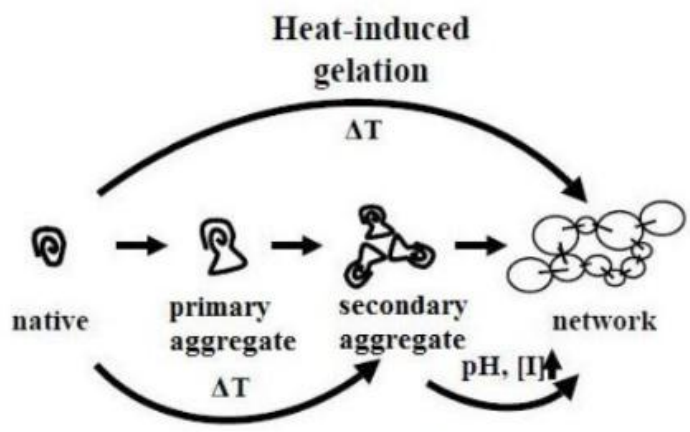

Cold-set gelation

Figure 1.1: Schematic representation of heat- and cold-set gelation, taken from [28]

The $\mathrm{pH}$ has a large influence on the structure of a gel [33, 34]. Far from the IEP, the proteins are more charged and repel each other. In cold-set acidinduced gelation, the aggregates can be gelled by adjusting the $\mathrm{pH}$ closer to the IEP, thereby reducing the repulsion, allowing the aggregates to approach each other, and allowing further aggregation [23, 35, 36]. Salt screens the repulsive forces between the aggregates, thereby also inducing aggregation. Salts of all valences screen the charges, however divalent salts such as $\mathrm{Ca}^{2+}$ have the additional effect that they can form salt bridges between two negatively charged groups. Divalent salts are therefore needed in lower concentrations than monovalent salt for cold-set, salt-induced gelation [37].

\section{Alginate}

Alginate is a naturally occurring polysaccharide extracted from brown seaweed [38]. It is well suited for encapsulations systems because it is lowcost, easy to use, bio-degradable and non-toxic [39]. A polysaccharide is a polyionic compound made from sugar molecules. Alginate consists of $\beta$-Dmannuronic and $\alpha$-L-guluronic acid, linked with glucose linkages, and is linear and unbranched. Both mannuronic and guluronic acid contain a carboxylic acid group, which means that above their pKa (3.5) [40] they are negatively charged. Two guluronic acid residues located next to each other create a negatively charged 'cup'. Alginate can form bonds with adjacent alginate molecules when two of these cups are bound together by a multivalent cation, usually a calcium ion, thereby forming an egg box like structure 
(Figure 1.2). The alginate solution will gel when more of these bonds are formed throughout the solution. Unlike with WPI, alginate only contains negative charges and can thus, in the absence of multivalent cations, not form bonds within itself. Alginate therefore does not require an unfolding step. Alginate can also be gelled by lowering the $\mathrm{pH}$ to below the $\mathrm{pKa}$, where the sugars will become neutral and associate with themselves, similar to what proteins do when approaching their IEP. However, because this only happens at very low $\mathrm{pH}$, lower than is practical for delivery systems, this gelling mechanism is not further considered in this thesis.
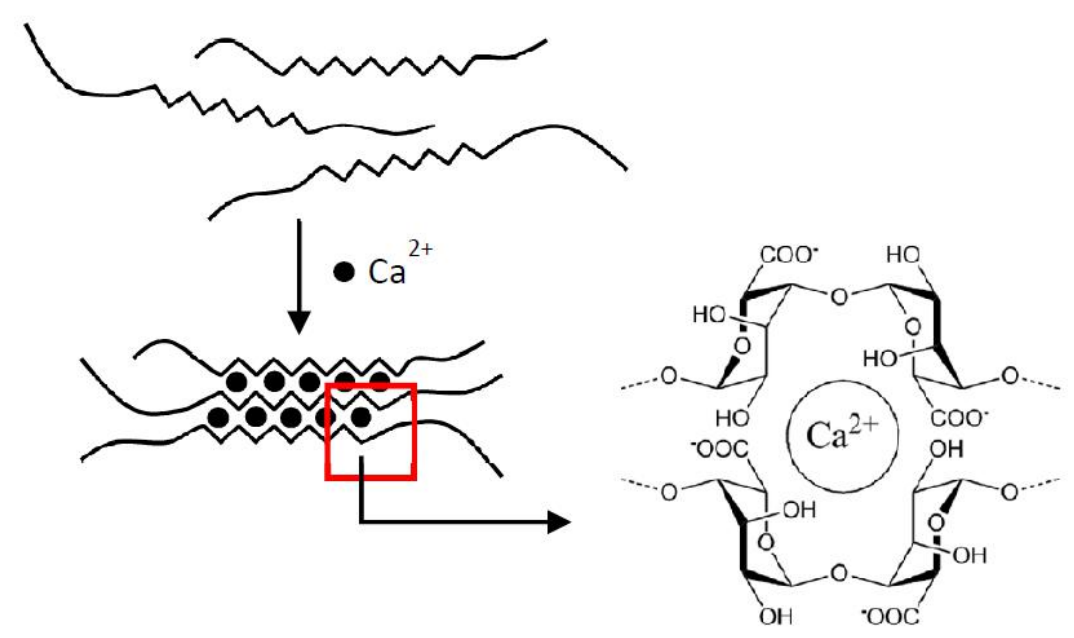

Figure 1.2: Formation of an alginate gel by calcium cations, taken from [41].

\subsection{Microbead production}

The size of the delivery system is very important to its application. Microbeads can be formed by a multitude of methods. Beads with diameters between 0.5 and $5 \mathrm{~mm}$, in this thesis called macrobeads, have been made by dripping a solution of polymer into a solution of gelling agent [42]. There is a limit to how small these beads can be made, which is governed by the dimensions of the extruding device, and the characteristics of the polymer solution [43]. The size of the beads can be further reduced to $50 \mu \mathrm{m}$ by more advance systems based on the dripping technique. An alternative to the dripping technique is air atomization which can form particles of between 5 - 
$200 \mu \mathrm{m}$ [44]. A detailed review of microbead production methods was published by Paques, et al. [42].

Emulsification has also been used to create micro- and nanobeads, and a schematic representation of this method can be found in Figure 1.3. In this process a polyionic solution is emulsified into an oil phase (A) after which the beads are gelled (B). The beads can then be washed, and transferred to a different continuous phase, such as water $(\mathrm{C})$. In this method, the droplets can again be gelled with heat, salt or acid. The eventual bead size depends on the emulsification technique and intensity. Saglam et al. have made heat-set $25 \%$ WPI beads with a diameter between 1 and $10 \mu \mathrm{m}$ [45]. Paques et al. have made calcium gelled alginate beads, with a diameter between $200 \mathrm{~nm}$ and $10 \mu \mathrm{m}$ [46].
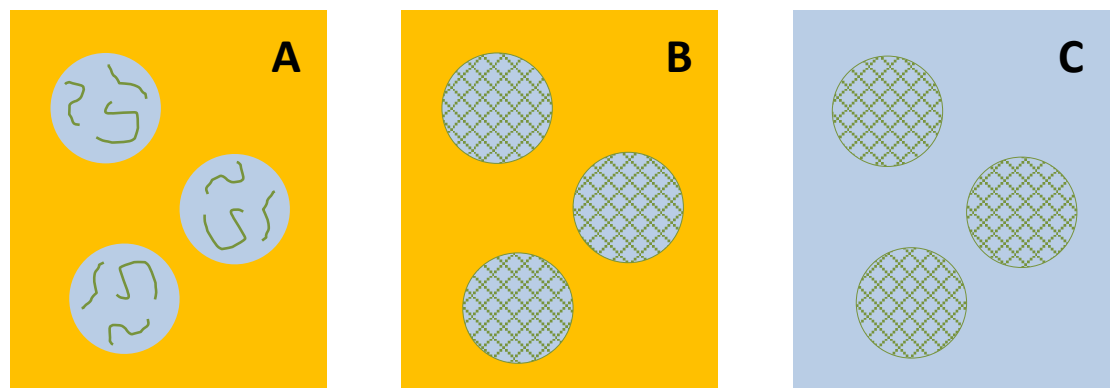

Figure 1.3: Formation of hydrogel microbeads by emulsification. A solution of polyions is emulsified into an oil phase (A), then the droplets are gelled (B), after which they are transferred to a different continuous phase, in this case water $(C)$.

\subsection{Diffusion}

The microbeads studied in this thesis are hydrogels, and thus porous objects. Small water-soluble molecules will be able to diffuse into or out of the bead. When living cells are encapsulated it is essential for nutrients to diffuse in, and waste products to diffuse out of the matrix. The rate of these processes is very important for the survival of the cells. Diffusion is driven by concentration gradients, and the flux of diffusing material can be described by Fick's first law: 


$$
J_{x}=-\mathrm{D} \frac{\partial C}{\partial x}
$$

Where $\mathrm{J}_{\mathrm{x}}$ is the flux in mol m $\mathrm{m}^{-2} \mathrm{~s}^{-1}, \mathrm{C}$ is the concentration in $\mathrm{mol} \mathrm{m} \mathrm{m}^{-3}$, $\mathrm{x}$ is the position in $\mathrm{m}$, and $\mathrm{D}$ is the diffusion coefficient in $\mathrm{m}^{2} \mathrm{~s}^{-1}$. This gives a parabolic differential equation where a change in concentration affects the entire system with unbounded speed. This is an unrealistic model for diffusion of components in a hydrogel and we will formulate a more appropriate model in chapter 5 .

The diffusion of a component into or out of a hydrogel microbead is determined by many factors, and these factors can be divided into characteristics of: the hydrogel bead, the diffusing component, and the continuous phase. Important hydrogel characteristics are: 1) the density of the gelled network, 2) the methodology used to make the beads, 3) the hydrocolloid from which the gel is made, 4) the size of the beads. The density influences the pore size, a higher density causes pores to become smaller [47, 48]. The methodology used affects the structure and porosity of the gel [14]. The hydrocolloid is important because it may attract or repel the diffusing component [48, 49]. The bead size influences the diffusion because smaller beads have a larger surface area per volume, compared to bigger beads $[47$, 50].

Important characteristics of the diffusing component are: 1) its size, 2) its shape, and 3) its charge. Bigger components diffuse slower [51], and at a certain size the component is too big to diffuse into the bead, which is often referred to as the molecular weight cut off size. With respect to shape, molecules come in a variety of shapes ranging from spheres to chains [52]. A component with a long, thin structure will diffuse faster than a spherical component with the same weight because the chain has the dimensions to be able to enter small pores where the spherical component cannot. The charge of the component $[51,53]$ will affect its interactions with the bead matrix, and depending on its charge the component may be attracted or repelled by the hydrogel matrix.

Important environmental conditions are: 1) the $\mathrm{pH}, 2$ ) the temperature, and 3) the ionic strength $[51,53,54]$. The $\mathrm{pH}$ influences the charge and conformation of the gel and the diffusing component [53]. The rate of diffusion is faster 
when the temperature is higher. The ionic strength affects the range of the electrostatic repulsion or attraction, through its effect on the Debye length.

The Debye length decreases with increasing ionic strength. When both the diffusing component and the hydrogel matrix carry a similar charge (e.g. negative) a lower salt concentration will give a larger Debye length, and this will decrease the effective porosity of the hydrogel matrix, and increase the effective size of the diffusing component.

\subsection{Hydrogel beads in food systems}

As mentioned above, the environment in which the microbead is to be used is an important factor in deciding the required characteristics of the microbeads. Encapsulation in food products is usually for the protection of bioactive components or probiotics [10,21, 55-58]. Foods may be stored for prolonged times and therefore require heat-treatment or extra preservation techniques such as drying. In food the beads will generally be in a neutral or slightly acidic environment with a low salt content. Particles in foods can give a sandy or gritty sensation, but beads smaller than $25 \mu \mathrm{m}$ do not have negative effects on taste [59]. Once consumed, the beads will go to the stomach, where there is a very low $\mathrm{pH}$, a higher salt content, and several types of digestive enzymes such as pepsin, which break down protein [60]. After, on average, 2 hours in the stomach, the beads move to the intestine where the $\mathrm{pH}$ is raised to neutral and slightly higher. Here, also other enzymes are added, which break down fat, protein and starch. The food resides in the intestine for approximately 2.5 hours [60]. The changing environment which the beads encounter gives opportunities for triggered release systems. Hydrogel beads made of proteins can be used for release in the stomach, where the pepsin will release the components carried within. Beads in which a compound, possibly captured in oil droplets, is bound in a matrix which does not digest in the stomach, can be used for protection in the stomach and active release in the intestine. 


\subsection{Aim and outline of this thesis}

The aim of the research reported in this thesis was to investigate the influence of the production of microbeads on their functionality as encapsulation devices. Factors that are important to the functionality are: the strength (chapter 2), breakdown behaviour (chapter 3) and diffusion of components (chapter 4 and 5).

In chapter 2 we investigate the influence of the building blocks, gelling agent and gelling method on the strength of microbeads.

In chapter 3 we produce WPI hydrogel beads with different methods and look at their breakdown behaviour in a simulated gastric systems by measuring the release of entrapped oil droplets.

In chapter 4 we describe the influence of alginate concentration, gelling agent concentration, and salt concentration in the environment on the diffusion of protein probes into alginate micro- and macrobeads.

In chapter 5 we investigate the diffusion of lipase into oil-filled alginate microand macrobeads in a simulated intestinal system.

Chapter 6 is a general discussion of this research in which findings, additional research into increasing hydrogel microbead functionality, and future possibilities are discussed. 


\section{References:}

1. Kumar, M., Nano and microparticles as controlled drug delivery devices. Journal of Pharmacy \& Pharmaceutical Sciences, 2000. 3(2): p. 234-258.

2. F. Gibbs, S.K.I.A.C.N.M.B., Encapsulation in the food industry: a review. International Journal of Food Sciences and Nutrition, 1999. 50(3): p. 213-224.

3. Nedovic, V., et al., An overview of encapsulation technologies for food applications. Procedia Food Science, 2011. 1: p. 1806-1815.

4. McClements, D.J., Emulsion Design to Improve the Delivery of Functional Lipophilic Components. Annual Review of Food Science and Technology, 2010. 1: p. 241-269.

5. Lim, F. and A.M. Sun, Microencapsulated islets as bioartificial endocrine pancreas. Science, 1980. 210(4472): p. 908-910.

6. Iwata, H., et al., Feasibility of agarose microbeads with xenogeneic islets as a bioartificial pancreas. Journal of Biomedical Materials Research Part A, 1994. 28(9): p. 1003-1011.

7. Zhou, H. and H.H.K. Xu, The fast release of stem cells from alginate-fibrin microbeads in injectable scaffolds for bone tissue engineering. Biomaterials, 2011. 32(30): p. 7503-7513.

8. Penolazzi, L., et al., Encapsulation of mesenchymal stem cells from Wharton's jelly in alginate microbeads. Tissue Engineering Part C: Methods, 2009. 16(1): p. 141155.

9. Covarrubias, S.A., et al., Alginate beads provide a beneficial physical barrier against native microorganisms in wastewater treated with immobilized bacteria and microalgae. Applied Microbiology and Biotechnology, 2012.93(6): p. 2669-2680.

10. Lee, K.-Y. and T.-R. Heo, Survival of Bifidobacterium longumImmobilized in calcium alginate beads in simulated gastric juices and bile salt solution. Applied and Environmental Microbiology, 2000. 66(2): p. 869-873.

11. Sohail, A., et al., Survivability of probiotics encapsulated in alginate gel microbeads using a novel impinging aerosols method. International Journal of Food Microbiology, 2011. 145(1): p. 162-168.

12. Bonaventure, J., et al., Reexpression of Cartilage-Specific Genes by Dedifferentiated Human Articular Chondrocytes Cultured in Alginate Beads. Experimental Cell Research, 1994. 212(1): p. 97-104.

13. Chan, E.-S., Preparation of Ca-alginate beads containing high oil content: Influence of process variables on encapsulation efficiency and bead properties. Carbohydrate Polymers, 2011. 84(4): p. 1267-1275.

14. van Leusden, P., et al., Structure engineering of filled protein microbeads to tailor release of oil droplets in gastric digestion. Food \& Function, 2016. 7(8): p. 35393547.

15. Hari, P., T. Chandy, and C.P. Sharma, Chitosan/calcium-alginate beads for oral delivery of insulin. Journal of Applied Polymer Science, 1996. 59(11): p. 1795-1801.

16. O'Neill, G.J., et al., Whey microbeads as a matrix for the encapsulation and immobilisation of riboflavin and peptides. Food Chemistry, 2014. 160: p. 46-52.

17. Pasparakis, G. and N. Bouropoulos, Swelling studies and in vitro release of verapamil from calcium alginate and calcium alginate-chitosan beads. International Journal of Pharmaceutics, 2006. 323(1-2): p. 34-42.

18. Liu, J., et al., Magnetically sensitive alginate-templated polyelectrolyte multilayer microcapsules for controlled release of doxorubicin. The Journal of Physical Chemistry C, 2010. 114(17): p. 7673-7679.

19. Ko, S. and S. Gunasekaran, Controlled Release of Food Ingredients, in Nano- and Microencapsulation for Foods. 2014, John Wiley \& Sons, Ltd. p. 325-343. 
20. Gunasekaran, S., S. Ko, and L. Xiao, Use of whey proteins for encapsulation and controlled delivery applications. Journal of Food Engineering, 2007. 83(1): p. 31-40.

21. Beaulieu, L., et al., Elaboration and Characterization of Whey Protein Beads by an Emulsification/Cold Gelation Process: Application for the Protection of Retinol. Biomacromolecules, 2002. 3(2): p. 239-248.

22. Fox, P. and P. McSweeney, Advanced dairy chemistry. Vol. 1, Proteins. P. A. 2003: Kluwer Academic/Plenum.

23. Bryant, C.M. and D.J. McClements, Molecular basis of protein functionality with special consideration of cold-set gels derived from heat-denatured whey. Trends in Food Science \& Technology, 1998. 9(4): p. 143-151.

24. Puyol, P., M.D. Pérez, and D.S. Horne, Heat-induced gelation of whey protein isolates (WPI): effect of $\mathrm{NaCl}$ and protein concentration. Food Hydrocolloids, 2001. 15(3): p. 233-237.

25. Corredig, M. and D.G. Dalgleish, Effect of temperature and $\mathrm{pH}$ on the interactions of whey proteins with casein micelles in skim milk. Food Research International, 1996. 29(1): p. 49-55.

26. Totosaus, A., et al., A review of physical and chemical protein-gel induction. International journal of food science \& technology, 2002. 37(6): p. 589-601.

27. Dill, K.A., Dominant forces in protein folding. Biochemistry, 1990. 29(31): p. 71337155.

28. Alting, A.C., et al., Number of thiol groups rather than the size of the aggregates determines the hardness of cold set whey protein gels. Food Hydrocolloids, 2003. 17(4): p. 469-479.

29. Sok Line, V.L., G.E. Remondetto, and M. Subirade, Cold gelation of $\beta$-lactoglobulin oil-in-water emulsions. Food Hydrocolloids, 2005. 19(2): p. 269-278.

$30 . \quad$ Rosa, P., et al., Cold gelation of whey protein emulsions. Journal of Texture Studies, 2006. 37(5): p. 516-537.

31. Ju, Z.Y. and A. Kilara, Gelation of pH-aggregated whey protein isolate solution induced by heat, protease, calcium salt, and acidulant. Journal of Agricultural and Food Chemistry, 1998. 46(5): p. 1830-1835.

32. Otte, J., et al., Protease-induced gelation of unheated and heated whey proteins: effects of $\mathrm{pH}$, temperature, and concentrations of protein, enzyme and salts. International Dairy Journal, 1999. 9(11): p. 801-812.

33. Hongsprabhas, P., S. Barbut, and A.G. Marangoni, The Structure of Cold-Set Whey Protein Isolate Gels Prepared With Ca++. LWT - Food Science and Technology, 1999. 32(4): p. 196-202.

34. Remondetto, G.E. and M. Subirade, Molecular mechanisms of Fe2+-induced $\beta$ lactoglobulin cold gelation. Biopolymers, 2003. 69(4): p. 461-469.

35. Ikeda, S. and V.J. Morris, Fine-Stranded and Particulate Aggregates of HeatDenatured Whey Proteins Visualized by Atomic Force Microscopy. Biomacromolecules, 2002.3(2): p. 382-389.

36. Alting, A.C., et al., Physical and chemical interactions in cold gelation of food proteins. Journal of Agricultural and Food Chemistry, 2002. 50(16): p. 4682-4689.

37. Kuhn, P.R. and E.A. Foegeding, Mineral salt effects on whey protein gelation. Journal of Agricultural and Food Chemistry, 1991. 39(6): p. 1013-1016.

38. Silva, T.H., et al., Materials of marine origin: a review on polymers and ceramics of biomedical interest. International Materials Reviews, 2012. 57(5): p. 276-306.

39. de Vos, P., et al., Polymers in cell encapsulation from an enveloped cell perspective. Advanced Drug Delivery Reviews, 2014. 67-68: p. 15-34.

40. Draget, K.I., G. Skjåk Bræk, and O. Smidsrød, Alginic acid gels: the effect of alginate chemical composition and molecular weight. Carbohydrate Polymers, 1994. 25(1): p. 31-38. 
41. Paques, J.P., Formation of alginate nanospheres. 2014: Wageningen University.

42. Paques, J.P., et al., Preparation methods of alginate nanoparticles. Advances in Colloid and Interface Science, 2014. 209(0): p. 163-171.

43. Gombotz, W.R. and S.F. Wee, Protein release from alginate matrices. Advanced Drug Delivery Reviews, 2012. 64: p. 194-205.

44. Kwok, K.K., M.J. Groves, and D.J. Burgess, Production of 5-15 $\mu$ m Diameter Alginate-Polylysine Microcapsules by an Air-Atomization Technique. Pharmaceutical Research, 1991. 8(3): p. 341-344.

45. Sağlam, D., et al., Preparation of high protein micro-particles using two-step emulsification. Food Hydrocolloids, 2011. 25(5): p. 1139-1148.

46. Paques, J.P., et al., Nanospheres of alginate prepared through $w / o$ emulsification and internal gelation with nanoparticles of CaCO3. Food Hydrocolloids, 2014. 40(0): p. 182-188.

47. Corstens, M.N., et al., Emulsion-alginate beads designed to control in vitro intestinal lipolysis: Towards appetite control. Journal of Functional Foods, 2017. 34(Supplement C): p. 319-328.

48. Martinsen, A., I. Storrø, and G. Skjårk-Bræk, Alginate as immobilization material: III. Diffusional properties. Biotechnology and Bioengineering, 1992. 39(2): p. 186194.

49. Liu, X.C., et al., Characterization of structure and diffusion behaviour of Ca-alginate beads prepared with external or internal calcium sources. Journal of microencapsulation, 2002. 19(6): p. 775-782.

50. Li, Y., et al., Control of lipase digestibility of emulsified lipids by encapsulation within calcium alginate beads. Food Hydrocolloids, 2011. 25(1): p. 122-130.

51. Stewart, W.W. and H.E. Swaisgood, Characterization of calcium alginate pore diameter by size-exclusion chromatography using protein standards. Enzyme and microbial technology, 1993. 15(11): p. 922-927.

52. Pluen, A., et al., Diffusion of Macromolecules in Agarose Gels: Comparison of Linear and Globular Configurations. Biophysical Journal, 1999. 77(1): p. 542-552.

53. Huguet, M.L. and E. Dellacherie, Calcium alginate beads coated with chitosan: Effect of the structure of encapsulated materials on their release. Process Biochemistry, 1996. 31(8): p. 745-751.

54. van Leusden, P., et al., Permeation of probe molecules into alginate microbeads: Effect of salt and processing. Food Hydrocolloids, 2017. 73(Supplement C): p. 255261.

55. Kaushik, V. and Y.H. Roos, Limonene encapsulation in freeze-drying of gum Arabicsucrose-gelatin systems. LWT - Food Science and Technology, 2007. 40(8): p. 13811391.

56. Yoo, S.-H., et al., Microencapsulation of $\alpha$-tocopherol using sodium alginate and its controlled release properties. International Journal of Biological Macromolecules, 2006. 38(1): p. 25-30.

57. Sultana, K., et al., Encapsulation of probiotic bacteria with alginate-starch and evaluation of survival in simulated gastrointestinal conditions and in yoghurt. International Journal of Food Microbiology, 2000. 62(1-2): p. 47-55.

58. Tønnesen, H.H. and J. Karlsen, Alginate in drug delivery systems. Drug development and industrial pharmacy, 2002. 28(6): p. 621-630.

59. Tyle, P., Effect of size, shape and hardness of particles in suspension on oral texture and palatability. Acta Psychologica, 1993. 84(1): p. 111-118.

60. Minekus, M., et al., A standardised static in vitro digestion method suitable for foodan international consensus. Food \& function, 2014. 5(6): p. 1113-1124 



\section{Chapter 2}

\section{Strength of microbeads for the encapsulation of heat sensitive, hydrophobic components}

This chapter has been published as: P. van Leusden, G.J.M. den Hartog, A. Bast, M. Postema, E. van der Linden, L.M.C. Sagis (2016) Strength of microbeads for the encapsulation of heat sensitive, hydrophobic components, Food Hydrocolloids, 56, 318-324 


\begin{abstract}
Hydrophobic food ingredients sensitive to degradation can be protected from their environment by microencapsulation. In an $\mathrm{O} / \mathrm{W}_{1} / \mathrm{W}_{2}$ system, these hydrophobic compounds are dissolved in oil droplets, dispersed within a gelled matrix microbead $\left(\mathrm{W}_{1}\right)$, which forms a barrier. The stability and degree of protection delivered by the gel matrix depends on its structure and strength, which in turn depend on the gelling process. For heat sensitive ingredients this process is typically a cold-set gelling process. We investigated the effect of variations in matrix polymer (alginate and WPI aggregates), gelling agent (acid and calcium), and method of gelation (internal and external), on the ability of microbeads to retain oil droplets, and retain a spherical shape during the extraction from the oil phase. External gelation with $\mathrm{CaCl}_{2}$ nanoparticles gave the smoothest and strongest microbeads for both protein and alginate, which we attribute to the formation of a shell at the interface of the bead during gelation. Microbeads produced by internal calcium gelation (induced with $\mathrm{CaCO}_{3}$ nanoparticles and GDL) containing the same amount of calcium showed less integrity and gave a mixture of smooth and rough beads. About half of the microbeads produced by acid induced gelation of WPI aggregates (using GDL to lower the internal $\mathrm{pH}$ ) remained intact. When the $\mathrm{pH}$ was brought further from the isoelectric point, fewer beads remained intact. The method of gelation proved to be more important for the microbead integrity than type of matrix polymer, and external gelling was clearly superior to internal and acid induced gelation.
\end{abstract}




\subsection{Introduction}

Bioactive components such as vitamins and antioxidants are sensitive components and can be protected from degradation during storage and digestion [1-3]. Protecting these components by encapsulation is a straightforward solution and, if the microcapsules are kept below $25 \mu \mathrm{m}$, will not negatively affect sensorial aspects [4]. Many types of microcapsules have been suggested and investigated. McClements presented an overview of the most commonly used systems, which includes the filled hydrogel particle [5]. This is an $\mathrm{O} / \mathrm{W}_{1} / \mathrm{W}_{2}$ system, in which the sensitive oil-soluble components are dispersed within a gelled matrix microbead $\left(\mathrm{W}_{1}\right)$. This gelled phase acts as a barrier against negative environmental influences.

Proteins are well suited for the encapsulation of bioactive compounds [2, 6] because they are safe for consumption, have a high nutritional value and are able to form gels and emulsions. Alginate is a polysaccharide that has already been extensively investigated for use in encapsulation [3, 7-9], including encapsulation of living cells [10-12]. Alginate is safe for consumption and cannot be digested, therefore having no nutritional value.

Walther et al. did a model study in which they investigated a method to form gelled protein droplets in an oil phase, by dripping a protein solution in a heated oil bath [13]. This concept was further developed into a method to create high-protein microparticles by emulsifying a concentrated protein solution into oil, and then inducing gelation by applying heat [14]. For protein microparticles, the effects of protein source, including the cold-setting gelatin, and the $\mathrm{pH}$ sensitivity of the microparticles was investigated [15].

The most conventional method to create alginate microparticles is by dripping an alginate solution into a bath with calcium ions, however this method gives microparticles much larger than $25 \mu \mathrm{m}$ [16]. Paques et al. showed that a method similar to the method of Saglam et al. [14] could be used to produce alginate microparticles much smaller than $25 \mu \mathrm{m}$ [17].

For heat sensitive components, the gelation method of the microbeads should be cold-set gelation. Cold set gels can be made with several methods, including acidification, addition of salts, enzymes and pressure. Acid induced gelation is done by decreasing the $\mathrm{pH}$ of the solution to a $\mathrm{pH}$ where the 
polyelectrolyte approaches a net zero charge and the molecules start associating. For WPI this is around pH 5.1 [18], for alginate this is below 3.5 [19]. For WPI gels, adding salts will cause repulsive forces between the protein molecules to be screened, thereby possibly inducing aggregation. All salts screen the charges, however, divalent salts such as $\mathrm{Ca}^{2+}$ have an additional effect as they are able to form salt bridges, thereby reducing the amount of salt necessary for gelation [20]. Salt bridges with $\mathrm{Ca}^{2+}$ are the usual and most effective method of gelation for the negatively charged alginate polymers.

The way in which the gelling agent is introduced into the system can affect the microstructure of the gel. Internal gelation is when the gelling agent is present within the matrix, and slowly causes the matrix to gel from within. Sometimes this gelling agent is activated by a trigger, for example, the insoluble $\mathrm{CaCO}_{3}$, which dissociates when the $\mathrm{pH}$ is lowered below $\mathrm{pH} 7$. External gelation uses a gelation source which is present outside the matrix, and the diffusion of the gelling agent into the matrix causes gelation. An example of external gelation is the creation of alginate beads by dripping an alginate solution into a solution with calcium ions. These two methods can give differences in the structure, properties, and therefore use of the microbeads. External gelation of alginate beads has been found to give smoother surfaces, smaller pores, slower diffusion and greater matrix strength, even though the amount of $\mathrm{Ca}^{2+}$ bridges formed in internal and external gelation was equal [21, 22]. Because acid is necessary for the dissociation of the $\mathrm{CaCO}_{3}$, it has been suggested that this method may reduce the $\mathrm{pH}$ inside the particles to such levels as to be harmful to the encapsulated component. Poncelet was however able to control the $\mathrm{pH}$ in alginate beads by varying the amount of glacial acetic acid added to the oil phase [23]. Additionally, variations in the spatial distribution of $\mathrm{CaCO}_{3}$ nanoparticles may cause differences between separate microbeads in the same batch, especially when making small beads which approach the size of the $\mathrm{CaCO}_{3}$ nanoparticles. The external gelation method of Paques et al. [17], which uses $\mathrm{CaCl}_{2}$ nanoparticles dispersed in the oil phase, seems able to avoid the problems of the spatial distribution of particles inside the beads, and the need for an external, acidic trigger to dissociate $\mathrm{CaCO}_{3}$. These calcium nanoparticles are created in an oil phase. After emulsification of the polyelectrolyte in the oil phase, this 
nanocrystals dispersion can be added to the emulsion, and the nanoparticles will diffuse to the interface where they dissolve and cause gelation.

Microstructure is dependent on the balance between attractive and repulsive forces of the building blocks. Fine-stranded protein gels are produced, at low salt concentration and a $\mathrm{pH}$ far from the isoelectric point (IEP). Protein gels with a more particulate structure are produced at higher salt concentrations or a $\mathrm{pH}$ closer to the IEP $[24,25]$. This microstructure is reflected in the macroscopic properties of the gels. Particulate gels are usually less elastic and fracture at a small strain and large stress $[26,27]$.

Methods have been developed to create microbeads that could potentially retain oil droplets within their matrix and much is known of different gelation techniques and their relation to gel strength. For microbeads smaller than 25 $\mu \mathrm{m}$ and containing small particles, the relation between different gelling techniques and the integrity of the microbead after gelling is not well investigated. In this study we compared systems to encapsulate hydrophobic components into microbeads by use of cold set gelation, and investigated the effects of differences in: matrix polymer (alginate and WPI), method of gelation (internal and external gelation), and gelling agent (acid and calcium nanoparticles). The effects of these parameters on gel strength were tested on macroscopic gels, the smoothness of the surface of microbeads without oil was investigated with SEM, and the integrity of microbeads with oil after processing was investigated with CLSM.

\subsection{Materials and Methods}

\subsubsection{Materials:}

Alginate (Texturas, Barcelona, Spain), Whey protein isolate (WPI) purity 98\% (Davisco Foods international, France), $\mathrm{CaCO}_{3}$ nanoparticles $(15-40 \mathrm{~nm})$ (purity 97.5\%) (SkySpring Nanomaterials, Inc., Houston, USA), $\mathrm{CaCl}_{2} \cdot 2 \mathrm{H}_{2} \mathrm{O}$ (purity $\geq 99 \%$ ) (GR for analyses, Merck), ethanol absolute (purity $\geq 99.2 \%$ ) (Merck), polyglycerol polyricinoleate (PGPR) 90 kosher (Danisco, Denmark), Medium Chain Triglycerides (MCT) (Miglyol 812 N) (Sasol, Germany), Glucono delta-lactone (GDL) (Fluka Chemika, Switzerland) were all used as received. Solutions were made in demineralized water. 


\subsubsection{Calcium nanocrystals}

Calcium nanocrystals were made according to the method of [17], resulting in a $5 \%$ calcium nanocrystal dispersion. In short, $5 \%(\mathrm{v} / \mathrm{v})$ of a 0.1 molal $\mathrm{CaCl}_{2} \cdot 2 \mathrm{H}_{2} \mathrm{O}$ in ethanol solution was emulsified in $\mathrm{MCT}$, containing $6 \%(\mathrm{w} / \mathrm{w})$ PGPR, with a Sonicator S-250A sonicator (Branson Ultrasonics, USA) for 1 minute. This emulsion was stirred on a magnetic stirrer and heated overnight at $60^{\circ} \mathrm{C}$ without a cover, allowing the ethanol to evaporate.

\subsubsection{Production of the protein aggregates}

Protein aggregates were made by making a $10 \%(\mathrm{w} / \mathrm{w})$ protein solution, which was stirred overnight to allow complete dissolution of the protein. The $\mathrm{pH}$ was adjusted to $\mathrm{pH} 8$ with $1 \mathrm{M} \mathrm{NaOH}$, and then the solutions were heated at $80^{\circ} \mathrm{C}$ for 30 minutes while stirring. After heating, the solutions were cooled with tap water and stored at $4^{\circ} \mathrm{C}$.

\subsubsection{Macro gels}

Acid induced protein macro gels were made by the adding GDL to a $10 \%$ $(\mathrm{w} / \mathrm{w})$ solution of protein aggregates. GDL was added in ratios of 0.1 and 0.2 gram per gram protein (respectively 1 and $2 \% \mathrm{GDL}$ ). $\mathrm{CaCO}_{3}$ induced protein macro gels were made by adding $30 \mathrm{mM}$ of $\mathrm{CaCO}_{3}$ to the protein aggregate solution, which was then sonicated for 90 seconds (output control level 8, duty cycle $80 \%$ ). For the $\mathrm{CaCO}_{3}$ induced alginate macro gels first a $22 \mathrm{mM} \mathrm{CaCO}_{3}$ dispersion was made and sonicated, after which $2.5 \%(\mathrm{w} / \mathrm{w})$ alginate was added. GDL was then added to both the protein and alginate solution in a $\mathrm{GDL} / \mathrm{CaCO}_{3}$ molar ration of $1.9 / 1$ to dissociate the $\mathrm{CaCO}_{3}$ [28]. The macro gels were analysed using a rheometer and $\mathrm{pH}$ meter (see Sec. 2.2.6 and 2.2.7). Because of the large dimensions of the macro gels, external gelation was inappropriate for making macro gels.

\subsubsection{Microbeads without encapsulated oil for SEM analysis}

Microbeads without oil droplets were made for SEM analysis. For protein microparticles, a volume ratio of $5 \%$ of protein aggregate solution was slowly added to MCT oil containing 2.5\% (w/w) PGPR (an oil soluble emulsifier), while mixing with the Ultra-Turrax (T 25, Germany) at $6500 \mathrm{rpm}$. After full addition, the emulsion was mixed for a further 3 minutes. For alginate microparticles, a volume of $4 \%$ of alginate solution was slowly added to MCT 
oil, containing 4\% (w/w) PGPR, while mixing with the Ultra-Turrax at 11500 rpm. After full addition, the emulsion was mixed for a further 90 seconds. For internal gelation gelling agents were added before emulsification in concentrations as mentioned before, and the microparticles were allowed to gel for 20 hours. For external calcium induced gelation, calcium nanocrystals were added to achieve the same concentration of calcium as added in the internally gelled microbeads.

To remove the protein microbeads from the oil phase, the dispersion was centrifuged at $2500 \mathrm{~g}$ for 2 hours. To remove the residual oil, the microbeads were washed. The beads were washed by redispersing the pellet in a $2 \%(\mathrm{w} / \mathrm{w})$ WPI solution, mixed with the Ultra-Turrax at $5000 \mathrm{rpm}$ for 2 minutes, homogenized (Delta instruments, Drachten, The Netherlands) at 100 bars for 2 passes and then centrifuged at $400 \mathrm{~g}$ for 40 minutes. This washing step was done twice, the last time redispersing in water instead of a WPI solution. To remove the alginate microbeads from the oil phase, the dispersion was centrifuged at $22000 \mathrm{rpm}(48646 \mathrm{~g})$ for 80 minutes. The pellet was redispersed in water and mixed with the Ultra-Turrax at $5000 \mathrm{rpm}$ for 90 seconds, homogenized at 100 bars for 2 passes, and then centrifuged at $660 \mathrm{~g}$ for 40 minutes. The pellet was then redispersed in water.

\subsubsection{Microbeads with encapsulated oil for CLSM analysis}

The inner oil droplets of the protein microbeads were made by adding 5.0\% $(\mathrm{w} / \mathrm{w}) \mathrm{MCT}$ to the protein aggregate solution while mixing with the UltraTurrax at $10000 \mathrm{rpm}$ for 5 minutes, which was then homogenized at 100 bars for 4 passes. The process then continued as described for the protein microparticles without interior oil droplets (Sec. 2.2.4). The inner oil droplets for the alginate microbeads were made by emulsifying $1 \%(\mathrm{w} / \mathrm{w}) \mathrm{WPI}$ and $5 \%$ $(\mathrm{w} / \mathrm{w}) \mathrm{MCT}$ in water. The mixture was first premixed with the Ultra-Turrax at $8000 \mathrm{rpm}$ for 1 minute and then homogenized at 180 bars for 3 passes. The emulsion was syringe filtered $(1.2 \mu \mathrm{m})$ to exclude large droplets and then centrifuged to remove the excess protein. The cream was redispersed in its original volume of water to which $2.5 \%(\mathrm{w} / \mathrm{w})$ alginate, and in the case of $\mathrm{CaCO}_{3}$ induced gels also $22 \mathrm{mM}$ sonicated $\mathrm{CaCO}_{3}$, was added. The process then continued as for the alginate microbeads for SEM analysis. In these beads for CLSM analysis, the total amount of matrix polymer to be gelled is lower because of the added volume of oil, which is not present in the beads for SEM 
analysis. The amount of $\mathrm{CaCl}_{2}$ nanocrystals was reduced to compensate for this reduction of matrix polymer.

\subsubsection{Rheological measurements}

Small oscillatory deformation measurements were performed with a Physica MCR 501 Rheometer (Anton Paar, Graz, Austria), with a concentric cylinder measuring geometry $(\mathrm{CC} 17 / \mathrm{TI}$, alginate samples used a sandblasted version of this geometry). Samples were pipetted into the cup immediately after addition of GDL and a thin layer of paraffin oil was applied to prevent evaporation of water. To monitor the gelation process, a frequency of $1 \mathrm{rad} / \mathrm{s}$ $(0.159 \mathrm{~Hz})$ was applied with a strain of $1 \%$ for the protein gels, and $0.002 \%$ for the alginate gels. The development of the storage modulus ( $\left.\mathrm{G}^{\prime}\right)$ and loss modulus (G”) during 23 hours at $30^{\circ} \mathrm{C}$ was monitored. To determine the maximum linear strain, a strain sweep was performed at a frequency of $1 \mathrm{rad} / \mathrm{s}$.

\subsection{8 $\mathrm{pH}$ over time}

A volume of $75 \mathrm{~mL}$ of alginate or protein aggregate solution was put in a 100 $\mathrm{mL}$ Schott bottle, which was put in a water bath of $30^{\circ} \mathrm{C}$. A pH meter with an analogue output was attached to a recorder and the probe was put in the middle of the bottle. After this the gelling agents were mixed into the solution and the $\mathrm{pH}$ during gelation was measured for 23 hours.

\subsubsection{Scanning electron microscopy (SEM)}

SEM (Magellan 400, FEI, Eindhoven, the Netherlands) was used to investigate the microstructure of the microbeads. Before viewing, the beads were first adhered to coverslips and critical point dried with carbon dioxide (CPD 030, Baltec, Liechtenstein), and were then sputter coated (Leica EM SCD 500, Leica, Vienna, Austria).

\subsubsection{Confocal laser scanning microscopy (CLSM)}

CLSM (Leica TCS-SP5, Leica Microsystems B.V., Rijswijk, Netherlands) with an Argon laser was used to image the distribution of oil droplets within the microbead matrix. Dispersions of the protein microbeads were stained with a few drops of $1 \%$ Nile Blue (hydrogen sulphate; Merk Millipore, Germany) and analysed immediately after. Nile blue can simultaneously stain MCT oil and whey protein. To visualise the oil, the sample was excited at 488 $\mathrm{nm}$ and detected between 505 and $600 \mathrm{~nm}$, to visualise the protein the sample 
was excited at $633 \mathrm{~nm}$ and detected above $650 \mathrm{~nm}$. No adequate stain for alginate could be found. The oil phase was stained with Nile red $(0.6 \mathrm{~g} / \mathrm{L})$ and the outside water phase was stained with fluorescein isothiocyanate dextran (FITC, MW 40 kDa; Sigma Aldrich, Steinheim, Germany). To visualise Nile red, samples were excited at $488 \mathrm{~nm}$ and detected above $560 \mathrm{~nm}$. To visualise FITC, the samples were excited at $488 \mathrm{~nm}$ and detected between 505 and 600 nm.

\subsection{Results and Discussion}

\subsubsection{Rheology and pH over time of macroscopic gels}

The development of the storage modulus and the development of $\mathrm{pH}$ over time of the macro gels are shown in Figure 2.1. The strongest gel is the protein gel gelled with $1 \% \mathrm{GDL}$, then the protein gel with $30 \mathrm{mM} \mathrm{CaCO}_{3}$, then the protein gel with $2 \%$ GDL and last the alginate gel with $22 \mathrm{mM} \mathrm{CaCO}_{3}$. For acid induced gels the $\mathrm{pH}$ of the solution should be close to the IEP to induce gelation. It was found that in the case of whey protein microgels, which are made heating a $4 \%(\mathrm{w} / \mathrm{w}) \mathrm{WPI}$ solution at $85^{\circ} \mathrm{C}$, the IEP was 4.82 [29]. In the case of the $1 \%$ GDL protein gel (A), the final $\mathrm{pH}$ of 4.8 indeed approaches the $\mathrm{pH}$ at the IEP. In the case of the $2 \%$ GDL protein gel (B), the $\mathrm{pH}$ goes through the IEP to 4.0. At the IEP, the gel is strongest, but when the $\mathrm{pH}$ is lowered further, the strength decreases again. This allows for only a narrow $\mathrm{pH}$ range in which to make acid induced, cold set, protein microbeads. When encapsulating an oil-soluble compound, as is done in this study, the $\mathrm{pH}$ of the gelled matrix generally has little short term effect on the encapsulated compound [30]. We note however, that the narrow $\mathrm{pH}$ range could pose problems when used to encapsulate other heat sensitive particles such as microorganisms or other living cells, which are very sensitive to the $\mathrm{pH}$.

For $\mathrm{CaCO}_{3}$ induced gels, only a slightly acidic environment is necessary to dissociate the $\mathrm{CaCO}_{3}$ and induce gelation. For the protein gel (C), the $\mathrm{pH}$ ends around 6.3, for the alginate gel (D) the $\mathrm{pH}$ ends around 5.6. The GDL concentration can be adjusted to have the $\mathrm{pH}$ end at any $\mathrm{pH}$ below 7.0. This confirms the findings of Poncelet, that the use of an acidic trigger to release $\mathrm{CaCO}_{3}$ does not necessarily lower the $\mathrm{pH}$ to extreme and possibly harmful levels [23]. 

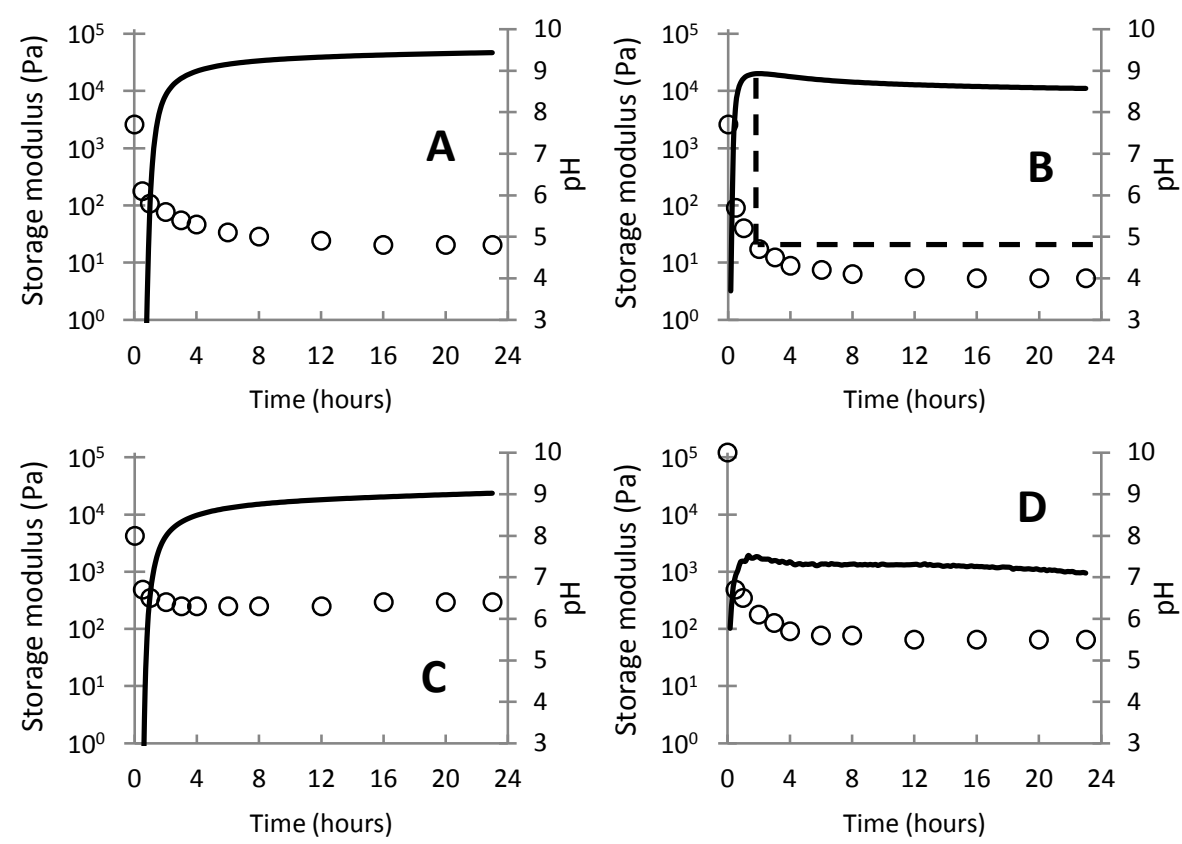

Figure 2.1: Development of gel strength (line) and pH (circles) over time of cold set gels. A) Protein gel gelled with $1 \% G D L, B)$ protein gel gelled with $2 \% \mathrm{GDL}, \mathrm{C})$ protein gel gelled with $30 \mathrm{mM} \mathrm{CaCO}_{3}$ and $\left.\mathrm{GDL}, \mathrm{D}\right)$ alginate gel gelled with $22 \mathrm{mM} \mathrm{CaCO}_{3}$ and $\mathrm{GDL}$.

The storage modulus for the protein gels is much higher than for the alginate gel. When looking at the strain sweep of the gels (Figure 2.2) the alginate gel is also much more brittle than any of the protein gels, decreasing in strength around $0.2 \%$ strain. The acid induced protein gels show a reduction of strength around $10 \%$ strain and the $\mathrm{CaCO}_{3}$ induced protein gels show a reduction of strength around $50 \%$ strain. The $\mathrm{CaCO}_{3}$ induced protein gels are thus less brittle than the acid induced gels, even though the final gel strength is similar.

The strength and elasticity of the beads are very important during processing, especially during the centrifugation and homogenization steps during washing. Centrifugation and homogenization apply harsh forces on the particles, which could mean that they could be made in the oil phase, but not recovered from the oil phase. Our rheological results suggest that the protein beads are more likely to remain intact during processing than the alginate beads, due to the higher strength and elasticity of the protein gels. 


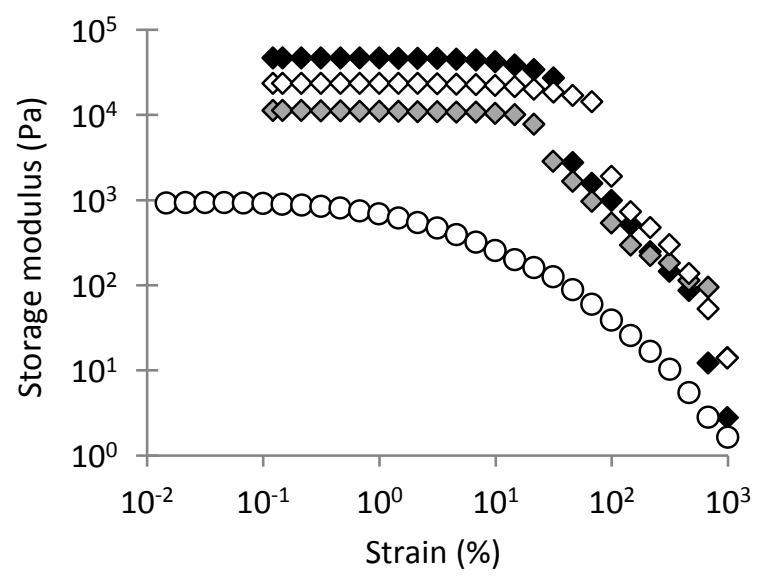

Figure 2.2: Gel strength with increasing strain of cold set gels. Diamonds: protein gel gelled with 1\% GDL (black), 2\% GDL (grey), $30 \mathrm{mM} \mathrm{CaCO}_{3}$ and $G D L$ (white), Circles: alginate gel gelled with $22 \mathrm{mM} \mathrm{CaCO}_{3}$ and $\mathrm{GDL}$ (white).

\subsubsection{Microstructure}

The SEM images of the microbeads are shown in Figure 2.3. Large differences in microstructure are visible. Both the alginate and protein externally gelled microbeads have very smooth surfaces. The surfaces of the acid induced microbeads are quite rough. Further from the IEP the microbeads become more rough. The $\mathrm{CaCO}_{3}$ induced microbeads have surfaces that are either rough or smooth. This is likely caused by the small dimensions of the microbeads and the high viscosity of both the protein aggregate and the alginate solutions, which caused the $\mathrm{CaCO}_{3}$ nanoparticles and the GDL to not be homogenously distributed. 

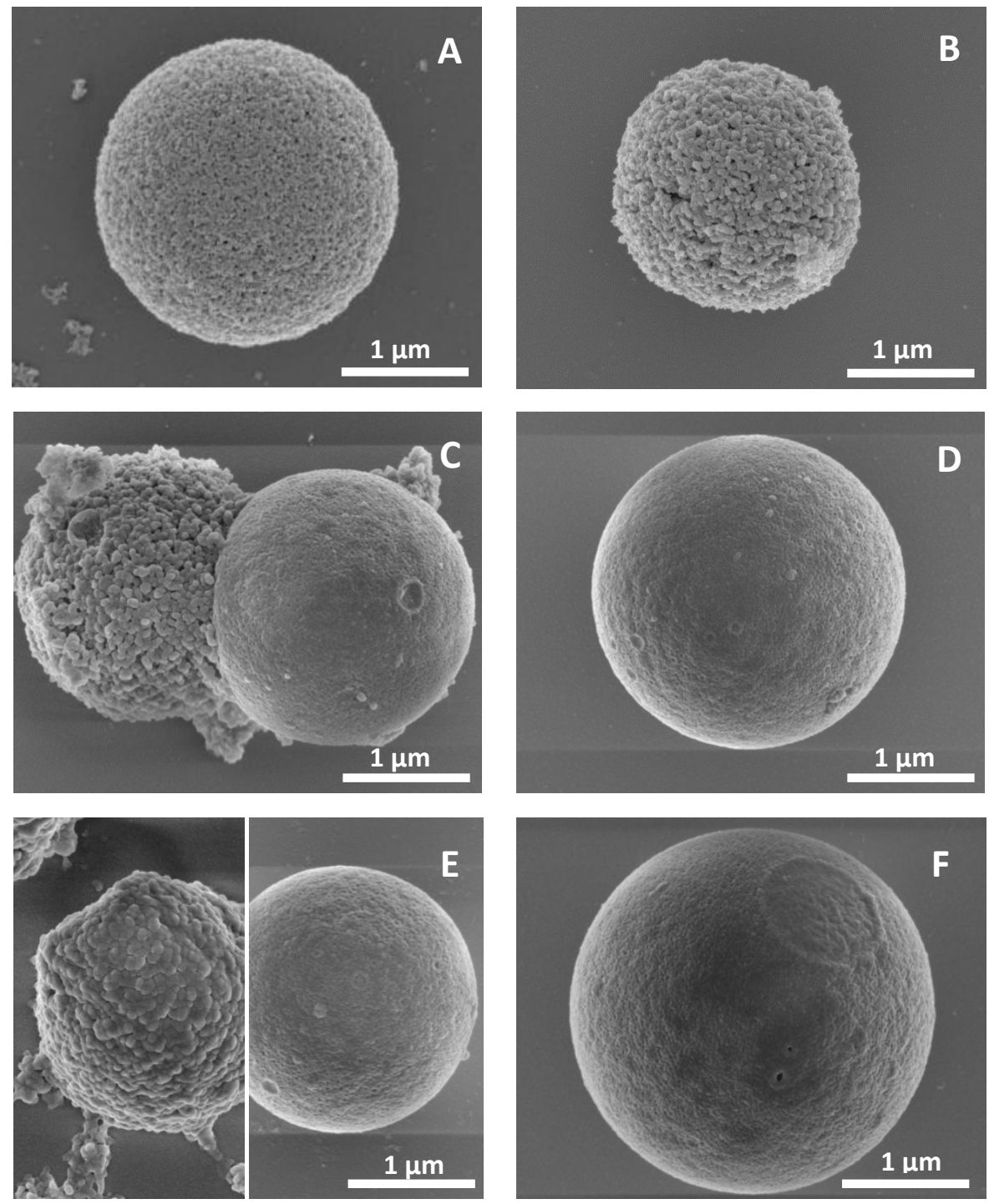

Figure 2.3: SEM images of cold set microbeads. A) Protein microbead internally gelled with $1 \%$ GDL, B) Protein microbead internally gelled with $2 \% \mathrm{GDL}, \mathrm{C})$ Protein microbead internally gelled with $30 \mathrm{mM} \mathrm{CaCO}$ and $G D L, D)$ Protein microbead externally gelled with $30 \mathrm{mM} \mathrm{CaCl}$ nanocrystals, E) Alginate microbead internally gelled with $22 \mathrm{mM} \mathrm{CaCO}_{3}$ and $\mathrm{GDL}, \mathrm{F})$ Alginate microbead externally gelled with $22 \mathrm{mM} \mathrm{CaCl}$ nanocrystals. 
Roughness of the surface of the microbeads can be caused by several factors. The concentration of gelling agent might be too high, leading to structures with thicker strands and bigger pores, as is the case for the $2 \%$ GDL protein microbeads. It is also possible that the beads shrunk after gelling, causing the surface to shrivel. Additionally, because of inhomogeneous gelation in the bead, as illustrated in Figure 2.4 (left), the surface of the bead might be weaker and parts of the surface might be peeled off during processing. Last, for internal gelation with calcium, $\mathrm{CaCO}_{3}$ nanoparticles are used, and some of them might be relatively big compared to the size of the microbead. These particles because of their size need more time to dissolve, which means that the bead may have gelled before the particle is completely dissolved, which may leave holes, and thus weaknesses, in the structure of the bead.

In the external gelation method, the calcium crystals are present in the oil phase and added after emulsification. During gelation the calcium crystals will move to the oil-water interface and the calcium will dissolve there. This method of gelation means that the interface of the droplet gels first and is able to form a 'shell', as illustrated in Figure 2.4 (right). This shell will increase the strength of the interface of the externally gelled microbeads and prevent shrinking and peeling.
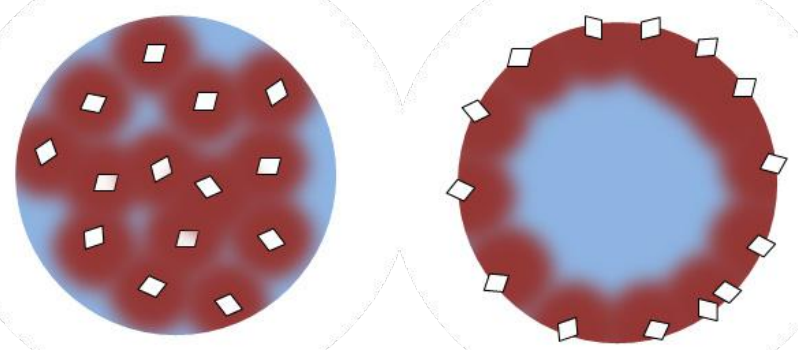

Figure 2.4: Representation of internal (left) versus external (right) gelation. The diamonds are the gelling agent, the red colour shows where the bead gels first.

The beads with the rough surfaces in the SEM test lack strength, have too much gelling agent, or have an inhomogeneity in the distribution of gelling agent. For the external gelled microbeads the surfaces are smooth, suggesting that a homogeneous and strong gel was made. 


\subsubsection{Structural integrity}

CLSM pictures of the microbeads can be found in Figure 2.5. No fragmented beads can be found in both the alginate and protein externally gelled microbeads. The $1 \%$ GDL protein microbeads show some fragmented beads and quite some whole microbeads, the $\mathrm{CaCO}_{3}$ induced protein microbeads show slightly more fragments, the $2 \%$ GDL protein induced microbeads have mostly fragmented. Very few $\mathrm{CaCO}_{3}$ gelled alginate beads are found. This means that most of the beads have broken, however because of the low density of the alginate gel these fragments have not sedimented during centrifugation, while fragments of protein microbeads have sedimented.

One would reason that the microbeads, which in the rheological tests were the strongest, would have the most resistance to the homogenization and the centrifugation steps during washing, and would thus show the least fragments here. When comparing the results of the 1 and $2 \%$ GDL protein microbeads, the results are as hypothesised: the rheological tests show that the $1 \%$ GDL is slightly stronger, SEM shows them having a more homogenous and smooth structure, and CLSM shows that more 1\% GDL microbeads remain intact throughout the washing process.

Rheology tests showed that $\mathrm{CaCO}_{3}$ and acid induced protein gels were of similar strength and CLSM showed that microbeads made of these compositions were a mixture of whole beads and fragments. When the calcium source is external, CLSM show only whole beads and no fragments. The externally gelled protein microbeads are therefore much stronger. In SEM they showed a much smoother surface than the internally gelled beads.

Similar as for the protein microbeads, the internal and external gelled alginate microbeads show large differences in strength, despite the equal amount of calcium and alginate in the systems. According to the rheological tests, the internally gelled alginate gel was the weakest. The CLSM results show that the internally gelled alginate microbeads are indeed some of the weakest, however the externally gelled alginate microbeads are some of the strongest, stronger than the internally gelled protein microbeads. This means that the way in which the calcium is introduced into the system, and thus the smoothness of the beads that results, is very important to the integrity of microbeads of this scale. This supports the theory that the calcium diffusing 
from outside into the microbead causes the formation of a strong, smooth shell, which protects the microbeads from destruction during processing.
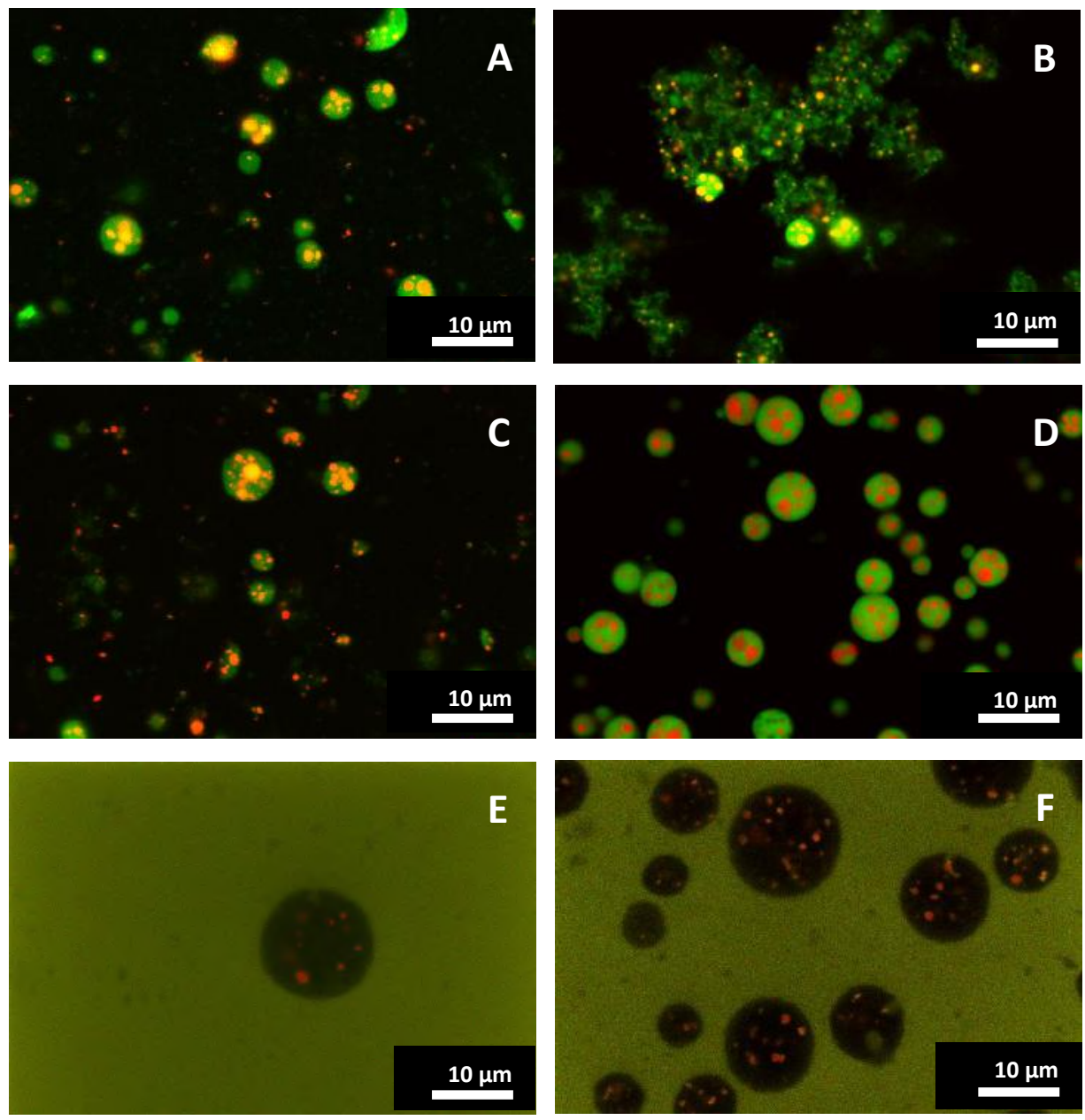

Figure 2.5: CLSM images of cold set microbeads. Red is oil. For A, B, C and $D$, green is protein, for $E$ and $F$, green is the background and black is the alginate bead. A) Protein microbead internally gelled with $1 \%$ GDL, B) Protein microbead internally gelled with 2\% GDL, C) Protein microbead internally gelled with $30 \mathrm{mM} \mathrm{CaCO}$ and $G D L$, D) Protein microbead externally gelled with $30 \mathrm{mM} \mathrm{CaCl}{ }_{2}$ nanocrystals, E) Alginate microbead internally gelled with $22 \mathrm{mM} \mathrm{CaCO}$ and $\mathrm{GDL}, \mathrm{F}$ ) Alginate microbead externally gelled with $22 \mathrm{mM} \mathrm{CaCl}{ }_{2}$ nanocrystals. 


\subsection{Conclusions}

In this study the importance of matrix polymer, method of gelation, and gelling agent on the strength and integrity of microbeads, smaller than $25 \mu \mathrm{m}$, containing oil droplets was studied. Both alginate and protein externally gelled microbeads have smooth surfaces and are sufficiently strong to survive centrifugation and homogenization steps in the production process. The $\mathrm{CaCO}_{3}$, internally gelled microbeads, containing the same amount of calcium, fragmented during production. This means that the method in which the calcium is introduced into the beads is important.

Externally gelled alginate beads were stronger than acid and $\mathrm{CaCO}_{3}$ gelled protein microbeads, even though in macroscopic gels the $\mathrm{CaCO}_{3}$ gelled alginate gel was much weaker and more brittle than the $\mathrm{CaCO}_{3}$ gelled protein gel. This means that the gelling mechanisms can be more important than the type of matrix polymer.

Acid induced gelation of the protein microbeads gives slightly rough microbeads and a strength which allows only half of the microbeads to remain intact throughout the production process. The $\mathrm{pH}$ range in which the strength is optimal is quite narrow and the current beads cannot be significantly improved further by further optimising the GDL concentration. Acid induced gelation is therefore not an adequate alternative of gelation for these types of microbeads.

This investigation shows that the technique of external gelation is more important to microbead integrity than the type of matrix polymer, and results in microbeads with mechanical properties superior to those produced with internal and acid induced gelation.

\section{Acknowledgements}

The research presented in this paper was financially supported by the Graduate School VLAG, of Wageningen University. 


\section{References:}

1. Kaushik, V. and Y.H. Roos, Limonene encapsulation in freeze-drying of gum Arabicsucrose-gelatin systems. LWT - Food Science and Technology, 2007. 40(8): p. 13811391.

2. Beaulieu, L., et al., Elaboration and Characterization of Whey Protein Beads by an Emulsification/Cold Gelation Process: Application for the Protection of Retinol. Biomacromolecules, 2002. 3(2): p. 239-248.

3. Yoo, S.-H., et al., Microencapsulation of $\alpha$-tocopherol using sodium alginate and its controlled release properties. International Journal of Biological Macromolecules, 2006. 38(1): p. 25-30.

4. Tyle, P., Tactile Pattern RecognitionEffect of size, shape and hardness of particles in suspension on oral texture and palatability. Acta Psychologica, 1993. 84(1): p. 111118.

5. McClements, D.J., Advances in fabrication of emulsions with enhanced functionality using structural design principles. Current Opinion in Colloid \& Interface Science, 2012. 17(5): p. 235-245.

6. Gunasekaran, S., S. Ko, and L. Xiao, Use of whey proteins for encapsulation and controlled delivery applications. Journal of Food Engineering, 2007. 83(1): p. 31-40.

7. Li, Y., et al., Control of lipase digestibility of emulsified lipids by encapsulation within calcium alginate beads. Food Hydrocolloids, 2011. 25(1): p. 122-130.

8. Lupo, B., et al., Preparation of alginate microspheres by emulsification/internal gelation to encapsulate cocoa polyphenols. Food Hydrocolloids, 2014. 38(0): p. 5665 .

9. Gombotz, W.R. and S.F. Wee, Protein release from alginate matrices. Advanced Drug Delivery Reviews, 2012. 64: p. 194-205.

10. Smidsrød, O. and G. Skja ${ }^{\circ} \mathrm{k}-\mathrm{Br} 1 \mathrm{k}$, Alginate as immobilization matrix for cells. Trends in Biotechnology, 1990. 8(0): p. 71-78.

11. Annan, N.T., A.D. Borza, and L.T. Hansen, Encapsulation in alginate-coated gelatin microspheres improves survival of the probiotic Bifidobacterium adolescentis 15703 during exposure to simulated gastro-intestinal conditions. Food Research International, 2008. 41(2): p. 184-193.

12. Allan-Wojtas, P., L. Truelstrup Hansen, and A.T. Paulson, Microstructural studies of probiotic bacteria-loaded alginate microcapsules using standard electron microscopy techniques and anhydrous fixation. LWT - Food Science and Technology, 2008. 41(1): p. 101-108.

13. Walther, B., et al., Flow processing and gel formation-a promising combination for the design of the shape of gelatin drops. Food Hydrocolloids, 2002. 16(6): p. 633643.

14. Sağlam, D., et al., Preparation of high protein micro-particles using two-step emulsification. Food Hydrocolloids, 2011. 25(5): p. 1139-1148.

15. Ince Coskun, A.E., et al., Preparation, structure and stability of sodium caseinate and gelatin micro-particles. Food Hydrocolloids, 2015(0).

16. Paques, J.P., et al., Preparation methods of alginate nanoparticles. Advances in Colloid and Interface Science, 2014. 209(0): p. 163-171.

17. Paques, J.P., et al., Alginate submicron beads prepared through w/o emulsification and gelation with CaCl2 nanoparticles. Food Hydrocolloids, 2012. 31(2): p. 428434.

18. Bryant, C.M. and D.J. McClements, Molecular basis of protein functionality with special consideration of cold-set gels derived from heat-denatured whey. Trends in Food Science \& Technology, 1998. 9(4): p. 143-151. 
19. Draget, K.I., G. Skjåk Bræk, and O. Smidsrød, Alginic acid gels: the effect of alginate chemical composition and molecular weight. Carbohydrate Polymers, 1994. 25(1): p. 31-38.

20. Kuhn, P.R. and E.A. Foegeding, Mineral salt effects on whey protein gelation. Journal of Agricultural and Food Chemistry, 1991. 39(6): p. 1013-1016.

21. Liu, X.C., et al., Characterization of structure and diffusion behaviour of Ca-alginate beads prepared with external or internal calcium sources. Journal of microencapsulation, 2002. 19(6): p. 775-782.

22. Chan, L.W., H.Y. Lee, and P.W.S. Heng, Mechanisms of external and internal gelation and their impact on the functions of alginate as a coat and delivery system. Carbohydrate Polymers, 2006. 63(2): p. 176-187.

23. Poncelet, D., Production of Alginate Beads by Emulsification/Internal Gelation. Annals of the New York Academy of Sciences, 2001. 944(1): p. 74-82.

24. Hongsprabhas, P., S. Barbut, and A.G. Marangoni, The Structure of Cold-Set Whey Protein Isolate Gels Prepared With Ca++. LWT - Food Science and Technology, 1999. 32(4): p. 196-202.

25. Remondetto, G.E. and M. Subirade, Molecular mechanisms of Fe2+-induced $\beta$ lactoglobulin cold gelation. Biopolymers, 2003. 69(4): p. 461-469.

26. Ikeda, S. and V.J. Morris, Fine-Stranded and Particulate Aggregates of HeatDenatured Whey Proteins Visualized by Atomic Force Microscopy. Biomacromolecules, 2002. 3(2): p. 382-389.

27. Stading, M. and A.-M. Hermansson, Large deformation properties of $\beta$-lactoglobulin gel structures. Food Hydrocolloids, 1991. 5(4): p. 339-352.

28. Paques, J.P., et al., Nanospheres of alginate prepared through w/o emulsification and internal gelation with nanoparticles of CaCO3. Food Hydrocolloids, 2014. 40(0): p. 182-188.

29. Schmitt, C., et al., Internal structure and colloidal behaviour of covalent whey protein microgels obtained by heat treatment. Soft Matter, 2010. 6(19): p. 4876-4884.

30. Huang, S.-W., et al., Effect of $p H$ on antioxidant activity of $\alpha$-tocopherol and trolox in oil-in-water emulsions. Journal of agricultural and food chemistry, 1996. 44(9): p. 2496-2502. 


\section{Chapter 3}

\section{Structure engineering of filled protein microbeads to tailor release of oil droplets in gastric digestion}

This chapter has been published as: P. van Leusden, G.J.M. den Hartog, A. Bast, M. Postema, E. van der Linden, L.M.C. Sagis (2016) Structure engineering of filled protein microbeads to tailor release of oil droplets in gastric digestion, Food \& Function, 7, 3539-3547 


\begin{abstract}
Oil-soluble components can be encapsulated in an O/W1/W2 microsystem, in which they are dissolved in oil droplets dispersed in a gelled microbead $\left(\mathrm{W}_{1}\right)$, which forms a barrier between the oil droplets and continuous, aqueous continuous phase $\left(\mathrm{W}_{2}\right)$. We investigated the rate and mechanism of breakdown of protein microbeads in a simulated gastric system, and studied the influence of microbead protein concentration, gelling method (cold-set, slow and fast heat-set), and further processing (freeze-drying), on the breakdown process. Breakdown rate decreased with increasing protein content of the beads, for the same method of production. Due to the porosity of the slowly-heated heat-set beads, breakdown occurred evenly throughout the entire bead. Cold-set microbeads of $10 \%$ protein broke down slightly slower than the heat-set microbeads of $15 \%$. The denser surface of the $10 \%$ beads slowed down the diffusion of the enzymes into the bead's interior, causing the beads to be broken down from the outside inward. All these beads broke down within one hour. Increasing the rate of temperature increase during the heating step dramatically slowed breakdown. There was no significant breakdown of rapidly heated beads within 138 minutes, even though no difference in microstructure between rapidly and slowly heated beads was visible with electron microscopy. Freeze-drying of the beads also slowed their breakdown. After 132 minutes more than half the measured particle volume of were intact beads. Freeze-drying changed the microstructure of the beads irreversibly: rehydrating the dried beads did not result in a breakdown behaviour similar to that of unprocessed beads.
\end{abstract}




\subsection{Introduction}

For encapsulation systems to be effective, functional ingredients need to be protected from external influences until they are delivered to specific locations where they need to be released. The filled hydrogel bead is one of the many types of encapsulation systems that have been developed and investigated in the past decades [1]. This is an $\mathrm{O} / \mathrm{W}_{1} / \mathrm{W}_{2}$ system in which sensitive oil soluble components are incorporated in an oil phase $(\mathrm{O})$ dispersed within gelled microbeads $\left(\mathrm{W}_{1}\right)$, which are dispersed in a liquid phase $\left(\mathrm{W}_{2}\right)[2]$.

Models describing the breakdown and digestion of nutrients generally lack consideration for the matrix in which the nutrients are entrapped [3]. Parada $\&$ Aguilera concluded that the bioavailability of a nutrient is more important than the actual amount of nutrient ingested, and that this depends on the matrix in which the nutrient is located [4]. The relatively large surface area of small oil droplets promotes digestion by lipases [5]. Li et al. have shown that encapsulating lipids into filled hydrogel beads made of alginate retards lipid digestion [6]. They ascribe this retardation to presence of the matrix, which slows the diffusion of both lipase to the interface and free fatty acids away from the interface of the oil droplets. Previously we have investigated the strength of smaller, similar beads, made of WPI or alginate [7]. However, while alginate is not digested in the stomach, protein is extensively digested in the stomach. The rate at which the protein matrix is digested will influence the rate of lipid digestion and release of compounds that may be located in the oil phase. Digestive stability of whey protein microcapsules has been investigated previously and have proven to protect certain strains of probiotic microorganisms, such as Lactobacillus rhamnosus and Bifidobacterium breve [8-10]. These studies vary widely in how the protein matrixes are created (spray drying, cold-set $\mathrm{Ca}^{2+}$ gelation, cold-set acid gelation, heat-set gelation). Because both the production of the matrices and the microorganism that is encapsulated vary, these studies do not allow comparison between different encapsulation systems.

Recently we established that the method of production greatly affected the mechanical strength of microbeads made with the same type and concentration of polymer. Both WPI or alginate beads were stronger if the gelling agent was added externally, through the continuous phase, instead of including it in the internal phase of the bead, and that this gelling method was more important to 
bead strength than the matrix polymer. It was concluded that the externally added gelling agent, which entered the system at the interface of the beads, created a dense 'shell' which was very resistant to the high shear and extensional forces applied on the beads during processing [7]. Internally gelled microbeads had a more open and porous structure and were severely damaged in conditions where externally gelled beads remained intact.

These differences in microstructure of the beads may not only affect mechanical stability of the beads, but also the rate of breakdown of the beads in the gastrointestinal tract. Guo et al. showed that protein gels with different hardness or different protein concentrations broke down differently in a simulated gastrointestinal system [11]. No exact description of the microstructure of the 'hard' or 'soft' macroscopic gel was given, however it was clear that pepsin had more effect on the soft gel. Luo et al. also found that heat-set WPI gels of 15 and $20 \%$ protein had different breakdown rates, with respectively $50 \%$ vs $11 \%$ of the gels broken down after 6 hours [12]. They also found that, at $\mathrm{pH} 3$, the breakdown was entirely caused by the presence of pepsin and not a result of the low $\mathrm{pH}$. Barbé et al. concluded that the rate of digestion of protein can be changed by applying different processes on the same mix of proteins, in their case heating and/or gelation of the protein mixes [13]. Microbeads produced with different methods and different gel strengths are therefore also likely to break down differently. The difference in gelling method and resulting microstructure would thus give opportunities for the development of different types of microencapsulation systems for release at different locations in the digestive tract.

For the rate of diffusion of a component into or out of a microbead, the porosity, size, and charge of the bead, and size and charge of the component are of great significance $[1,14]$. For filled hydrogel beads, the encapsulated components are oil soluble and are therefore generally slow or unable to diffuse out of the microbead. Lipase itself may diffuse through the bead, digesting and releasing small amounts of fatty acids, but for complete and rapid digestion to occur the matrix of the bead should be broken down. Current knowledge on how such beads break down, and which variables determine the rate of the process is still lacking.

In the gastrointestinal tract food encounters a wide range of $\mathrm{pH}$ 's and enzymes, which digest food. The structure and material of the beads will 
determine how well and how long the sensitive component inside is protected. A larger size, a higher polymer concentration and higher degree of crosslinking will slow down the release of the component. The porosity may also play a role, because a finer gel with smaller pores may slow down the diffusion of the enzyme into the bead. When the rate of the enzymatic reaction is much higher than the enzyme can diffuse into the interior of the bead we call the system diffusion limited, and the system will break down from the outside in. This would be visible in a size distribution of the beads as a gradual shift to smaller bead sizes. When the enzyme diffuses into the beads much faster than the enzyme needs to break down the substrate, we call the system reaction limited. In this case the bead will be digested evenly over its entire volume, which would be visible in the size distribution as a gradual decrease of the intensity of the peak representing the average bead size, and an increase in intensity for the peak representing free oil droplets.

The charge of WPI is dependent on the $\mathrm{pH}$, which in turn has an effect on the microstructure of the gelled beads. At the isoelectric point (WPI: 5.1) [15] the molecules will exhibit a net attraction between each other. This will cause the beads to shrink, which might reduce access of proteolytic enzymes. In addition, beads may aggregate into clusters, possibly reducing enzyme access even further. Exposing beads to the low $\mathrm{pH}$ of the stomach however, proteins become more positively charged, causing repulsion between the molecules and swelling of the bead [3]. This leads to bigger pores and easier access for enzymes.

Recent research has shown that digestion of proteins is affected by changing the processing of the proteins $[11-13,16]$. For the creation and development of new, protein gel-based, delivery systems, we need a better understanding of the relation between microstructure and the rate of breakdown of the delivery systems, and also the factors that are important to the rate of breakdown. The objective of this study was to investigate the impact of variations of the microstructure, created by changing the interior protein concentration and the production and processing method, on the gastric digestion rates and mechanisms of oil filled protein beads. 


\subsection{Materials and methods}

\subsubsection{Materials}

Whey protein isolate (WPI) purity $98 \%$ (Davisco Foods international, France), Alginate (Texturas, Barcelona, Spain), $\mathrm{CaCl}_{2} \cdot 2 \mathrm{H}_{2} \mathrm{O}$ (purity $\geq 99 \%$, Merck, Germany), ethanol absolute (purity $\geq 99.2 \%$, Merck, Germany), polyglycerol polyricinoleate (PGPR) 90 kosher (Danisco, Denmark), Medium Chain Triglycerides (MCT) (Miglyol 812 N, Sasol, Germany), Dextran-FITC (40 $\mathrm{kDa}$ ), (Sigma Aldrich, Germany) were all used as received. For the simulated gastric system, $\mathrm{KCl}, \mathrm{NaCl}, \mathrm{MgCl}_{2},\left(\mathrm{NH}_{4}\right)_{2} \mathrm{CO}_{3}$ (Sigma Aldrich, USA), $\mathrm{KH}_{2} \mathrm{PO}_{4}, \mathrm{NaHCO}_{3}$ (Merck, Germany) were used. Pepsin from porcine gastric mucosa (EC.3.4.23.1, Sigma Aldrich, USA) had an activity of $3802 \mathrm{U} / \mathrm{mg}$. Solutions were made in demineralized water.

\subsubsection{Production of WPI heat-set beads $(15 \%, 20 \%, 25 \%$, and rapidly heated $25 \%$ )}

A primary emulsion, which later formed the inner oil phase, was made by mixing $5 \%(\mathrm{w} / \mathrm{w}) \mathrm{MCT}$ in a 15,20 or $25 \%(\mathrm{w} / \mathrm{w})$ protein in water solution (pH 6.8) with the Ultra-Turrax (T 25, Germany) at $8000 \mathrm{rpm}$ for 2 minutes. The emulsion was then further homogenized (Delta instruments, Drachten, The Netherlands) for 4 passes at 100 bar. The primary emulsion itself was then emulsified by slowly adding $10 \%(\mathrm{v} / \mathrm{v})$ to an MCT solution containing $2.5 \%$ (w/w) PGPR, while mixing with the Ultra-Turrax at $4200 \mathrm{rpm}$, thereby creating an $\mathrm{O} / \mathrm{W} / \mathrm{O}$ emulsion. After full addition, the double emulsion was mixed for another 4 minutes. The double emulsion was then put in a water bath of $80^{\circ} \mathrm{C}$ for 20 minutes, while continuously stirring to allow the protein in the water phase to gel.

The rapidly heated $25 \%$ beads were made by slowly adding (in about 10 minutes) the double emulsion to MCT containing 2.5\% PGPR which was preheated to $80^{\circ} \mathrm{C}$. The temperature of the mixture was kept above $79^{\circ} \mathrm{C}$ during the addition of the double emulsion, after which the emulsion was stirred for 20 more minutes at $80^{\circ} \mathrm{C}$. Since the continuous phase is already at about $80^{\circ} \mathrm{C}$ upon addition of the double emulsion droplets, these beads are produced at a much higher temperature gradient $\left(\sim 10^{6} \mathrm{~K} / \mathrm{m}\right)$, then beads produced from double emulsions prepared at room temperature, followed by heating of the entire double emulsion $\left(\sim 10^{3} \mathrm{~K} / \mathrm{m}\right)$. 
For both methods the beads were cooled to room temperature using tap water and stored at $4^{\circ} \mathrm{C}$ for at least a night and until use.

\subsubsection{Production of $\mathrm{CaCl}_{2}$ nanocrystals}

Calcium nanocrystals were made according to the method of Paques et al. [17]. A volume of $5 \%$ of a solution of 0.1 molal $\mathrm{CaCl}_{2} \cdot 2 \mathrm{H}_{2} \mathrm{O}$ in ethanol was emulsified in MCT containing 6\% (w/w) PGPR, with a sonicator (Sonicator S-250A, Branson Ultrasonics, USA) for 1 minute. The emulsion was stirred and heated overnight at $60^{\circ} \mathrm{C}$ without a cover, which allowed the ethanol to evaporate, giving a $5 \% \mathrm{CaCl}_{2}$ nanocrystals dispersion.

\subsubsection{Production of WPI externally gelled beads}

Protein aggregates were made by heating a $10 \%(\mathrm{w} / \mathrm{w})$ protein solution of $\mathrm{pH}$ 8 for 30 minutes at $80^{\circ} \mathrm{C}$ while stirring. After heating, the solutions were cooled with tap water and stored at $4^{\circ} \mathrm{C}$. The double emulsion was prepared as for the heat-set protein beads, however instead of using a 15,20 or $25 \%$ WPI solution the 10\% WPI aggregate solution was used. After emulsification the double emulsion was gelled with calcium by adding the $\mathrm{CaCl}_{2}$ nanocrystal dispersion in a ratio of $7.23 \mathrm{~mL}$ per $10 \mathrm{~mL}$ of double emulsion and stirring it overnight. The beads were stored at $4^{\circ} \mathrm{C}$ until use.

\subsubsection{Removal of beads from the outer oil phase}

Protein microbeads were removed from the oil phase by centrifuging the dispersion at $2500 \mathrm{~g}$ for 2 hours. To remove residual oil sticking to the surface of the beads, the beads were washed. The pellet was redispersed in a $2 \%(\mathrm{w} / \mathrm{w})$ WPI solution, mixed with the Ultra-Turrax at $6000 \mathrm{rpm}$ for 2 minutes and then homogenized at 100 bar for 2 passes. The dispersion was then again centrifuged, now at $400 \mathrm{~g}$ for 45 minutes. The redispersion, mixing, and centrifugation steps were repeated twice, after which the pellet was redispersed in water.

\subsubsection{Freeze-dried protein beads}

The redispersed beads were frozen with liquid nitrogen and Freeze-dried (Christ Alpha 2-4 LD plus, Martin Christ, Germany). The powder was stored in a desiccator until use. 


\subsubsection{Surface morphology}

Surface morphology was examined by scanning electron microscopy (SEM; Magellan 400, FEI, Eindhoven, the Netherlands). The samples were adhered to coverslips, critical point dried with $\mathrm{CO}_{2}$, and then sputter coated (Leica EM SCD 500, Leica, Vienna, Austria) with a $10 \mathrm{~nm}$ iridium layer.

\subsubsection{Protein and oil content}

To measure the encapsulation efficiency the beads were freeze-dried to remove all water. The protein content of the dried beads was measured by DUMAS (Flash EA 1112 Analyzer, Thermo Fisher Scientific, USA). The rest of the weight was assumed to be oil.

\subsubsection{Dry matter content}

Addition of the amount of beads to the simulated gastrointestinal system was based on equal amounts of beads, which was based on dry matter content. A measured volume of dispersion was put in an oven of $105^{\circ} \mathrm{C}$ overnight. Based on the dry matter content a calculation was made (with the assumption that no oil was added or lost during the second emulsification step) to find the volume of beads. The bead dispersion was diluted to a volume fraction of 0.20 . MCT is not volatile and did not noticeably evaporate during 20 hours at $105^{\circ} \mathrm{C}$.

\subsubsection{Simulated gastric system}

The gastrointestinal system was made as described by Minekus et al. [18]. We assumed the beads to be present in a liquid phase, thereby bypassing the oral phase. Simulated gastric fluid (SGF) electrolyte stock solutions were made as described. A $20 \%(\mathrm{v} / \mathrm{v})$ bead dispersions and the $\mathrm{CaCl}_{2}$ solution were added to SGF after which the $\mathrm{pH}$ was adjusted to 3 . The solution was put on an automatic stirrer at $37^{\circ} \mathrm{C}$. Then pepsin was added in the concentrations mentioned $(2000 \mathrm{U} / \mathrm{mL})$. Every 6 minutes, before and during enzyme treatment, samples were taken and bead size was measured.

\subsubsection{Size distribution}

The size distribution of the beads, before and during the treatment in the simulated gastrointestinal system, was measured with the Mastersizer (Malvern Mastersizer 2000, Malvern Instruments, UK) using laser diffraction. The volume percent of the beads, oil droplets, and aggregates was determined 
by calculating the surface area of the respective peaks in the particle size distribution curve. The results shown are an average of two measurements, the error bars show the standard deviation.

\subsubsection{Light microscopy}

Pictures of the rehydrating freeze-dried $25 \%$ beads were made with a light microscope (Axioskop 2 plus, Carl Zeiss, Germany)

\subsubsection{Diffusion of probe molecules}

To further investigate whether the breakdown of the protein beads was diffusion or reaction limited, the diffusion through the matrix was investigated using a tracer particle of similar molecular weight as pepsin. Dextran-FITC (40 kDa) was added in $20 \mathrm{mmol}$ (similar as to the pepsin concentration in the stomach) to $1 \%$ samples of the $25 \%$ heat-set, $25 \%$ rapidly heated, $25 \%$ hydrated freeze-dried and 10\% cold-set beads in simulated gastric fluid (SGF) at $\mathrm{pH}$ 3. The diffusion of the Dextran-FITC over time was examined by confocal laser scanning microscopy (CSLM, Leica TCS-SP5, Leica Microsystems B.V., Rijswijk, Netherlands).

\subsection{Results and discussion}

\subsubsection{Surface morphology}

Protein beads were created by the various preparation methods and imaged with SEM, the results of which can be found in Figure 3.1. The 15, 20, 25 and rapidly heated $25 \%$ heat-set beads have an open and porous structure. The pores appear to be large enough for a pepsin molecule (34620 Da, about 10 $\mathrm{nm}$ ) to enter, which suggests that these beads should display a reaction-limited breakdown. The $10 \%$ cold-set beads have a much denser surface structure. There are still pores visible, however they are much smaller than in the heatset beads. This might slow or completely stop the diffusion of pepsin into the beads, therefore the cold-set beads are more likely to give a diffusion limited breakdown. The actual concentration of protein in the $10 \%$ cold-set bead is however lower than for the heat-set beads, which are made from protein concentrations of $15 \%$ and above, which means that less protein needs to be broken down before the inner oil droplets are released. The freeze-dried 25\% 
beads show a very dense surface with several large surface defects. The surface of the $25 \%$ heat-set beads is thus changed by the process of freezing and freeze-drying. The denser the surface, the more likely it is to hinder diffusion and access of pepsin. The cracks in the surface are however likely to promote bead breakdown.

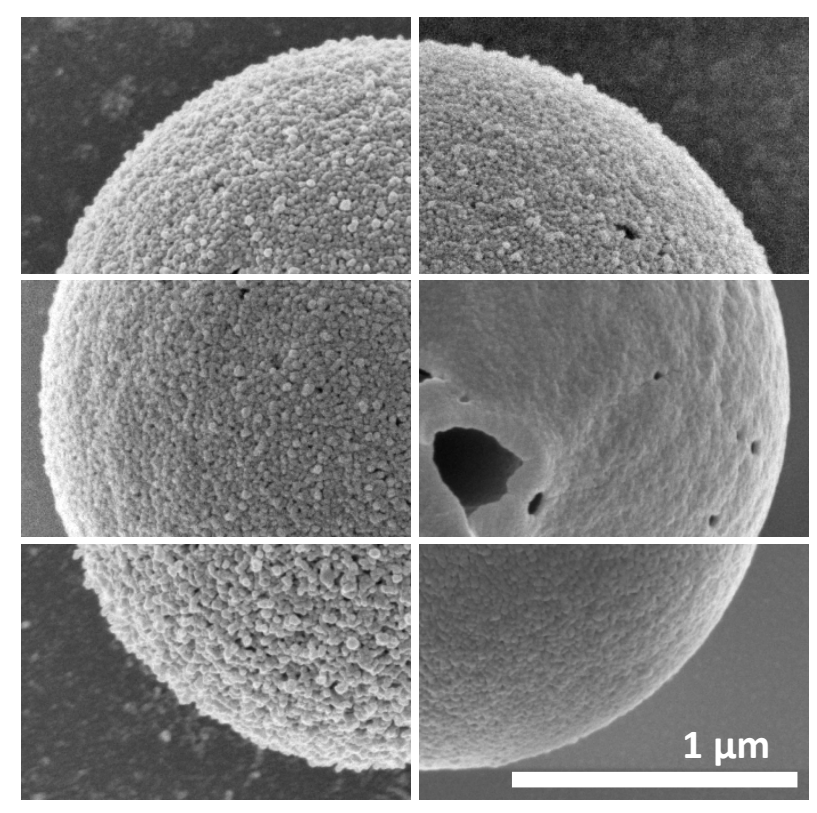

Figure 3.1: SEM images of sections of protein microbeads. Left-hand side, up-down: 25\%, 20\%, 15\% heat-set. Right-hand side, up-down: rapidly heated $25 \%$ heat-set, freeze-dried $25 \%$ heat-set, $10 \%$ cold-set.

\subsubsection{Protein content}

The measured vs. the calculated protein content is shown in Table 3.1. The calculated protein content is the amount of protein that was put into the system. The measured protein content is the amount of protein actually measured by DUMAS. Since the sample was completely dried, we have assumed for the calculated value that the beads consist primarily of protein and oil, and have neglected any contributions from salts to the total weight. Based on the DUMAS results, it can be seen that for all samples the measured protein content is lower than the expected protein content. This reduction of 
protein content means that either extra oil was emulsified into the protein phase during the double emulsification step, or that protein was lost from the matrix during washing. It is probable that during the washing steps, protein that was not tightly bound in the matrix was washed out. The $10 \%$ beads which were gelled with the cold-set method lost the most protein, about $9 \%$ while the other samples lost on average about $2 \%$. The amount of aggregation that occurs between proteins is dependent on the protein concentration [19]. The cold-set gel of only $10 \%$ protein is therefore expected to have the highest concentration of non-aggregated protein present. These non-aggregated proteins can diffuse out of the bead during washing. Other authors also saw loss of protein from their system $[8,20,21]$. Though it is impossible to say if oil was lost during emulsification and gelation, based on the DUMAS results it can be concluded that a large amount of the oil originally added to the interior of the beads is still present.

Table 3.1: The expected amount and the measured amount of protein in the beads are given.

\begin{tabular}{l|cr} 
Microbead & $\begin{array}{c}\text { Expected protein } \\
\text { content } \%(\mathrm{w} / \mathrm{w})\end{array}$ & $\begin{array}{l}\text { Measured protein content } \\
\%(\mathrm{w} / \mathrm{w})\end{array}$ \\
\hline $25 \%$, heat-set & 82.46 & $81.02( \pm 0.36)$ \\
$20 \%$, heat-set & 79.00 & $77.45( \pm 0.36)$ \\
$15 \%$, heat-set & 73.83 & $70.70( \pm 0.08)$ \\
$10 \%$, cold-set & 65.29 & $55.95( \pm 0.10)$ \\
$25 \%$, quick heat-set & 82.46 & $79.98( \pm 0.19)$
\end{tabular}

\subsubsection{Bead breakdown}

The graphs of Figure 3.2 show the size distribution of components present during the breakdown of the beads in SGF. Enzyme was added separately after 6 minutes, to see if the beads react to the SGF itself. 

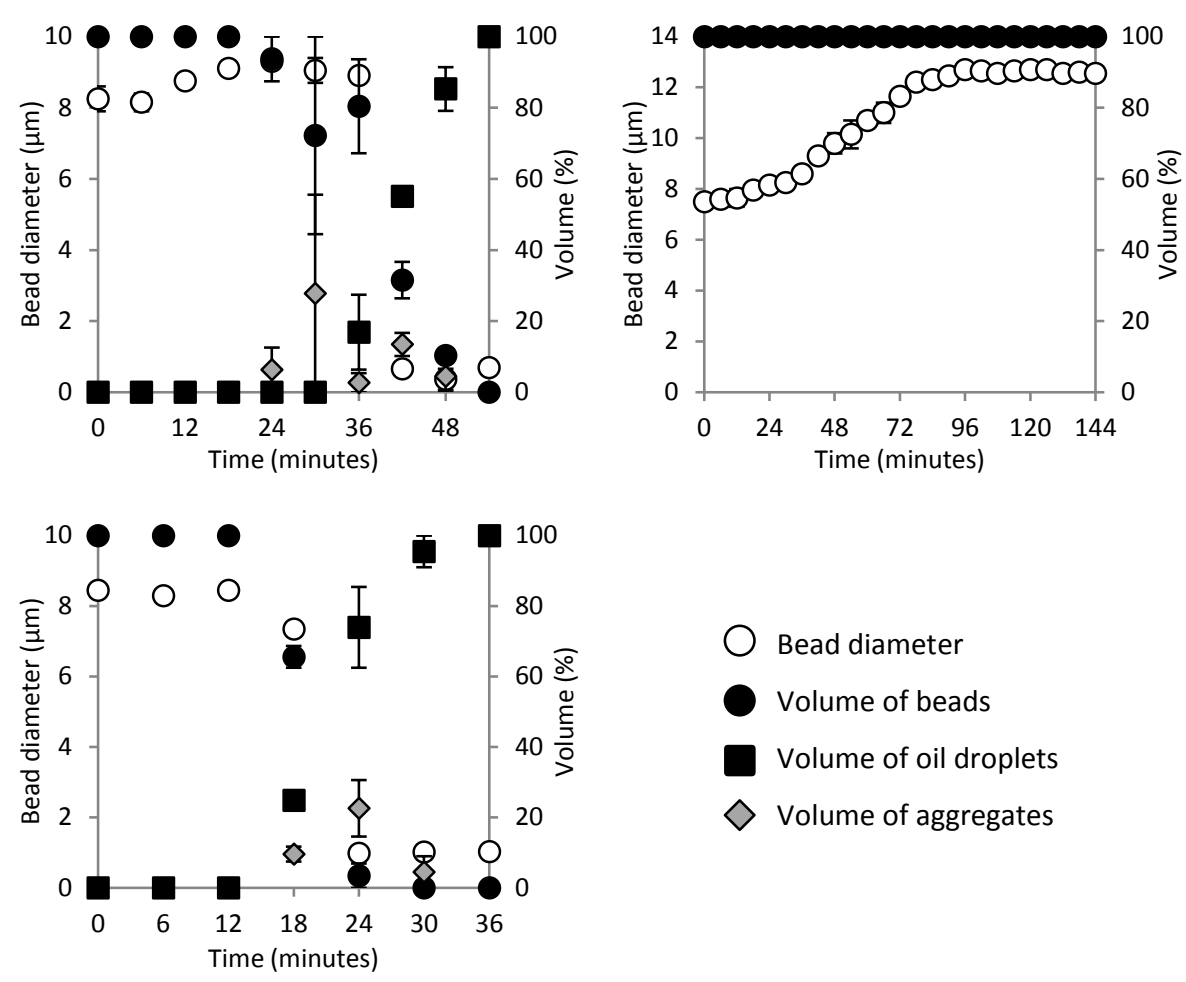

Bead diameter

Volume of beads

Volume of oil droplets

$\diamond$ Volume of aggregates
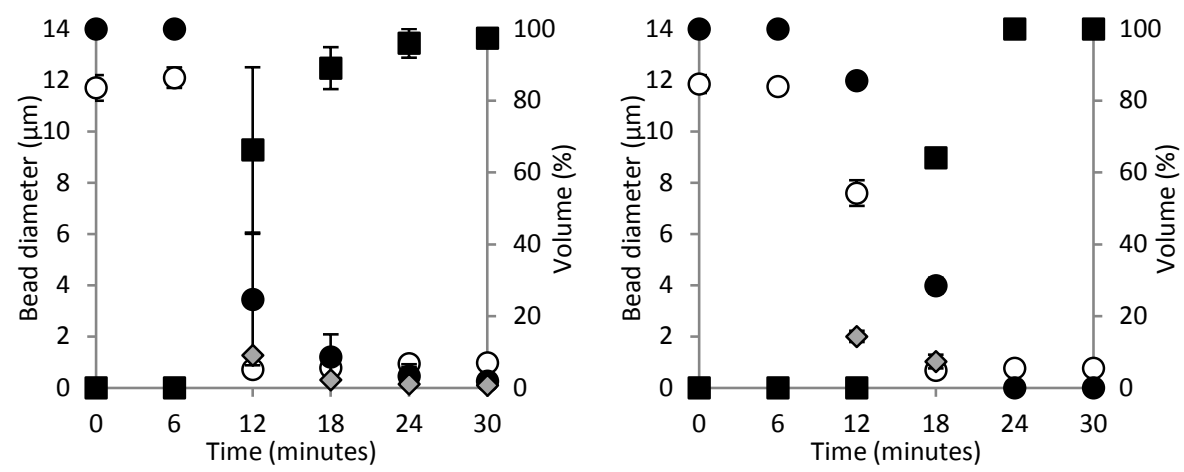

Figure 3.2: Breakdown of WPI beads made with different WPI concentrations and process conditions. Left, top to bottom: 25\%, 20\%, 15\% heat-set. Right, top to bottom: rapidly heated $25 \%$ heat-set, $10 \%$ cold-set. 
During the breakdown of the beads we determined the size distribution of the beads as a function of time. Figure 3.3 shows an example of the size distribution graphs over time. The solid line is the size distribution of the oil droplets in the $25 \%$ WPI solution, after the first emulsification, but before the second emulsification and gelation step. At $\mathrm{t}=0$ (min.) a sample was taken just before the addition of pepsin. The size distribution shows only the beads which are about $10 \mu \mathrm{m}$ in size. During the breakdown of the beads, sometimes particles were detected with a size of around $100 \mu \mathrm{m}$. These large particles were few in number and were most likely aggregates of beads and/or oil droplets. These peaks always disappeared when the beads were completely broken down which suggests that flocculation was induced by the partially broken down protein. The actual content of these peaks are discussed per sample. At $\mathrm{t}=42$ (min.) the breakdown is in progress, oil droplets, beads and aggregates are present. At $\mathrm{t}=54$ ( $\mathrm{min}$.) no further breakdown occurs and only oil droplets, which are not affected by the presence of pepsin, are present.

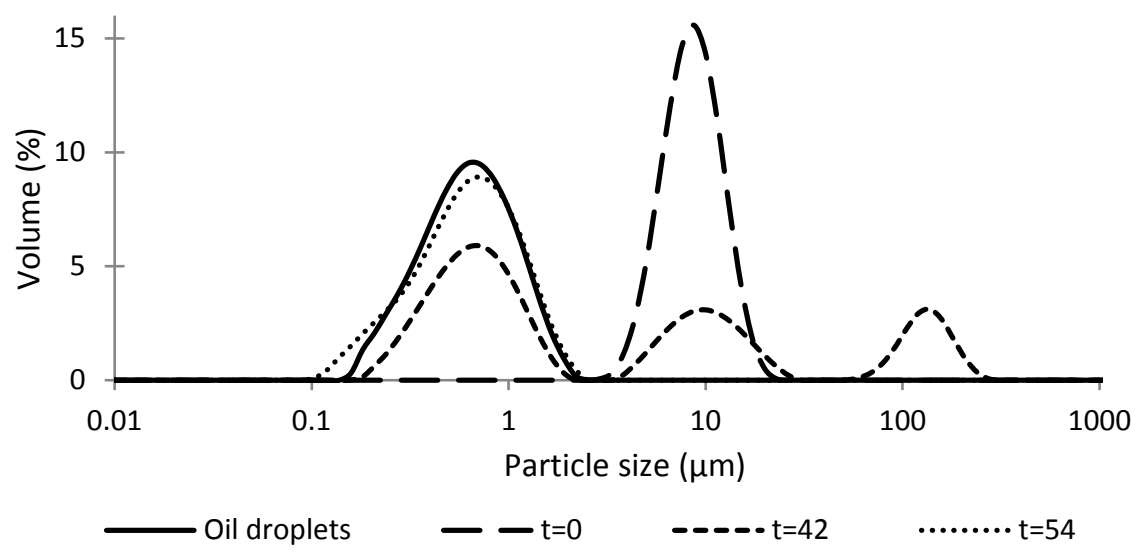

Figure 3.3: Size distribution graph during the breakdown of the 25\% heat set beads, time is in minutes

For the $25 \%$ beads, after the enzyme was added, the average diameter of the beads increased over 18 minutes, from about $8 \mu \mathrm{m}$ to $9 \mu \mathrm{m}$. This suggests that the enzymes diffused into the beads where they have broken bonds. Together with the low $\mathrm{pH}$ of the system, this led to swelling of the beads. After 18 minutes the bead diameter decreased, which suggests a breakdown of the 
beads. Single oil droplets were first detected 30 minutes after the addition of pepsin. When about $20 \%$ of the volume represented single oil droplets, and thus a significant amount of beads had broken down, the diameter of the beads $(8.9 \mu \mathrm{m})$ was still larger than the diameter of the beads before pepsin was added $(8.2 \mu \mathrm{m})$. These observations suggest a mechanism where the pepsin was able to diffuse into the bead relatively fast. Subsequently the enzyme started to break down the protein matrix throughout the entire bead, and when enough bonds had been broken the bead disintegrated into smaller pieces, releasing the oil droplets. The smaller pieces initially (at least partially) aggregated into larger clusters, and are subsequently broken down even further. Therefore for the $25 \%$ heat-set beads the breakdown mechanism is reaction limited. Within 48 minutes of the beads entering the simulated gastric system, all the internal oil droplets were released.

The 20\% WPI beads started releasing oil droplets 12 minutes after addition of the enzyme. No significant increase in diameter was seen as for the $25 \%$ beads. However, because of their microstructure, which is similar to that of the $25 \%$ beads (as seen in the SEM images) and the lower amount of protein present, we assume that here the enzymes were also able to diffuse relatively fast throughout the bead, and the breakdown mechanism is reaction limited. After the first 12 minutes, where oil droplets were first observed, most of the beads broke down within the next 12 minutes. For the $20 \%$ beads, both the lag time before release of oil droplets and the time within which the oil droplets were completely released were significantly shorter than for the $25 \%$ heat-set beads.

The $15 \%$ heat-set beads started releasing their oil immediately after addition of pepsin which is too fast to allow any conclusions about the mechanism of breakdown. From the similarities in microstructure observed in the SEM images between the $15 \%$ beads and the 25 and $20 \%$ heat-set beads, it is reasonable to assume that the breakdown was again reaction limited. Where the $25 \%$ beads were stable for 24 minutes, and the $20 \%$ beads were stable for 12 minutes, the $15 \%$ beads were stable for less than 6 minutes. Extrapolating these observations, the $10 \%$ beads were expected to break down more quickly than the $15 \%$ beads.

However the $10 \%$ cold-set beads showed a release of individual oil droplets 12 minutes after pepsin addition. In that same time span the peak height in the 
volume distribution of the beads reduced by about $20 \%$ and the bead diameter was reduced from 12 to about $8 \mu \mathrm{m}$. This more gradual decrease (compared to that observed in the 15 to $25 \%$ beads) in size suggests that the beads were broken down from the outside in, and the breakdown is therefore predominantly diffusion limited, which is different from the heat-set beads. A decrease in diameter from 12 to $8 \mu \mathrm{m}$ corresponds to a decrease in volume of the beads of $70 \%$. With such an extent of breakdown and the fact that oil droplets were present throughout the bead, it is unlikely that oil droplets were not released during the first 12 minutes. The oil droplets may have initially been in a flocculated state and hence represented by the aggregate peak.

When comparing the extent of breakdown of the beads after 12 minutes it is visible that for the $15 \%$ heat-beads the amount of beads has decreased more than for the $10 \%$ cold-set beads, about $75 \%$ decrease versus $15 \%$. The $15 \%$ heat-set beads thus broke down faster than the $10 \%$ cold-set beads, despite the lower protein content of the $10 \%$ beads. The SEM results show that the $10 \%$ beads have a much denser surface and this denser surface may slow down the diffusion of pepsin into the interior of the beads. As a result the breakdown mechanism has shifted from reaction limited to diffusion limited.

The rapidly-heated $25 \%$ heat-set beads broke down much more slowly than the standard $25 \%$ heat-set beads. The rapidly-heated beads showed a much more significant degree of swelling of the beads in this initial phase of the breakdown (from 7.5 to $13.6 \mu \mathrm{m}$ ). After 90 minutes, the radius did not increase further, and remained stable. No significant release of oil droplets was registered in a time span of 138 minutes, which is longer than the average residence time of 2 hours in the stomach, according to Minekus et al. [18]. Beads which are put in SGF without pepsin did not show a significant change in radius (results not shown) so the pepsin clearly plays a role in the increase in radius. The fast temperature increase from room temperature to $80^{\circ} \mathrm{C}$, apparently resulted in a significantly different protein matrix which was much more resistant to enzymatic breakdown. This difference in matrix is however not visible in SEM analysis and there was also no significant difference in protein content of the beads.

The difference in protein matrix that was found between the $25 \%$ heat- set and rapidly-heated $25 \%$ heat-set beads might be found in the mechanism of protein gelation. Protein gelation occurs roughly in two steps: the unfolding of the 
protein and the progressive aggregation of the unfolded protein until a network is formed. The rapid heating most likely did not allow for complete unfolding of the protein before aggregation occurred, resulting in a network with proteins with more native folds than a network induced by slow heating. Barbé et al. found that unheated $\beta$-lactoglobulin shows more resistance to hydrolysis in the stomach than heated $\beta$-lactoglobulin, which breaks down more easily [13]. Dalgalarondo et al. similarly found that $\beta$-lactoglobulin was only cleaved in ethanol concentrations higher than $20 \%$, where the presence of ethanol caused changes in the structure of $\beta$-lactoglobulin [22].
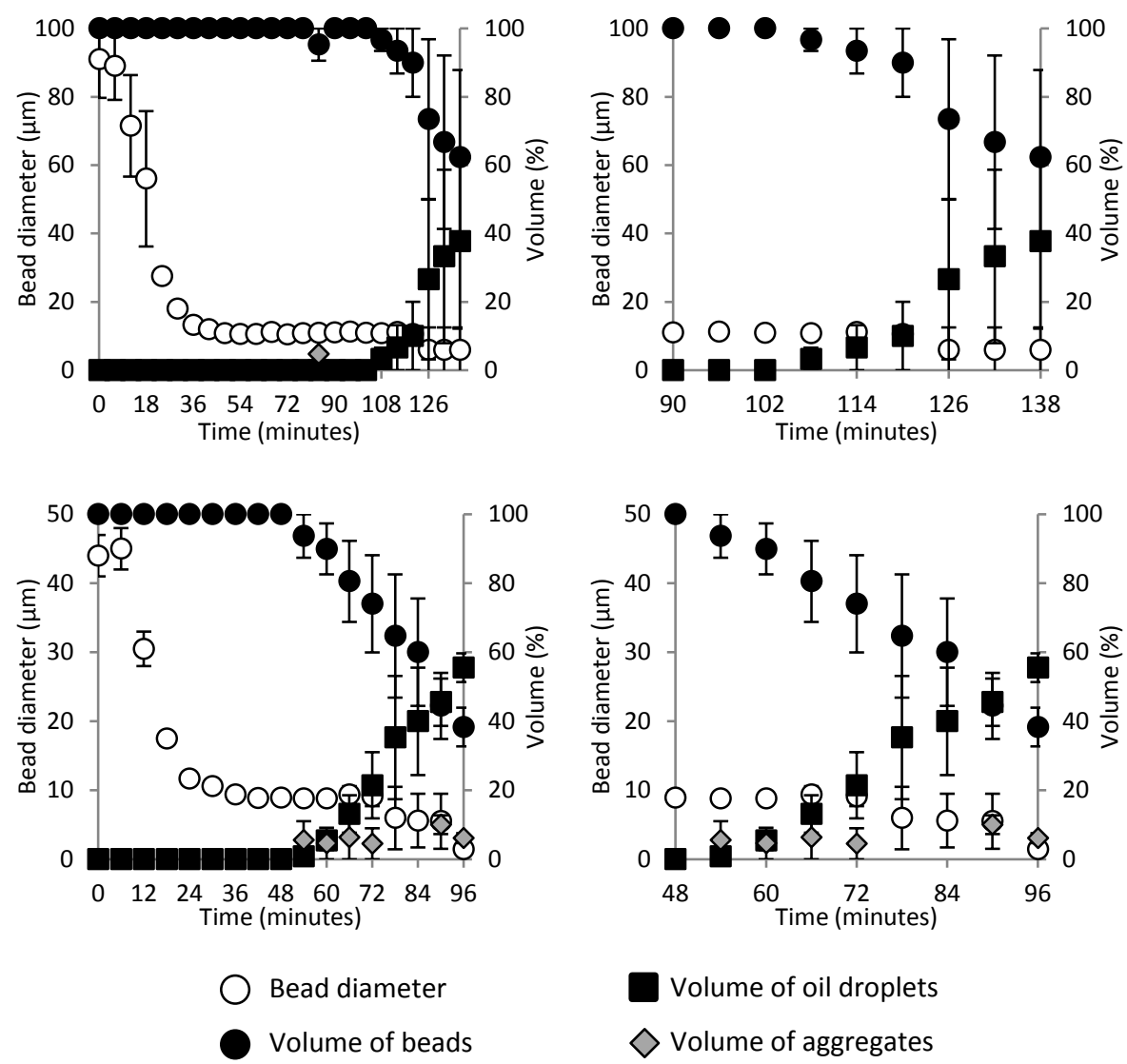

Figure 3.4: Breakdown of WPI beads. Top: left: freeze-dried beads, right: detail of a single measurement. Bottom: left: hydrated freeze-dried beads, right: detail of a single measurement. 
Figure 3.4 shows the breakdown of freeze-dried, $25 \%$ heat-set beads. The freeze-dried $25 \%$ beads broke down slower than the standard $25 \%$ heat-set beads. At the start of the measurement we observed large aggregates, which were most likely flocs of beads, which were slowly broken up by gentle stirring, both in water and after addition of SGF. The addition of pepsin increased the rate in which the flocs fell apart into separate beads. After 30 minutes most beads appeared to be separated. Their size and number was then stable for another 66 minutes before oil droplets were released. The data shows more variation here. However, on average, after an enzyme treatment of 132 minutes, longer than the average residence time of 2 hours in the stomach, about $60 \%$ of the volume still consisted of intact beads. These beads hence broke down much more slowly than the standard $25 \%$ heat-set beads.

Upon microscopic observation of the freeze-dried 25\% heat-set beads during enzymatic breakdown in the simulated gastric system, a distinct line within the beads was observed, which moved further inward over time (Figure 3.5, left). This is most likely a hydration front which slowly moved into the bead. The breakdown of the beads might be slowed down by the time the bead needs to fully hydrate. In regions that are not fully hydrated, the enzyme cannot diffuse easily and thus cannot break down the matrix. To see if the removal of this hydration time would give a similar breakdown pattern as the standard $25 \%$ heat-set beads, a sample of the freeze-dried beads was left in water overnight and given the SGF and pepsin treatment the next day. Microscopic observation showed that this hydration line was not present anymore and full hydration was assumed (Figure 3.5, right).
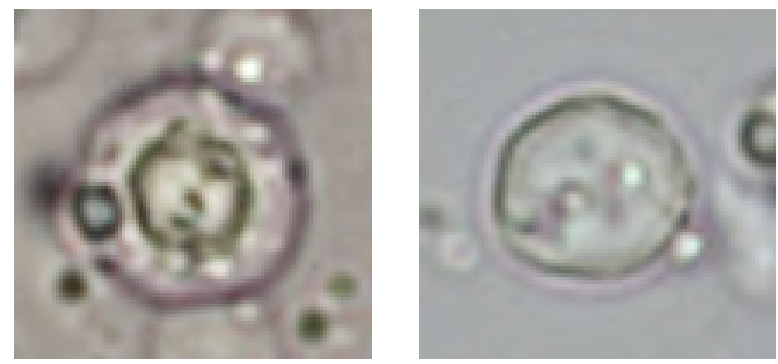

Figure 3.5: Microscopic observations of freeze-dried WPI beads during gastric treatment. After 60 minutes in SGF (left), after overnight stirring in water (right). 
The hydrated, freeze-dried beads also showed flocs at the start of the measurement, but these were smaller than those observed in the sample which was not rehydrated. After about 18 minutes (compared to 30 minutes for the freeze-dried sample) the flocs were broken down to single beads by the presence of pepsin. After 36 more minutes, 6 minutes more than for the standard $25 \%$ heat-set beads but 36 minutes less than for the freeze-dried beads, individual oil droplets started being released. Again the data shows significant variation here, but substantial release occurs within the average time of 2 hours that food stays in the stomach.

In the detailed graph of the freeze-dried and rehydrated, freeze-dried beads, it can be seen that when oil droplets were released, the bead diameter was still as large as it was before oil droplets were released, as was also with the standard $25 \%$ beads. This means that, though the breakdown was markedly slower than the standard $25 \%$ beads, it was still a reaction limited breakdown.

Compared to the normal $25 \%$ heat-set beads, it took more time before oil droplets were released from the hydrated beads, and it took more time before all beads were broken down. Compared to the freeze-dried beads, it took less time before oil droplets were released from the hydrated beads and it took less time for the beads to break down. This was partly caused by the flocculation and dehydration, as hydrated freeze-dried beads broke down more quickly, but removal of the flocculation and dehydration did not revert the freeze-dried sample to the behaviour of the non- freeze-dried sample. The breakdown was still markedly slower. In the SEM results it can be seen that the surface morphology of the freeze-dried and non-freeze-dried samples was very different. Strambini and Gebellieri found that changes in secondary and tertiary structure occur in single tryptophan molecules when freezing [23]. Li et al. found that freeze-drying increased aggregate size of soy proteins [24]. The freezing and freeze-drying process thus changed the structure markedly, as also seen in the SEM images. This change slowed down the breakdown of the beads. Because both systems are reaction limited, we expect that the process of freeze-drying created protein structures within the bead, which were harder for pepsin to cut. 


\subsubsection{Diffusion of probe molecules}

Images of the diffusion of Dextran-FITC through the beads can be found in Figure 3.6. The green areas in the image indicate where Dextran-FITC is present. Images $\mathrm{A}, \mathrm{B}$ and $\mathrm{C}$ show that Dextran-FITC diffuses into and throughout the $25 \%$ heat-set, $25 \%$ rapidly heated and $25 \%$ hydrated freezedried beads within 1.5 minutes. For the $25 \%$ heat-set and $25 \%$ hydrated freezedried, and thereby by extension also $20 \%$ and $15 \%$ heat-set beads, the diffusion is therefore confirmed to be very fast and the breakdown of the beads is predominantly reaction limited. Images D show that the Dextran-FITC does not diffuse easily into the $10 \%$ cold-set bead. After 1.5 minutes, there is clearly more Dextran-FITC at the outer perimeter than in the centre of the bead. Only after 12 minutes is the Dextran-FITC homogenously distributed throughout the bead. The mechanism of breakdown for the $10 \%$ beads is therefore more likely to be diffusion than reaction limited.
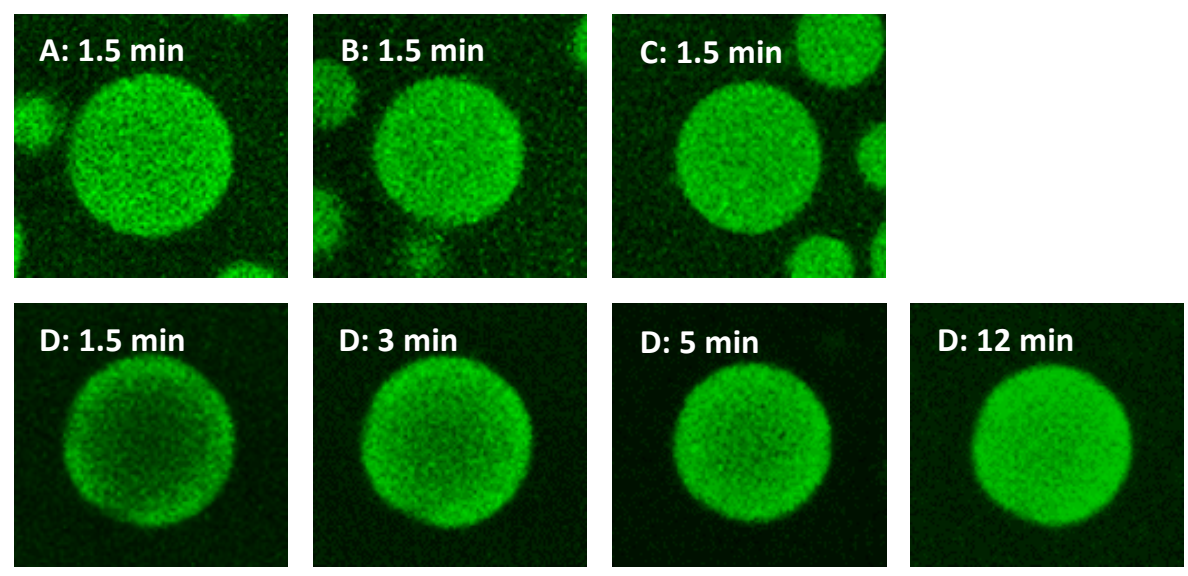

Figure 3.6: Diffusion of Dextran-FITC through 25\% heat-set (A), 25\% rapidly heated (B) 25\% freeze-dried, hydrated (C) and 10\% cold-set (D) beads over time in minutes.

The results of this study have been summarised in Table 3.2 In this study we showed that the structure of filled hydrogel beads is important for the rate and way these beads break down and release their load. The variations of release found in this study, while using the same building blocks, gives opportunities in the creation of novel targeted release systems. When a quick release of the 
encapsulated compound is required, a low protein concentration and a reduced heating gradient during gelation are recommended. When a delayed release in the intestinal tract is required, a high protein concentration, external gelation, an increased heating gradient during gelation and application of freeze-drying should be used. In the case of slow release systems, and thus slow digestion of the proteins, one must however be aware that the release and digestion can be so slow as to reduce the nutritional availability and also that not fully digested proteins can cause allergic reactions in the intestine [25]. 
Table 3.2: Summary of rate and way of breakdown of WPI beads with different protein concentrations, gelation methods and further processing, in order of breakdown rate.

\begin{tabular}{|c|c|c|c|c|}
\hline $\begin{array}{l}\text { Bead type } \\
\text { (in order of } \\
\text { breakdown } \\
\text { rate) }\end{array}$ & Microstructure & $\begin{array}{l}\text { Type of } \\
\text { breakdown }\end{array}$ & $\begin{array}{l}\text { Start } \\
\text { release } \\
\text { (minutes) }\end{array}$ & $\begin{array}{l}\text { Complete } \\
\text { breakdown } \\
\text { (minutes) }\end{array}$ \\
\hline $\begin{array}{l}15 \% \text { protein } \\
\text { Heat-set }\end{array}$ & & $\begin{array}{l}\text { Reaction } \\
\text { limited }\end{array}$ & 6 & 18 \\
\hline $\begin{array}{l}10 \% \text { protein } \\
\text { External - } \\
\text { Cold-set }\end{array}$ & & $\begin{array}{l}\text { Diffusion } \\
\text { limited }\end{array}$ & 6 & 18 \\
\hline $\begin{array}{l}20 \% \text { protein } \\
\text { Heat-set }\end{array}$ & & $\begin{array}{l}\text { Reaction } \\
\text { limited }\end{array}$ & 12 & 24 \\
\hline $\begin{array}{l}25 \% \text { protein } \\
\text { Heat-set }\end{array}$ & & $\begin{array}{l}\text { Reaction } \\
\text { limited }\end{array}$ & 18 & 48 \\
\hline \multirow[t]{2}{*}{$\begin{array}{l}25 \% \text { protein } \\
\text { Freeze-dried - } \\
\text { Hydrated }\end{array}$} & & $\begin{array}{l}\text { Reaction } \\
\text { limited }\end{array}$ & 54 & $>90^{\mathrm{a}}$ \\
\hline & \multicolumn{4}{|c|}{2 hours: average residence time of food in the stomach } \\
\hline $\begin{array}{l}25 \% \text { protein } \\
\text { Freeze-dried }\end{array}$ & & $\begin{array}{l}\text { Reaction } \\
\text { limited }\end{array}$ & 120 & $>132^{b}$ \\
\hline $\begin{array}{l}25 \% \text { protein } \\
\text { Heat-set - Fast } \\
\text { heat increase }\end{array}$ & & $\begin{array}{l}\text { No } \\
\text { breakdown, } \\
\text { some } \\
\text { swelling }\end{array}$ & $>148$ & $>148^{\mathrm{c}}$ \\
\hline
\end{tabular}

a: about $60 \%$ of the volume at the time mentioned is released oil droplets

b: about $60 \%$ of the volume at the time mentioned is released oil droplets

c: about $0 \%$ of the volume at the time mentioned is released oil droplets 


\subsection{Conclusions}

In this study we investigated the influence of protein concentration, method of gelation, and freeze-drying on the rate and way of breakdown of oil filled protein microbeads.

Similarly produced microbeads with a higher protein concentration break down slower. The porous nature of the heat-set beads assured that the pepsin could diffuse throughout the bead and break the entire bead down evenly, resulting in a reaction limited breakdown process. The cold-set $10 \%$ protein microbead was broken down slightly slower than the $15 \%$ heat-set beads. Because of the method of gelation, the surface of the $10 \%$ beads was much denser, which resulted in a diffusion barrier for the pepsin and resulted in a diffusion-limited breakdown of the beads. Increasing the rate of temperature increase of the heating step changed the breakdown kinetics of the $25 \%$ heatset beads, and these beads needed more than 2 hours to break down. Both the standard $25 \%$ and rapidly heated $25 \%$ heat-set beads allowed diffusion of enzyme throughout the bead and no difference in surface morphology or probe diffusion was seen. When the $25 \%$ beads are freeze-dried, the rate of breakdown is greatly slowed. Flocculation and dehydration of the beads were important factors but rehydrating did not revert the breakdown kinetics of the freeze-dried beads back to that of the standard $25 \%$ beads. The freeze-drying altered the microstructure of the beads, therefore it took longer for the pepsin to break down the structure.

\section{Acknowledgements}

The research presented in this paper was financially supported by the Graduate School VLAG, of Wageningen University. 


\section{References:}

1. McClements, D.J., Nanoparticle-and microparticle-based delivery systems: Encapsulation, protection and release of active compounds. 2014: CRC Press.

2. McClements, D.J., Advances in fabrication of emulsions with enhanced functionality using structural design principles. Current Opinion in Colloid \& Interface Science, 2012. 17(5): p. 235-245.

3. Singh, H., A. Ye, and M.J. Ferrua, Aspects of food structures in the digestive tract. Current Opinion in Food Science, (0).

4. Parada, J. and J.M. Aguilera, Food Microstructure Affects the Bioavailability of Several Nutrients. Journal of Food Science, 2007. 72(2): p. R21-R32.

5. Armand, M., et al., Effects of droplet size, triacylglycerol composition, and calcium on the hydrolysis of complex emulsions by pancreatic lipase: an in vitro study. The Journal of Nutritional Biochemistry, 1992. 3(7): p. 333-341.

6. Li, Y., et al., Control of lipase digestibility of emulsified lipids by encapsulation within calcium alginate beads. Food Hydrocolloids, 2011. 25(1): p. 122-130.

7. Van Leusden, P., et al., Strength of microbeads for the encapsulation of heat sensitive, hydrophobic components. Food Hydrocolloids, 2016. 56: p. 318-324.

8. Doherty, S.B., et al., Development and characterisation of whey protein micro-beads as potential matrices for probiotic protection. Food Hydrocolloids, 2011. 25(6): p. 1604-1617.

9. Picot, A. and C. Lacroix, Encapsulation of bifidobacteria in whey protein-based microcapsules and survival in simulated gastrointestinal conditions and in yoghurt. International Dairy Journal, 2004. 14(6): p. 505-515.

10. Reid, A.A., et al., Microentrapment of probiotic bacteria in a Ca2+-induced whey protein gel and effects on their viability in a dynamic gastro-intestinal model. Journal of Microencapsulation, 2005. 22(6): p. 603-619.

11. Guo, Q., et al., Disintegration kinetics of food gels during gastric digestion and its role on gastric emptying: an in vitro analysis. Food \& Function, 2015. 6(3): p. 756764.

12. Luo, Q., R.M. Boom, and A.E.M. Janssen, Digestion of protein and protein gels in simulated gastric environment. LWT - Food Science and Technology, 2015. 63(1): p. 161-168.

13. Barbé, F., et al., The heat treatment and the gelation are strong determinants of the kinetics of milk proteins digestion and of the peripheral availability of amino acids. Food Chemistry. 136(3-4): p. 1203-1212.

14. Gombotz, W.R. and S.F. Wee, Protein release from alginate matrices. Advanced Drug Delivery Reviews, 2012. 64: p. 194-205.

15. Bryant, C.M. and D.J. McClements, Molecular basis of protein functionality with special consideration of cold-set gels derived from heat-denatured whey. Trends in Food Science \& Technology, 1998. 9(4): p. 143-151.

16. Kim, S.B., et al., Peptic and tryptic hydrolysis of native and heated whey protein to reduce its antigenicity. Journal of Dairy Science, 2007. 90(9): p. 4043-4050.

17. Paques, J.P., et al., Alginate submicron beads prepared through w/o emulsification and gelation with CaCl2 nanoparticles. Food Hydrocolloids, 2012. 31(2): p. 428434.

18. Minekus, M., et al., A standardised static in vitro digestion method suitable for foodan international consensus. Food \& function, 2014. 5(6): p. 1113-1124.

19. Alting, A.C., et al., Number of thiol groups rather than the size of the aggregates determines the hardness of cold set whey protein gels. Food Hydrocolloids, 2003. 17(4): p. 469-479. 
20. Croguennoc, P., et al., Self-diffusion of Native Proteins and Dextran in Heat-set Globular Protein Gels. The Journal of Physical Chemistry B, 2001. 105(24): p. 57825788.

21. Wu, C., et al., Release Behavior of Non-Network Proteins and Its Relationship to the Structure of Heat-Induced Soy Protein Gels. Journal of Agricultural and Food Chemistry, 2015. 63(16): p. 4211-4219.

22. Dalgalarrondo, M., et al., Proteolysis of $\beta$-lactoglobulin and $\beta$-casein by pepsin in ethanolic media. International Dairy Journal, 1995. 5(1): p. 1-14.

23. Strambini, G.B. and E. Gabellieri, Proteins in frozen solutions: evidence of iceinduced partial unfolding. Biophysical journal, 1996. 70(2): p. 971.

24. Li, X., et al., Effect of concentration, ionic strength and freeze-drying on the heatinduced aggregation of soy proteins. Food Chemistry, 2007. 104(4): p. 1410-1417.

25. Wickham, M., R. Faulks, and C. Mills, In vitro digestion methods for assessing the effect of food structure on allergen breakdown. Molecular Nutrition \& Food Research, 2009. 53(8): p. 952-958. 


\section{Chapter 4}

\section{Permeation of probe molecules into alginate microbeads: Effect of salt and processing}

This chapter has been published as: P. van Leusden, G.J.M. den Hartog, A. Bast, M. Postema, E. van der Linden, L.M.C. Sagis (2017) Permeation of probe molecules into alginate microbeads: Effect of salt and processing, Food Hydrocolloids, 73, 255-261 


\begin{abstract}
The ability to exclude harmful factors from a hydrogel microbead is important for the degree of protection the beads offers to what is encapsulated within. The permeability of alginate microbeads, prepared by water-in-oil emulsification, was investigated by their ability to exclude FITC-labelled protein probes. The influence of alginate concentration, calcium concentration and method of addition, and salt content of the environment was investigated. The permeability was also compared to the permeability of beads made by the traditional method of dripping an alginate solution into a $\mathrm{CaCl}_{2}$ solution. Beads produced with low amounts of $\mathrm{CaCl}_{2}$ show a significant degree of swelling and are therefore very permeable $\left(\mathrm{C} / \mathrm{C}_{0}(\mathrm{BSA})=0.62\right.$, where $\mathrm{C}$ is the final concentration of BSA-FITC in the bead, and $\mathrm{C}_{0}$ the concentration of BSA-FITC in the continuous phase). With additional calcium, either by adding more calcium crystals after the emulsification step or by washing with a $\mathrm{CaCl}_{2}$ solution, beads swell less and are less permeable $\left(\mathrm{C} / \mathrm{C}_{0}(\mathrm{BSA})=0.13\right.$ and 0.12 ). Beads made by dripping are very permeable $\left(C / \mathrm{C}_{0}(\mathrm{BSA}) \sim 0.60\right)$. Because in this process the droplets of alginate are not constrained by a wateroil boundary, the beads can swell during gelation. The salt concentration in the continuous phase influences the strength of the electrostatic repulsion between the probes and the alginate network and hence affects the permeation of the probes into the beads. In the absence of salt, even FITC (389Da) is mostly excluded from the interior of the beads $\left(\mathrm{C} / \mathrm{C}_{0}(\mathrm{FITC}) \sim 0.09\right)$.
\end{abstract}




\subsection{Introduction}

Microencapsulation is the process of enclosing components within a microsystem to protect them from harmful factors in their environment. Hydrogel beads have been used to encapsulate living cells, and for delivery and controlled release of chemicals. Alginate is often used to create hydrogel beads because it is easily formed into beads and is generally qualified as safe for human application [1]. Alginate beads have been used to encapsulate living cells such as chondrocytes [2], islet cells [3] and bacteria [4, 5] and chemicals such as Blue dextran [6], oil droplets [7-9], proteins such as BSA and insulin [10], and drugs such as verapamil [11] and doxorubicin [12]. For hydrogel beads to function as a protective barrier between a component and its environment, the ability of molecules from the surrounding phase to diffuse into the bead is a key design parameter.

An important factor determining the permeability of a bead is the pore size of the hydrogel matrix. The pore size affects the molecular weight cut off (MWCO) of species able to enter/leave the bead, and influence the drag forces on the components. The porosity of alginate microbeads is determined by the type of alginate [13-15], and its concentration [15, 16], the type [13], concentration [16] and method of addition of the gelling agent [17, 18], and the properties of the environment of the bead, which includes factors such as the $\mathrm{pH}$, ionic strength, and temperature.

The most common method to make alginate beads is by dripping an alginate solution into a calcium chloride solution. This method typically produces beads larger than $300 \mu \mathrm{m}$ [19], though beads around $100 \mu \mathrm{m}$ in size can be made with additional techniques like the JetCutter [20]. This process is difficult to scale up because of the large number of nozzles required, and problems with sanitation and nozzle blockage. A comprehensive review on the preparation methods of alginate micro- and nanobeads has recently been published [21]. Paques et al. [22] presented a new method to create smaller alginate microbeads. The alginate solution is emulsified in oil, after which a dispersion of calcium nanocrystals in oil is added. These crystals diffuse to the oil-alginate interface, where they dissolve and gel the bead externally. For this new method, the diffusive properties of the beads are still unknown. The difference in method of supplying the calcium ions between the W/O 
emulsification and the dripping method may have an effect on the gel morphology, and thus the porosity, of the bead.

In biotechnology and medicine, where alginate beads are typically used to encapsulate living cells, the porosity of alginate beads has been well investigated. The porosity is of importance because small nutrients and waste products should be able to freely diffuse in or out of the bead, while reactions with parts of the immune system such as immunoglobulins should be inhibited to protect the cells [23]. In these studies the beads are tested in specific environments, such as $0.1 \mathrm{M}$ Tris-buffer or saline solution $(154 \mathrm{mM})$ with a $\mathrm{pH}$ of $7.4[10,13,14,24,25]$, in simulated gastric fluid, [11, 26] or in waste water [5]. The environmental factors in other applications of alginate microbeads, such as foods or cosmetics, cover a much broader range and their effects on particle porosity is less well investigated. Ionic strength and $\mathrm{pH}$ will likely have an effect on the swelling behavior of the beads, the charge of the beads and probes, and the thickness of the Debye layer. Apart from the charge, these factors have barely been investigated in studies investigating the diffusive processes in alginate beads.

With respect to the influence of charge, several investigations [15, 27-29] found that probes, including proteins and ions, with an opposite charge to the gel were attracted to the network, while probes with similar charge were repelled. The diffusion of neutral probes was related to their molecular weight.

Permeability of microbeads is an important factor for the degree of protection a microbead provides their cargo from its environment. Digestive enzymes such as pepsin or immunoproteins such as immunoglobulins should be excluded from the inside of the bead as much as possible. In this study, we investigated the permeability of alginate microbeads, prepared by the $\mathrm{W} / \mathrm{O}$ emulsification method described by Paques et al. [22], and the effect of alginate concentration, calcium concentration and method of addition, and salt concentration of the environment on the permeation of fluorescein isothiocyanate (FITC) and FITC-labelled protein probes through the alginate microbeads. The $\zeta$-potential, size and microstructure of the beads were investigated to further understand the properties influencing the permeability of the beads for these probes. Furthermore the difference in permeability of microbeads prepared with the emulsification method was compared to microbeads prepared by dripping an alginate solution into a $\mathrm{CaCl}_{2}$ bath. 


\subsection{Materials and methods}

\subsubsection{Materials}

$\mathrm{CaCl}_{2} \cdot \mathrm{H}_{2} \mathrm{O}$ (GR for analyses, Merck, Germany), ethanol absolute (Merck, Germany), Polyglycerol polyricinoleate (PGPR) 90 Kosher (Danisco, Denmark), Medium chain Triglycerides (MCT) (Miglyol 812 N) (Sasol, Germany), Sodium alginate extracted from brown algae (Algin, Texturas, Barcelona, Spain), $\beta$-lactoglobulin, ovalbumin and bovine serum albumin, FITC (Sigma Aldrich, Germany) were all used as received. Solutions were made in demineralized water.

\subsubsection{Preparation of Ca nanocrystals}

Calcium nanocrystals were prepared according to the method of Paques et al. [30]. In short, $5 \%(\mathrm{v} / \mathrm{v})$ of a 0.1 molal $\mathrm{CaCl}_{2} \cdot \mathrm{H}_{2} \mathrm{O}$ in ethanol solution was emulsified for 1 minute in MCT containing 6\% (w/w) PGPR with a Sonicator S-250A sonicator (Branson Ultrasonics, USA). This emulsion was heated overnight at $60^{\circ} \mathrm{C}$, while stirring continuously, to allow the ethanol to evaporate.

\subsubsection{Preparation of microbeads by $\mathrm{W} / \mathrm{O}$ emulsification}

The method to prepare alginate microbeads was based on the method described by van Leusden et al. [9]. Solutions of 1 and $2 \%(w / w)$ of alginate were made. To create the beads, a volume of $16 \%$ of the alginate solution was slowly added to MCT oil containing 4\% (w/w) PGPR, while mixing with an Ultra-Turrax (Ultra-Turrax T 25, IKA Werke, Germany) at 4200 (2\%) or 3000 (1\%) rpm. After complete addition, the mixture was mixed for another 3 minutes. Per $\mathrm{mL}$ of emulsified alginate solution, 5 or $10 \mathrm{~mL}$ of nanocrystal dispersion was added. The emulsion was allowed to set for at least 20 hours with continuous stirring on a magnetic stirrer.

The beads were removed from the oil phase by centrifuging the dispersion at $5000 \mathrm{~g}$ for 2 hours. The beads were washed to remove the residual oil, which was done by redispersing the pellet in water, homogenizing three times at 80 bar and then centrifuging at $2500 \mathrm{~g}$. Part of the beads were, in the first washing cycle, washed with $25 \mathrm{mM} \mathrm{CaCl}_{2}$ solution. The beads were washed 3 more times, either with demi-water or with an $\mathrm{NaCl}$ solution (either 25 , or $100 \mathrm{mM}$ ). 


\subsubsection{Preparation of large microbeads by dripping method}

Microbeads were prepared based on the method described by Li et al. [8]. Approximately $2 \mathrm{~mL}$ of a $2 \%$ alginate solution was dripped into a $25 \mathrm{mM}$ $\mathrm{CaCl}_{2}$ bath of $100 \mathrm{~mL}$ while stirring with a magnetic stirrer and allowed to set for 2 hours at room temperature. The needle had a diameter of $0.3 \mathrm{~mm}$ and the syringe was gently tapped to allow droplets to fall off the needle more quickly, creating beads of about $1 \mathrm{~mm}$. After gelation the beads were rinsed with either demi-water or 25 or $100 \mathrm{mM} \mathrm{NaCl}$ solution.

\subsubsection{Dynamic light scattering}

The size distribution of the microbeads was measured with a Mastersizer (Malvern Mastersizer 2000, Malvern Instruments, UK) using laser diffraction. The $\zeta$-potential of the beads and probes was measured with a Malvern Zetasizer (Malvern Instruments, UK). Obscuration was between 5 and 15\% and the refractive index of calcium alginate gels was assumed to be 1.45.

\subsubsection{CLSM}

The permeability of the beads was investigated with CLSM (Zeiss LSM5 Pascal confocal system, Carl Zeiss group, the Netherlands). The argon laser was used to excite the FITC molecules at $488 \mathrm{~nm}$ and the emission fluorescence was observed after passing a $505 \mathrm{~nm}$ BP filter. Fluorescent probes of different radii were made by binding FITC to $\beta$-lactoglobulin ( 2.26 $\mathrm{nm})$ [31], ovalbumin $(3.20 \mathrm{~nm})$ and BSA (3.93 nm) [32]. FITC was dissolved in DMSO in $2 \mathrm{mg} / \mathrm{mL}$ and protein solutions of $1 \%(\mathrm{w} / \mathrm{w})$ were prepared in $100 \mathrm{mM}$ carbonate buffer $(\mathrm{pH} 9.0)$. A volume of 50uL FITC solution was added per $\mathrm{mL}$ of $1 \%$ protein solution, and allowed to react for 5 hours. After incubation the FITC-protein solutions were transferred to dialysis membranes and dialysed against carbonate buffer (4 times), and demi-water or $100 \mathrm{mM}$ $\mathrm{NaCl}$ solution (3 times). The unbound FITC was also used as a probe. The probe solutions were added to the bead solution in a ratio of 1:4, giving a probe concentration of $0.2 \%(\mathrm{w} / \mathrm{w})$. The $\mathrm{pH}$ was 6.9 and the solutions had ionic strengths of 0,25 or $100 \mathrm{mM}$. To investigate the permeation of the probes into the bead the intensity of the fluorescence of the entire surface of at least 10 beads was measured and compared with the intensity of the fluorescence outside the beads, giving a ratio $\mathrm{I} / \mathrm{I}_{0}$, which is assumed to be equal to the ratio of the concentration of the probes in the bead $\mathrm{C}$, and the concentration of the 
probe in the continuous phase $\mathrm{C}_{0}$. The intensities were measured with the software ImageJ. Equilibrium was achieved within 2 minutes for the W/O beads and after about 15 minutes for the beads produced by dripping. Measurements were taken after 4 hours when equilibrium was established.

\subsubsection{SEM}

The microstructure of the beads was investigated with scanning electron microscopy (SEM; Magellan 400, FEI, Eindhoven, the Netherlands). The samples were adhered to poly-L-lysine coated coverslips and fixed with a 3\% glutaraldehyde solution. Next the samples were dehydrated using a series of 30, 50, 70 and $100 \%(\mathrm{v} / \mathrm{v})$ acetone solutions after which the samples were critical point dried. The large beads were not adhered to the cover slips but dried as loose beads. The dried, large beads were cut open with a knife and mounted on a stub using carbon adhesive tape. The samples were coated with a layer of $10 \mathrm{~nm}$ tungsten.

\subsection{Results and discussion}

\subsection{1 $\zeta$-potential}

The $\zeta$-potential is an important factor in whether permeation of a probe molecule into a porous bead is possible. The $\zeta$-potential of the protein probes in $100 \mathrm{mM} \mathrm{NaCl}$ solution was measured to be: $\beta$-lactoglobulin $-11.1( \pm 0.1)$ $\mathrm{mV}$, Ovalbumin $-10.6( \pm 0.4) \mathrm{mV}$ and BSA $-10.7( \pm 0.2) \mathrm{mV}$. FITC was also used as a probe, but due to its small size its $\zeta$-potential cannot be measured with a Zetasizer. The mixture of alginate beads and FITC solution in $100 \mathrm{mM}$ $\mathrm{NaCl}$ had a $\mathrm{pH}$ of 6.9. The $\mathrm{pKa}$ of FITC is 6.35 [33], therefore under these circumstances the molecules are mostly negatively charged. The $\zeta$-potential of the various alginate microbeads can be found in Table 4.1.

We observe that under the conditions used in this study, all probes and beads are negatively charged, and the resulting repulsion between probe and bead matrix can affect the permeation of the probes into the bead. 


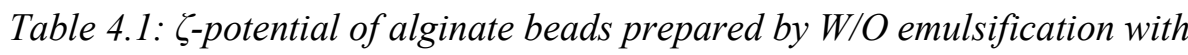
varying alginate concentrations, various methods of adding additional calcium (0: without extra calcium, 25: washed with $25 \mathrm{mM}$ calcium solution, $D$ : with double the amount of calcium crystals), and in solutions with varying $\mathrm{NaCl}$ concentration.

\begin{tabular}{ccc|c}
$\begin{array}{l}{[\mathrm{Alg}]} \\
\%(\mathrm{w} / \mathrm{w})\end{array}$ & Calcium & \multicolumn{1}{l}{$\begin{array}{l}{[\mathrm{NaCl}]} \\
(\mathrm{mM})\end{array}$} & \multicolumn{1}{l}{$\begin{array}{l}\zeta \text {-potential } \\
(\mathrm{mV})\end{array}$} \\
\hline 2 & 0 & 100 & $-26.8( \pm 0.7)$ \\
& 25 & 100 & $-24.3( \pm 0.6)$ \\
& $\mathrm{D}$ & 100 & $-25.5( \pm 1.1)$ \\
\hline 1 & 0 & 100 & $-24.8( \pm 0.9)$ \\
& 25 & 100 & $-25.3( \pm 1.3)$ \\
& $\mathrm{D}$ & 100 & $-25.5( \pm 0.3)$ \\
\hline 2 & 25 & 0 & $-40.6( \pm 1.0)$ \\
& 25 & 25 & $-38.2( \pm 0.5)$ \\
& 25 & 100 & $-24.3( \pm 0.6)$
\end{tabular}

\subsubsection{Swelling}

The swelling of the beads is important because when a bead swells, the MWCO of molecules which can permeate into the bead also increases [34]. The $\zeta$-potential showed that the beads were negatively charged at $\mathrm{pH} 6.9$, and will repel other negatively charged colloids. This however also means that there is repulsion between the polysaccharides within the bead, which can lead to swelling. The degree of swelling is dependent on the charge of the polysaccharides, the ionic strength of the environment, and the gel characteristics of the beads themselves, such as alginate concentration and type and number of junction zones. The results of the bead size measurements can be found in Table 4.2. 
Table 4.2: Average diameter $\left(D_{43}\right)$ of alginate beads prepared by $W / O$ emulsification with varying alginate concentrations, various methods of adding additional calcium (0: without extra calcium, 25: washed with $25 \mathrm{mM}$ calcium solution, D: with double the amount of calcium crystals), at various $\mathrm{NaCl}$ concentrations.

\begin{tabular}{ccc|c}
$\begin{array}{l}{[\mathrm{Alg}]} \\
\%(\mathrm{w} / \mathrm{w})\end{array}$ & Calcium & $\begin{array}{c}{[\mathrm{NaCl}]} \\
(\mathrm{mM})\end{array}$ & Diameter $(\mu \mathrm{m})$ \\
\hline 2 & 0 & 100 & $14.67( \pm 0.02)$ \\
& 25 & 100 & $13.49( \pm 0.12)$ \\
& $\mathrm{D}$ & 100 & $11.28( \pm 0.01)$ \\
\hline 1 & 0 & 100 & $11.25( \pm 0.01)$ \\
& 25 & 100 & $11.11( \pm 0.01)$ \\
& $\mathrm{D}$ & 100 & $11.40( \pm 0.05)$ \\
\hline 2 & 25 & 0 & $8.71( \pm 0.00)$ \\
& 25 & 25 & $11.39( \pm 0.02)$ \\
& 25 & 100 & $13.49( \pm 0.12)$ \\
\hline $2 \%$ alginate emulsion & & $10.57( \pm 0.03)$ \\
$1 \%$ alginate emulsion & & $10.13( \pm 0.06)$
\end{tabular}

For the $1 \%$ beads, all the beads swelled when removed from the oil. The swelling of the $1 \%$ alginate beads was not affected by the addition of extra $\mathrm{CaCl}_{2}$, and was $39 \pm 6 \%(\mathrm{v} / \mathrm{v})$, which means that the extra calcium, either in the form of extra crystals or in solution, did not create a stronger structure, more resistant to swelling. The $2 \%$ beads washed with $\mathrm{CaCl}_{2}$ solution and $2 \%$ beads without extra calcium swelled more than the $1 \%$ beads, respectively $108 \%$ and $167 \%(\mathrm{v} / \mathrm{v})$. The $1 \%$ and $2 \%$ beads are prepared with equal amounts of calcium, but the higher concentration of alginate in the $2 \%$ beads is assumed to result in a longer segment length between junction zones. This results in a more flexible structure which can swell more. The $2 \%$ beads that were gelled with extra calcium nanocrystals were smaller than the beads washed with $\mathrm{CaCl}_{2}$ solution, and showed a swelling of about $22 \%(\mathrm{v} / \mathrm{v})$. When the extra calcium is added while the bead is removed from the oil phase, which happens when the bead is washed with a calcium solution, the bead can swell before the additional calcium can rigidify the structure, since it takes time for the calcium ions to diffuse into the bead. When the extra calcium is added while 
the bead is still within the oil phase, as is the case when extra calcium nanocrystals are added to the oil, the additional calcium can rigidify the bead matrix before it is transferred to the water phase, thereby reducing the degree of swelling. The beads that swelled least were expected to be the least porous.

\subsubsection{Permeability}

A selection of CLSM images showing different degrees of permeation of probes (FITC, $\beta$-lac and BSA) into $2 \%$ alginate beads treated with different amounts of calcium (without extra calcium, washed with a calcium solution, and gelled with extra calcium crystals) in $100 \mathrm{mM} \mathrm{NaCl}$ solution after 4 hours is shown in Figure 4.1. The intensity of at least 10 beads was compared to the intensity of the signal outside the beads, from which we calculated $\mathrm{C} / \mathrm{C}_{0}$. The results for $\mathrm{C} / \mathrm{C}_{0}$ are presented in Figures 4.2 through 4.4.
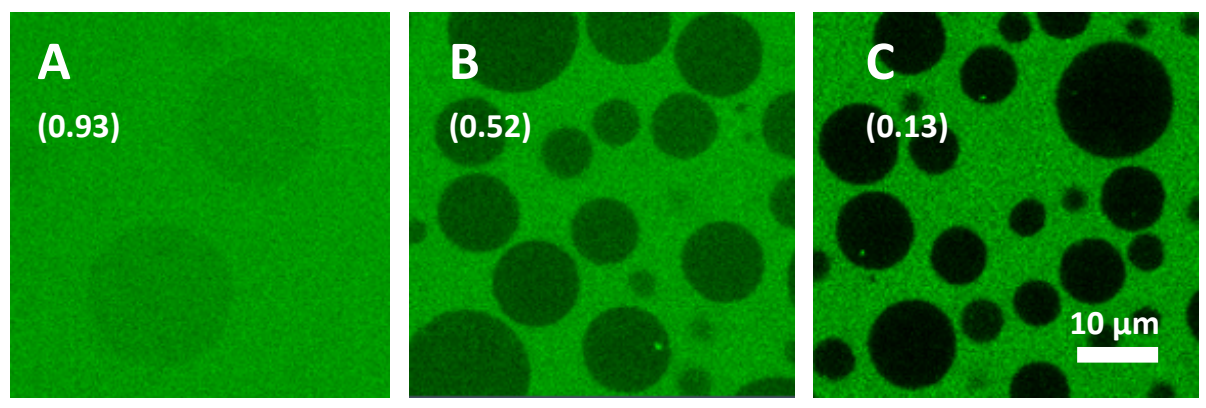

Figure 4.1: Example of differences in probe diffusion in 2\% beads in 100 $\mathrm{NaCl}, \mathrm{C} / \mathrm{C}_{0}$ between brackets: A: FITC permeation in microbeads without additional calcium; $B$ : $\beta$-lac permeation in microbeads washed with a $25 \mathrm{mM}$ $\mathrm{CaCl}_{2}$ solution; $\mathrm{C}$ : BSA permeation in microbeads gelled with double the amount of calcium crystals.

\section{$\mathbf{2 \%}$ Alginate beads prepared by $\mathrm{W} / \mathrm{O}$ emulsification}

Figure 4.2 shows the permeation of the FITC labelled probes through the alginate beads, made with $2 \%$ alginate, after 4 hours, in $100 \mathrm{mM} \mathrm{NaCl}$. There is an overall decrease in permeation when the size of the probe increases. Between the 3 calcium concentrations it is obvious that the beads that have not been treated with extra calcium show a much higher degree of permeation of the probes. For ovalbumin there is 3 times more probe present in the beads prepared without extra calcium as opposed to the ones which were prepared 
with additional calcium, either through an increase of nanocrystals in the exterior oil phase, or by washing with $\mathrm{CaCl}_{2}$ solution. When considering the swelling results, it can be seen that the size of the beads increased from 10.57 $\mu \mathrm{m}$ to $14.68 \mu \mathrm{m}$, which allowed for the permeation of more and larger probe molecules. There is little difference in permeation between the samples treated with extra calcium, either by addition of extra nanocrystals or by washing with $\mathrm{CaCl}_{2}$ solution. There is however a large difference in swelling between these beads, which have a final average diameter of 11.28 and $13.49 \mu \mathrm{m}$ respectively. The degree of swelling by itself is therefore not a sufficient characteristic to base the expected permeation on. Though swelling is likely to have an influence, because it increases the average pore size, additional changes in the microstructure induced by the different modes of adding the additional calcium appear to play a role in the observed permeability.

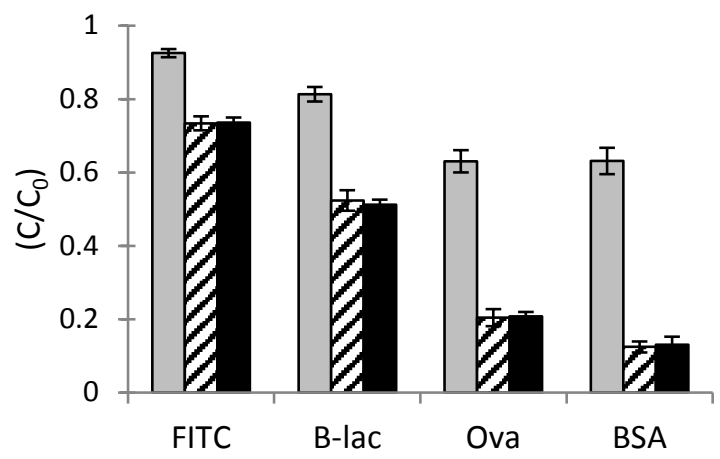

Figure 4.2: Degree of permeation of probes into $2 \%$ alginate beads with varying amounts of additional calcium (grey: without extra calcium, shaded: washed with $25 \mathrm{mM}$ calcium solution, black: with double the amount of calcium crystals) in $100 \mathrm{mM} \mathrm{NaCl}$ solution, after 4 hours. 


\section{$1 \%$ Alginate beads prepared by $\mathrm{W} / \mathrm{O}$ emulsification}

The experiment was repeated with microbeads with a $1 \%$ alginate concentration, the results of which can be found in Figure 4.3. The beads washed with demi-water allow for most permeation, followed by the beads washed with $25 \mathrm{mM}$ calcium solution and the beads prepared with a higher concentration of crystals in the oil phase. For ovalbumin the probe concentration in the beads without extra calcium is 1.2 times higher than for the beads with extra calcium. The degree of permeation into the beads treated with additional calcium is higher than their counterparts prepared with $2 \%$ alginate, specifically, for ovalbumin it is twice as high. The lower amount of alginate present created a more porous structure. The difference between the beads prepared with and without extra calcium is however not as high and there is less probe present in the $1 \%$ beads without extra calcium than in the $2 \%$ beads without extra calcium. The swelling of the $1 \%$ beads is also less than that of the $2 \%$ beads, $37 \%$ vs $167 \%$ (v/v). The $1 \%$ and $2 \%$ beads were prepared with the same amount of $\mathrm{CaCl}_{2}$, which means that the calcium to alginate ratio in the $1 \%$ beads is twice as high as in the $2 \%$ beads. This may have resulted in more crosslinks per alginate chain, thereby creating a less flexible structure. Beads made with $1 \%$ alginate and half the original amount of calcium crystals were weak and fractured during extraction from the oil phase.

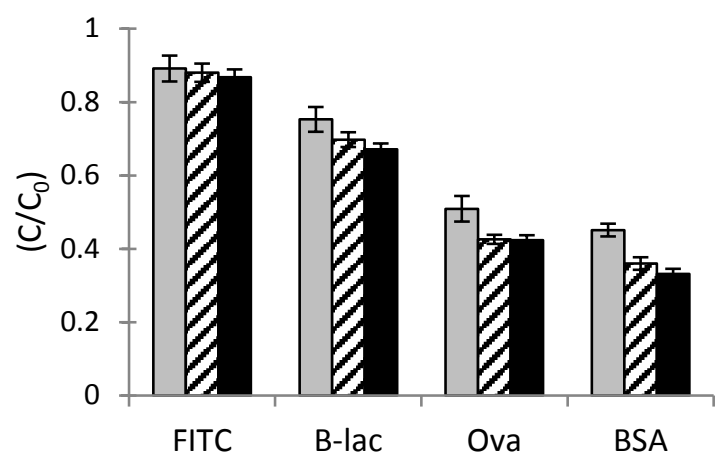

Figure 4.3: Degree of permeation of probes into 1\% alginate beads with varying amounts of additional calcium (grey: without extra calcium, shaded: washed with $25 \mathrm{mM}$ calcium solution, black: with double the amount of calcium crystals) in $100 \mathrm{mM} \mathrm{NaCl}$ solution, after 4 hours. 


\section{Effects of salt concentration}

Figure 4.4 shows the effect of the salt concentration of the continuous phase on the permeation of the protein probes in the $2 \%$ beads washed with $25 \mathrm{mM}$ calcium solution.

In the absence of sodium chloride not even FITC can diffuse into the alginate bead. The physical pores of the alginate bead are large enough for this molecule to enter the bead, because at a salt concentration of $100 \mathrm{mM} \mathrm{NaCl}$, ovalbumin, which has a molecular weight about 100 times higher than FITC (389 Da vs. $44 \mathrm{kDa}$ ), can diffuse into the bead. The volume of the beads at 0 and $100 \mathrm{mM} \mathrm{NaCl}$ differs only by a factor of 3.7. The inability of FITC to penetrate the bead therefore cannot just be attributed to the shrinkage of the beads. The $\zeta$-potential of both the beads and the probes is negative (Table 4.1) which results in a repulsion between the probe and the bead, and this significantly reduces the permeation of the probes into the beads. Electrostatic interactions are dependent on both the charge of the particles, and the width of the electrical double layer (the Debye length). The charge and concentration of the ions is very important for the thickness of this layer.

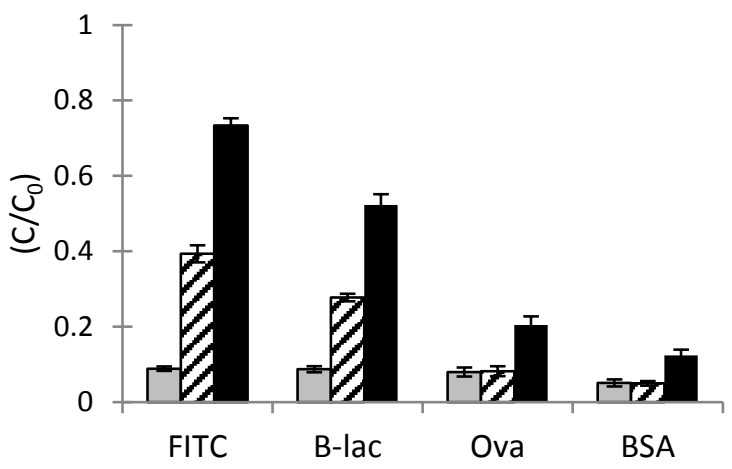

Figure 4.4: Degree of permeation of probes into 2\% alginate beads washed with $25 \mathrm{mM}$ calcium solution, in solutions with varying $\mathrm{NaCl}$ concentrations (grey: $0 \mathrm{mM}$, shaded: $25 \mathrm{mM}$, black: $100 \mathrm{mM}$ ) after 4 hours.

At $100 \mathrm{mM}$, the Debye length is about $1 \mathrm{~nm}$. When decreasing the $\mathrm{NaCl}$ concentration from $100 \mathrm{mM}$ to $25 \mathrm{mM}$, the Debye length doubles. When comparing the results of beads in $25 \mathrm{mM}$ and $100 \mathrm{mM} \mathrm{NaCl}$ we find that for FITC and $\beta$-lac the amount of probe able to diffuse into the beads is both 1.9 
times higher at $100 \mathrm{mM}$ than at $25 \mathrm{mM} \mathrm{NaCl}$. Our observation therefore confirms the effects of the Debye length on permeation. The influence of charge and ionic strength can only be disregarded when either the ionic strength is very high or the probe or bead is entirely without charge.

When investigating the pore size of a gelled material, this size is not simply given by the maximum size of the probe which can still permeate into the gel. The range of the repulsive interactions between the probe and the alginate bead, as represented schematically in Figure 4.5, should also be taken into account. This also explains why the concentration of probe in the bead $\left(\mathrm{C} / \mathrm{C}_{0}\right)$ in this study is never equal to the concentration outside the bead. A part may be ascribed to excluded volume of the alginate network itself, but part is caused by the repulsion resulting from the negative charges of the alginate molecules in the network. In this study the influence of $\mathrm{pH}$ was not investigated. Probes will be more charged far above their $\mathrm{pKa}$ or far from their iso electric point. Hence we expect that the permeability of the microbeads for certain probes will also be affected by the $\mathrm{pH}$ of the continuous phase.

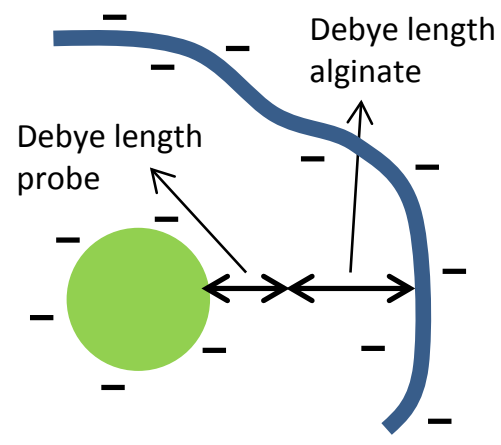

Figure 4.5: Schematic representation of interactions of the probe and the alginate matrix.

\section{Beads made by dripping}

The permeability of the alginate beads produced with the method of Paques et al. (2012), followed by washing with calcium chloride solution has also been compared with the porosity of alginate beads produced with the common dripping method. The results of beads made with the dripping method can be found in Figure 4.6. 


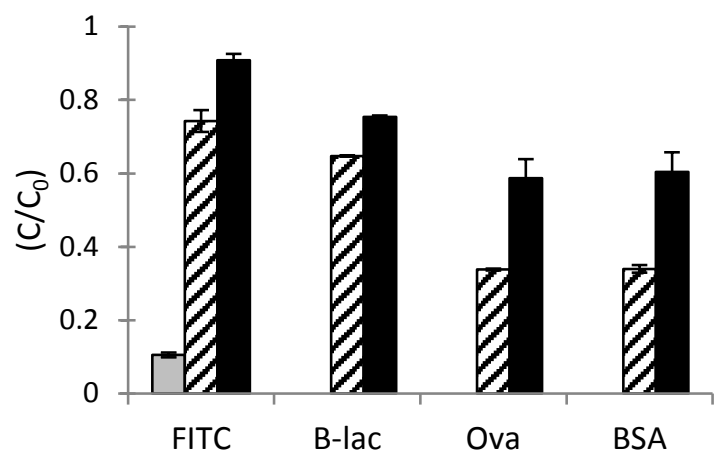

Figure 4.6: Degree of permeation of probes into 2\% alginate beads produced by dripping alginate into $25 \mathrm{mM} \mathrm{CaCl}$ solution in varying $\mathrm{NaCl}$ solutions (grey: $0 \mathrm{mM}$, shaded: $25 \mathrm{mM}$, black: $100 \mathrm{mM}$ ) after 4 hours.

Here too, when no salt is present in the continuous phase, only a small amount of FITC can permeate through the bead. Beads dispersed in $100 \mathrm{mM} \mathrm{NaCl}$ have a 1.74 times higher diffusion of ovalbumin into the bead than beads dispersed into $25 \mathrm{mM} \mathrm{NaCl}$. This difference is similar to the difference in permeability of the emulsified beads dispersed in 25 and $100 \mathrm{mM} \mathrm{NaCl}$ (1.86). The overall permeation of the probes in beads prepared with the dripping method is higher than for beads prepared with the W/O emulsification method. For ovalbumin in $100 \mathrm{mM} \mathrm{NaCl}$, the amount of probe present in the beads made with the dripping method is almost 3 times as high as in the beads made with the method of Paques et al. (2012). With both methods it is assumed that a surplus of calcium was present and thus the optimal ratio of alginate and calcium was achieved. The different method to create and gel the beads has thus influenced the pore size of the network. There are two possible reasons why this difference exists, either because of the different introduction of calcium into the system, or because of the different environments in which the beads are formed.

Skjak-Braek et al. [17] investigated inhomogeneity in macroscopic calciumgelled polysaccharide cylinders with a diameter of 14 or $19 \mathrm{~mm}$. They found that the calcium concentration in the external phase was very important during external gelation of alginate. Because of a steep concentration gradient between gelled alginate at the interface of the cylinders, and unbound alginate away from the interface, unbound alginate diffuses to the interface. At $5 \mathrm{mM}$ 
calcium concentration in the external bath, the centre of an alginate tube contained $0.2 \%$ alginate, while at the surface the alginate concentration was $6 \%$. At higher calcium concentrations in the bath, and in the presence of other ions this difference in alginate concentration between inner and outer part of the cylinders decreased. With the new method of alginate bead gelation that Paques et al. presented, the solid calcium crystals diffuse to the interface where they dissolve and gel the alginate. This method most likely gives a relatively lower concentration of calcium at the interface of the bead when compared to dripping alginate droplets in a calcium chloride bath. This lower concentration allows for more diffusion of alginate to the interface, giving a denser surface of the bead when compared to the common dripping method. Previously we found that [35] cold-set protein beads of $10 \%$ whey protein isolate, also externally gelled with calcium nanocrystals, could delay diffusion of FITC-Dextran $(40 \mathrm{kDa})$ to the centre of the bead by several minutes, while a heat-set protein bead of $25 \%$ WPI could not. For the alginate beads in this study we could not observe a delayed diffusion of probe into the beads, since here the degree of permeation was measured after 4 hours, and equilibrium was already reached within several minutes.

The difference in permeability of the beads made by dripping versus the method of Paques, et al. could be caused by the different environments in which the beads are created. When the beads are dripped into the calcium bath the beads can swell during gelation. The beads made by the method of Paques are constrained by their oil-water interface and cannot swell during gelation. Only after the first gelation step, when introduced into the $25 \mathrm{mM}$ calcium solution, is the bead able to swell. King [34] previously concluded that swelling might be accommodated by an increase in permeability. Most likely both these factors play a role when explaining the difference between the different calcium concentrations in the 1 and $2 \%$ beads, and between the beads prepared by dripping and beads made with the W/O emulsification method.

\subsubsection{Microstructure}

Previously we found that, though there is a difference in swelling between the $2 \%$ beads washed with $\mathrm{CaCl}_{2}$ solution, and beads gelled with double the amount of calcium crystals, there is little difference in permeability. We also found that the microbeads made with the W/O emulsification method had a far lower permeability than the beads made by dripping an alginate solution 
in a $\mathrm{CaCl}_{2}$ bath, despite both having been exposed to a surplus of calcium ions. To further investigate these two observations we investigated the microstructure of the beads with SEM, see Figure 4.7. Important to note is that, although the structure of the beads have been fixed during the sample preparation procedure, slight swelling or shrinking might still occur during the dehydration step, especially for weaker structures.
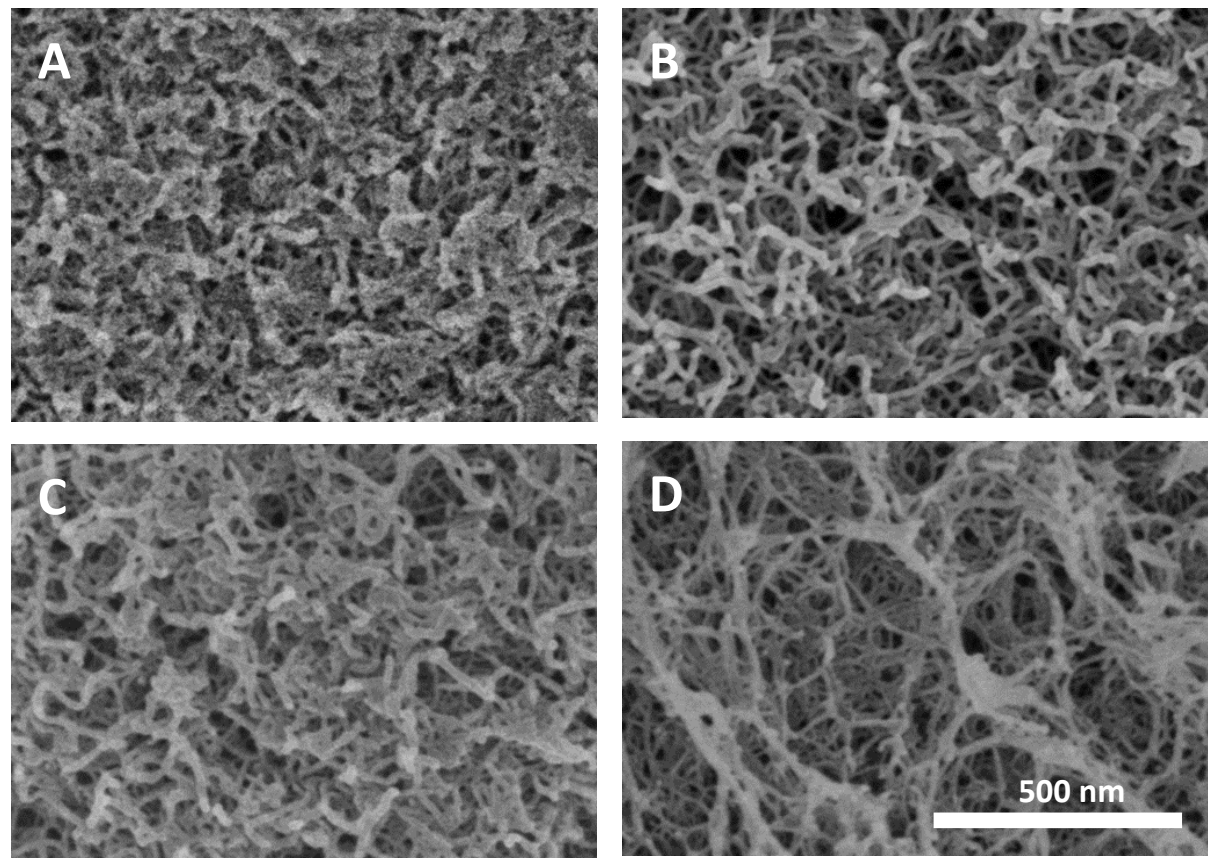

Figure 4.7: SEM images of alginate microbeads A: washed with $25 \mathrm{mM}$ $\mathrm{CaCl}_{2}, \mathrm{~B}$ : gelled with double the amount of calcium crystals, $C$ : without extra calcium, D: large beads made by dripping alginate solution in $25 \mathrm{mM} \mathrm{CaCl} 2$ solution.

When comparing the beads washed with $\mathrm{CaCl}_{2}$ solution and the beads made by dripping in a $\mathrm{CaCl}_{2}$ solution, a large difference in structure can be seen. Despite having both been exposed to a surplus of calcium ions, the beads made by dripping have a thick stranded and much more open structure. It is likely that the beads made by the W/O method have a much denser structure because they have been constrained by the oil-water interface of the emulsion droplet during gelation, while the beads made by dripping in a $\mathrm{CaCl}_{2}$ solution had time to swell before the structure was fully gelled, thereby creating a much 
more open structure. Although the exact rate of release of calcium from the calcium crystals at the interface is unknown, it is likely that the slower release of calcium into the system, as opposed to the quick diffusion of calcium ions when creating beads made by dripping, allowed for the formation of a more fine stranded structure.

When comparing the beads washed with $\mathrm{CaCl}_{2}$ solution and the beads gelled with extra calcium crystals a difference in homogeneity can be seen. The higher amount of calcium crystals caused a higher amount of calcium to be released at the interface, thereby creating a more inhomogeneous structure with larger pores. Where the beads washed with $\mathrm{CaCl}_{2}$ solution had a higher permeation because the beads swelled before being fully gelled, the permeation of the beads gelled with extra calcium crystals had a higher permeation because of the bigger pores in the microstructure.

Little difference is seen between the beads washed with $\mathrm{CaCl}_{2}$ solution and beads without extra calcium. We expected to see much larger pores in the beads without extra calcium. These beads are however quite weak because of their low amount of calcium ions and may have shrunk during the dehydration step. 


\subsection{Conclusions}

In this study we investigated the difference between the permeation of probe molecules into alginate beads made under various conditions to compare their ability to prevent harmful factors from diffusion into the interior of the bead.

At low calcium concentrations, swollen and porous beads are created. Additional calcium ions can be added by washing the beads with a $\mathrm{CaCl}_{2}$ solution. This creates a stronger structure with small pores, which swells little and allows for less permeation. Additional calcium ions can also be added by adding extra calcium crystals in the exterior oil phase. These beads were most resistant to swelling, but the higher concentration of calcium ions created a structure with larger pores, which thus gave a similar permeability to the beads washed with $\mathrm{CaCl}_{2}$ solution.

The W/O emulsification method creates smaller and less permeable alginate networks than the dripping method. The constraints of the emulsion droplet and the slower release of calcium ions into the system created a more fine stranded and denser structure than for the beads made by dripping.

The $\zeta$-potential and Debye length are very important for the diffusion of charged probes in a charged network. Even very small molecules can be excluded from an alginate network when no salt is present.

\section{Acknowledgments}

The research presented in this paper was financially supported by the Graduate School VLAG, of Wageningen University. M. Postema has received funding from the European Union's Horizon 2020 research and innovation programme under the Marie Skłodowska-Curie grant agreement No 665790. 


\section{References}

1. de Vos, P., et al., Polymers in cell encapsulation from an enveloped cell perspective. Advanced Drug Delivery Reviews, 2014. 67-68: p. 15-34.

2. Bonaventure, J., et al., Reexpression of Cartilage-Specific Genes by Dedifferentiated Human Articular Chondrocytes Cultured in Alginate Beads. Experimental Cell Research, 1994. 212(1): p. 97-104.

3. Lim, F. and A.M. Sun, Microencapsulated islets as bioartificial endocrine pancreas. Science, 1980. 210(4472): p. 908-910.

4. Sultana, K., et al., Encapsulation of probiotic bacteria with alginate-starch and evaluation of survival in simulated gastrointestinal conditions and in yoghurt. International Journal of Food Microbiology, 2000. 62(1-2): p. 47-55.

5. Covarrubias, S.A., et al., Alginate beads provide a beneficial physical barrier against native microorganisms in wastewater treated with immobilized bacteria and microalgae. Applied Microbiology and Biotechnology, 2012. 93(6): p. 2669-2680.

6. Kim, C.-K. and E.-J. Lee, The controlled release of blue dextran from alginate beads. International Journal of Pharmaceutics, 1992. 79(1): p. 11-19.

7. Chan, E.-S., Preparation of Ca-alginate beads containing high oil content: Influence of process variables on encapsulation efficiency and bead properties. Carbohydrate Polymers, 2011. 84(4): p. 1267-1275.

8. Li, Y., et al., Control of lipase digestibility of emulsified lipids by encapsulation within calcium alginate beads. Food Hydrocolloids, 2011. 25(1): p. 122-130.

9. Van Leusden, P., et al., Strength of microbeads for the encapsulation of heat sensitive, hydrophobic components. Food Hydrocolloids, 2016. 56: p. 318-324.

10. Hari, P., T. Chandy, and C.P. Sharma, Chitosan/calcium-alginate beads for oral delivery of insulin. Journal of Applied Polymer Science, 1996. 59(11): p. 1795-1801.

11. Pasparakis, G. and N. Bouropoulos, Swelling studies and in vitro release of verapamil from calcium alginate and calcium alginate-chitosan beads. International Journal of Pharmaceutics, 2006. 323(1-2): p. 34-42.

12. Liu, J., et al., Magnetically sensitive alginate-templated polyelectrolyte multilayer microcapsules for controlled release of doxorubicin. The Journal of Physical Chemistry C, 2010. 114(17): p. 7673-7679.

13. Mørch, Ý.A., et al., Effect of $\mathrm{Ca} 2+, \mathrm{Ba} 2+$, and $\mathrm{Sr} 2+$ on alginate microbeads. Biomacromolecules, 2006. 7(5): p. 1471-1480.

14. Martinsen, A., G. Skjåk-Bræk, and O. Smidsrød, Alginate as immobilization material: I. Correlation between chemical and physical properties of alginate gel beads. Biotechnology and bioengineering, 1989. 33(1): p. 79-89.

15. Martinsen, A., I. Storrø, and G. Skjårk-Bræk, Alginate as immobilization material: III. Diffusional properties. Biotechnology and Bioengineering, 1992. 39(2): p. 186194.

16. Tanaka, H., M. Matsumura, and I.A. Veliky, Diffusion characteristics of substrates in Ca-alginate gel beads. Biotechnology and Bioengineering, 1984. 26(1): p. 53-58.

17. Skjåk-Bræk, G., H. Grasdalen, and O. Smidsrød, Inhomogeneous polysaccharide ionic gels. Carbohydrate Polymers, 1989. 10(1): p. 31-54.

18. Liu, X.C., et al., Characterization of structure and diffusion behaviour of Ca-alginate beads prepared with external or internal calcium sources. Journal of microencapsulation, 2002. 19(6): p. 775-782.

19. Uludag, H., P. De Vos, and P.A. Tresco, Technology of mammalian cell encapsulation. Advanced drug delivery reviews, 2000. 42(1): p. 29-64. 
20. Koch, S., et al., Alginate encapsulation of genetically engineered mammalian cells: comparison of production devices, methods and microcapsule characteristics. Journal of microencapsulation, 2003. 20(3): p. 303-316.

21. Paques, J.P., et al., Preparation methods of alginate nanoparticles. Advances in Colloid and Interface Science, 2014. 209(0): p. 163-171.

22. Paques, J.P., et al., Alginate submicron beads prepared through w/o emulsification and gelation with CaCl2 nanoparticles. Food Hydrocolloids, 2012. 31(2): p. 428434.

23. Schuldt, U. and D. Hunkeler, Characterization methods for microcapsules. Minerva Biotecnologica, 2000. 12(4): p. 249.

24. Laca, A., et al., Protein diffusion in alginate beads monitored by confocal microscopy. The application of wavelets for data reconstruction and analysis. Journal of Industrial Microbiology and Biotechnology, 1999. 23(3): p. 155-165.

25. Schaink, H.M., et al., Crystal network for edible oil organogels: Possibilities and limitations of the fatty acid and fatty alcohol systems. Food Research International, 2007. 40(9): p. 1185-1193.

26. Lee, K.-Y. and T.-R. Heo, Survival of Bifidobacterium longumImmobilized in calcium alginate beads in simulated gastric juices and bile salt solution. Applied and Environmental Microbiology, 2000. 66(2): p. 869-873.

27. Gehrke, S.H., et al., Factors determining hydrogel permeability. Annals of the New York Academy of Sciences, 1997. 831(1): p. 179-184.

28. Huguet, M.L. and E. Dellacherie, Calcium alginate beads coated with chitosan: Effect of the structure of encapsulated materials on their release. Process Biochemistry, 1996. 31(8): p. 745-751.

29. Matsuyama, H., Y. Kitamura, and Y. Naramura, Diffusive permeability of ionic solutes in charged chitosan membrane. Journal of applied polymer science, 1999. 72(3): p. 397-404.

30. Paques, J.P., et al., Food-Grade Submicrometer Particles from Salts Prepared Using Ethanol-in-Oil Mixtures. Journal of Agricultural and Food Chemistry, 2012. 60(34): p. 8501-8509.

31. Roefs, P. and K.G. de Kruif, Association behavior of native $\beta$-lactoglobulin. Biopolymers, 1999. 49: p. 11-20.

32. Pluen, A., et al., Diffusion of Macromolecules in Agarose Gels: Comparison of Linear and Globular Configurations. Biophysical Journal, 1999. 77(1): p. 542-552.

33. Lavis, L.D., T.J. Rutkoski, and R.T. Raines, Tuning the $p K(a)$ of Fluorescein to Optimize Binding Assays. Analytical chemistry, 2007. 79(17): p. 6775-6782.

34. King, G., et al., Alginate-Polylysine Microcapsules of Controlled Membrane Molecular Weight Cutoff for Mammalian Cell Culture Engineering. Biotechnology Progress, 1987. 3(4): p. 231-240.

35. van Leusden, P., et al., Structure engineering of filled protein microbeads to tailor release of oil droplets in gastric digestion. Food \& Function, 2016. 7(8): p. 35393547 . 



\section{Chapter 5}

\section{Lipase diffusion in oil-filled, alginate micro- and macrobeads}

This chapter has been submitted as: P. van Leusden, G.J.M. den Hartog, A. Bast, M. Postema, E. van der Linden, L.M.C. Sagis. Lipase diffusion in oilfilled, alginate micro- and macrobeads 


\begin{abstract}
Triglycerides, which are broken down in the lower part of the intestinal tract, give a stronger ileal brake feedback, resulting in a feeling of satiety and causing people to eat less. The digestion of triglycerides into fatty acids by lipase in the intestine can be delayed by encapsulating oil droplets. In this study the release of fatty acids and oil droplet breakdown in a simulated intestinal system was investigated, for oil droplets encapsulated in alginate micro- $(10.7 \mu \mathrm{m})$ and macrobeads $(1.77 \mathrm{~mm})$. It was found that fatty acid release rate was greatly decreased by encapsulating the oil droplets into an alginate matrix compared to loose droplets. Microscopic imaging of the breakdown of the oil droplets showed a sharp front moving from the bead interface to the centre of the bead, and the change in position of the front scaled linear with time. The motion of the front is well described by combining the mass balance for lipase with a Maxwell-Cattaneo type equation, for the mass flux vector. The front in microbeads seemed to move slightly slower $(0.15( \pm 0.04) \mu \mathrm{m}$ per minute $)$ than for the macrobeads $(0.20( \pm 0.02) \mu \mathrm{m}$ per minute). The release of free fatty acids in microbeads was faster than in macrobeads, despite the slower front movement, because of the larger amount of surface area available.
\end{abstract}




\subsection{Introduction}

Lipids which are digested in the ileum of the intestinal tract induce a negative feedback mechanism, which increases feelings of satiety, causing people to eat less [1-4]. This effect is called the ileal brake, and is stronger the further along in the intestinal tract the lipids are digested [2]. Forcing lipids to be digested further down the intestinal tract might have an application in the treatment or prevention of obesity. Lipase is an enzyme, which breaks down triglycerides into glycerol and free fatty acids (FFA), and is active at the oilwater interface. Therefore most systems intending to delay lipid digestion are based on decreasing the accessibility of lipase to the triglyceride interface. One method to slow the diffusion of lipase to the oil-water interface is by encapsulating oil droplets into a hydrogel bead, where the porous gel acts as a barrier between the lipase and the oil droplets $[5,6]$. Because the lipase first has to diffuse through the matrix before it reaches the oil droplet interface, fatty acid release can be slowed down until the ileum is reached.

Alginate is a polysaccharide that has often been used for medical purposes, including encapsulation of cells and drugs [7-12]. It is a non-toxic and biodegradable polymer which gels in the presence of divalent cations. The method of gelation is very gentle, and thus appropriate for compounds sensitive to heat or strong chemicals. Paques et al. developed a water-in-oil emulsification method that is capable of creating beads of approximately 10 $\mu \mathrm{m}[13,14]$. Because particles smaller than $25 \mu \mathrm{m}$ do not negatively affect sensorial aspects of food, these microbeads can be added without affecting sensorial perception [15].

The factors that influence the rate of diffusion of components in gels include: gel type [16, 17] and density [6, 16], the component size [18], shape [19], and charge $[18,20]$, and environmental conditions such as $\mathrm{pH}[20]$ and ionic strength $[14,18,20]$. In diffusion in hydrogel beads, also the size of the beads is important $[5,6]$.

When oil is encapsulated in alginate beads for the delayed release of fatty acids, one cannot change the diffusing component (lipase) or environment, because those are naturally present in the human biological system. We can however, control the gel properties. Li et al. showed that the digestion of oil droplets encapsulated in alginate beads decreased with increasing bead size 
(0.8 to $3.4 \mathrm{~mm}$ ), and increased degree of cross-linking with calcium [5]. Corstens et al. also showed that digestion of oil droplets encapsulated in alginate beads decreased with increasing bead size $(0.55$ to $1.15 \mathrm{~mm})$, and with increasing alginate concentration, which influences the mesh size of the alginate gel [6].

Encapsulating oil droplets in an indigestible hydrogel matrix delays the release of fatty acids in the intestinal tract. The rate of the digestion is entirely dependent on the rate with which lipase is able to diffuse into the bead and reach the oil droplets. In this study we investigated the diffusion of lipase in gelled alginate beads. We investigated the influence of size in a wider range than previously reported: macrobeads of $1.77 \mathrm{~mm}$ vs. microbeads of $10.7 \mu \mathrm{m}$. We determined the rate of free fatty acid release, for both macro and microbeads, and used microscopic imaging to track the breakdown of oil droplets as a function of time. We show that this process displays non-Fickian behavior, and is described well by combining the mass balance for diffusion of lipase in the bead with a Maxwell-Cattaneo type equation for the mass flux vector.

\subsection{Materials and Methods}

\subsubsection{Materials}

$\mathrm{CaCl}_{2} \cdot 2 \mathrm{H}_{2} \mathrm{O}$, ethanol absolute, $\mathrm{NaOH}, \mathrm{NaCl}$ (Merck millipore, Darmstadt, Germany), Tween 60, Lipase from porcine pancreas (Sigma, Steinheim, Germany), Polyglycerol polyricinoleate (PGPR) 90 Kosher (Danisco, Kopenhagen, Denmark), Medium Chain Triglycerides (MCT) (Miglyol 812 $\mathrm{N}$, Sasol, Germany), and Sodium alginate extracted from brown algae (Algin, Texturas, Barcelona, Spain), were all used as received. Solutions were made in demineralized water.

\subsubsection{Production of Calcium nanocrystals}

Calcium nanocrystals were made according to the method of Paques et al. [21]. In short: A dispersion was made of $6 \%$ PGPR in MCT oil and allowed to mix for 2 hours. A volume of $5 \%$ of a 0.1 molal $\mathrm{CaCl}_{2} \cdot 2 \mathrm{H}_{2} \mathrm{O}$ solution in ethanol was added to this MCT solution and emulsified (Sonicator S-250A sonicator, Branson Ultrasonics, USA) for 2 minutes. The resulting mixture 
was heated and stirred overnight at $60{ }^{\circ} \mathrm{C}$ without cover to allow the ethanol to evaporate, producing a dispersion of calcium nanocrystals in oil.

\subsubsection{Production of the microbeads}

Oil filled alginate microbeads were made based on the method described by Van Leusden et al. [14]. The inner oil droplets were made by mixing 5.0\% (w/w) MCT with demi-water containing $0.3 \%(w / w)$ Tween 60 with an UltraTurrax (Ultra-Turrax T 25, IKA Werke, Germany) at 8000 rpm for 2 minutes. The emulsion was further homogenized (Delta instruments, Drachten, The Netherlands) at 180 bar for 3 passes. To the emulsion $2.0 \%(\mathrm{w} / \mathrm{w})$ alginate was added and allowed to dissolve for 2 hours. While mixing with the UltraTurrax at $8800 \mathrm{rpm}, 10 \%(\mathrm{v} / \mathrm{v})$ of the previous emulsion was slowly added to MCT oil containing 4\% (w/w) PGPR. After full addition the double emulsion was mixed for a further 3 minutes. After mixing, $5 \mathrm{~mL}$ of calcium nanocrystal dispersion was added per $\mathrm{mL}$ of primary emulsion. This mixture was gently stirred for at least 18 hours to allow gelation of the beads.

The beads were removed from the oil phase by successive centrifugation and redispersion steps. The beads were centrifuged for 2 hours at $3500 \mathrm{~g}$. The pellet was redispersed in $25 \mathrm{mM} \mathrm{CaCl}_{2}$ solution, homogenised at 100 bar for 3 passes and then once again centrifuged at $1000 \mathrm{~g}$ for 1 hour. The sediment was redispersed in demi-water, after which the centrifugation was repeated. The highly concentrated beads were stored in demi-water and diluted before use.

\subsubsection{Production of the macrobeads}

Oil filled alginate macrobeads were made based on the method described by [14]. The inner oil droplets with alginate were made as described in the section of the production of microbeads. The emulsion was put in a syringe and expressed through a needle of $0.3 \mathrm{~mm}$ (BD Microlance $0.3 \times 13 \mathrm{~mm}$ ) into a 25 $\mathrm{mM} \mathrm{CaCl} l_{2}$ water bath, where the droplets were formed approximately $5 \mathrm{~cm}$ above water level. The beads were stirred for 1 hour and then stored in the $\mathrm{CaCl}_{2}$ solution, at $4{ }^{\circ} \mathrm{C}$, for a further 24 hours. The beads were taken from the $\mathrm{CaCl}_{2}$ solution, the excess solution was absorbed with filter paper, and then stored in high concentrations in demi-water. 


\subsubsection{Size determination}

The size of the beads was measured by light microsocopy (Axioskop 50) equipped with a camera (AxioCam HRc) (both from Zeiss, Germany). Images were analysed with ImageJ.

\subsubsection{Lipase accessibility}

The lipase accessibility to the oil droplets was investigated in: 1) a $2.0 \%(\mathrm{v} / \mathrm{v})$ dispersion of microbeads, 2) a $2.0 \%(\mathrm{v} / \mathrm{v})$ dispersion of macrobeads, 3 ) an equivalent amount of unencapsulated emulsion, as made for the production of the alginate beads, but before addition of the alginate. The volume fraction was estimated by drying samples of the beads overnight in an oven at $105^{\circ} \mathrm{C}$. The dry weight of the beads was used to calculate the volume fraction of the beads, assuming no swelling or shrinking or loss of oil occurred. The accessibility was measured in a diluted, simulated intestinal system based on the system described by [22]. This consisted of $150 \mathrm{mM}$ of $\mathrm{NaCl}$ and $1 \mathrm{mg} / \mathrm{mL}$ pancreatic lipase at $\mathrm{pH} 7.0$ and $37^{\circ} \mathrm{C}$. The conversion of MCT to the acidic fatty acids was followed by the amount of $\mathrm{NaOH}$ that needed to be added to keep the $\mathrm{pH}$ at 7.0. This was done with the pH-STAT (Metrohm, Herisau, Switzerland). The reaction was followed for 2.5 hours and duplicate experiments were performed. The free fatty acid release was calculated with the following equation:

$$
\text { FFA } \%=\frac{V_{N a O H} M_{N a O H} M_{w, l i p i d}}{3 \omega_{\text {lipid }}}
$$

where $V_{\mathrm{NaOH}}$ is the volume of $\mathrm{NaOH}$ titrated into the solution to keep it at $\mathrm{pH}$ $7.0, M_{\mathrm{NaOH}}$ the molarity of the $\mathrm{NaOH}$ solution, $M_{\mathrm{w}, \text { lipid }}$ the molecular weight of the MCT oil, which was calculated to be $508 \mathrm{~g} / \mathrm{mol}$ and $\omega_{\text {lipid }}$ the amount of lipid present in the beginning of the experiment. The factor 3 is present because every triglyceride contains 3 fatty acids which can be released.

The oil droplet breakdown was also followed with light microscopy. The same method as for the pH-STAT was used, and at regular time intervals a small sample of the solution was taken. The sample was immediately heated to $80^{\circ} \mathrm{C}$ for 10 minutes to inactivate the lipase. For every sample at least 25 microbeads were investigated in the range of 9.0 to $12 \mu \mathrm{m}$. The macrobeads were cut in 
half and viewed in a microscope slide with a dip, to prevent the pressure of the cover slide to influence the measurements. For every sample at least four macrobeads were investigated, and the location of the breakdown front was determined at different points along the circumference of the bead.

\subsection{Results and Discussion}

The amount of FFA released from oil droplets encapsulated in microbeads and macrobeads, and non-encapsulated droplets, over time is presented in Figure 5.1. Approximately $70 \%$ of the lipids of the non-encapsulated droplets were released within 6 minutes. After this point, the breakdown proceeds more slowly. This change in rate could be the result of the fact that pancreatic lipase can cut the fatty acids from the 1 and 3 position from the glycerol backbone very quickly, while the fatty acid from the 2 position of the monoglyceride occurs only after isomerisation of the monoglyceride [23-25]. In addition, as a result of the breakdown, the available surface area is reduced, and the fraction of lipase which participates in the process is reduced.

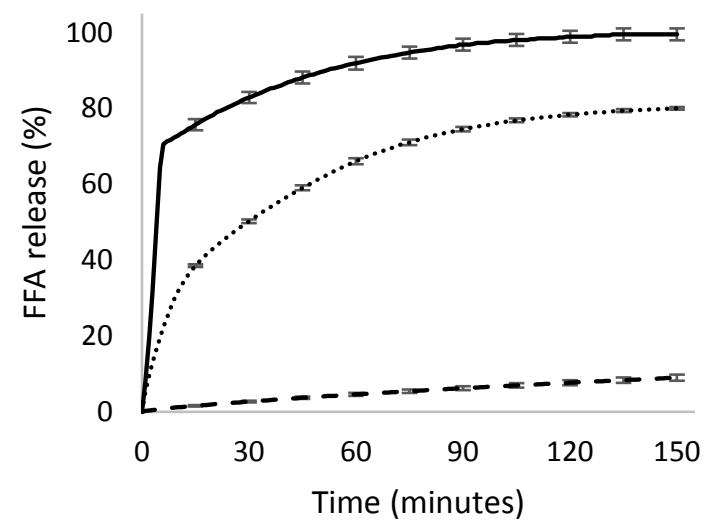

Figure 5.1: Free fatty acid release from oil droplets (solid line), oil droplets encapsulated in microbeads (dotted line) and oil droplets encapsulated in macrobeads (dashed line) in a simulated intestinal system, as a function of time. 
The rate of lipolysis of encapsulated oil droplets is far slower than for nonencapsulated droplets. Lipase first needs to diffuse to the oil-water interface of the oil droplets, and adsorb at this interface. For non-encapsulated droplets in a stirred vessel, this adsorption process is fast. For encapsulated oil droplets, lipase first has to diffuse through the gel matrix of the beads before it can adsorb at the oil-water interface [5,6]. After 2.5 hours, $9.0 \%$ of the lipids in the macrobeads has been broken down. The amount of FFA released is almost linear in time, which means the release rate is nearly constant up to 150 minutes. For the microbeads, after 150 min, approximately $80 \%$ of the lipids has been broken down. Here, the rate of lipid breakdown decreases over time. The difference between micro- and macrobeads can be explained by the difference in specific surface area of the beads. It is known that lipase diffuses more slowly through a gelled matrix than in a solution.

The progression of oil droplet breakdown in time in macro- and microbeads was followed by microscopy (Figure 5.2, and 5.3).
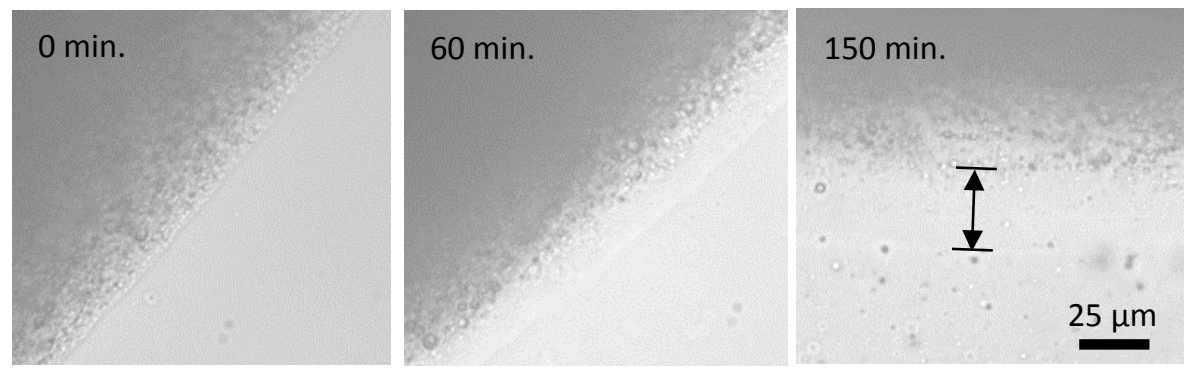

Figure 5.2: Microscopic images of macrobeads during digestion of the oil droplets in a simulated intestinal system, over time. The lines and arrow indicate the locations of the bead interface and the lipase front.
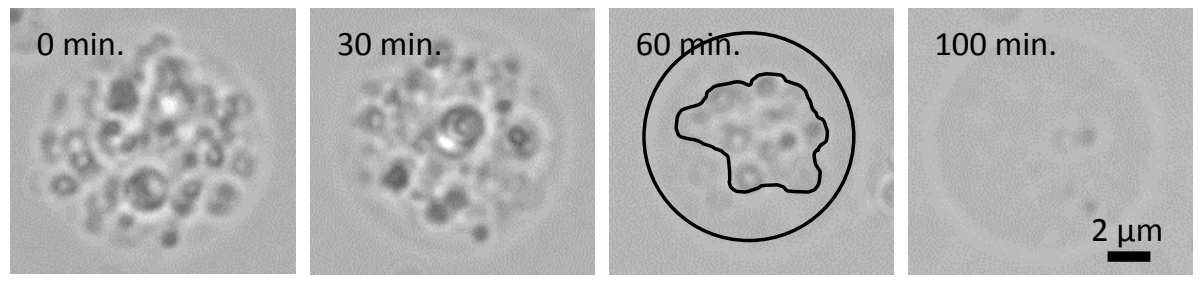

Figure 5.3: Microscopic images of microbeads during digestion of the oil droplets in a simulated intestinal system, over time. The lines indicate the locations of the bead interface and the lipase front. 
As can be seen from the images, for both the micro- and macrobeads there appears to be a front moving inwards over time, separating a volume where oil-droplets have been broken down, from a volume where they appear to be unaffected. The fact that an inward moving front is visible indicates that the breakdown process is diffusion limited, and that the diffusion process itself is non-Fickian. From a previous study it is known that BSA, which has a radius of $3.9 \mathrm{~nm}$ [19], diffuses throughout similarly made micro- and macrobeads within several minutes [14]. Lipase is smaller than BSA (2.8 nm) [26] and the salt concentration in the current study is higher $(100$ vs. $150 \mathrm{mM} \mathrm{NaCl})$, so we would expect lipase diffusion through the gel matrix of the bead to be faster. However, when the lipase diffuses into the beads and encounters an oil droplet, it will adsorb on the oil-water interface, and will essentially be trapped there until the oil droplet is digested. When the volume fraction of encapsulated droplets is high enough, this trapping will result in an effective diffusion process with a non-Fickian appearance. Additionally, it is possible that the presence of the lipase in the pores of the alginate gel may thereby also block other lipase molecules of diffusing through.

The displacements of the fronts for both macro and microbeads were determined from image analysis of Figures 5.2 and 5.3. The results are shown in Figure 5.4.

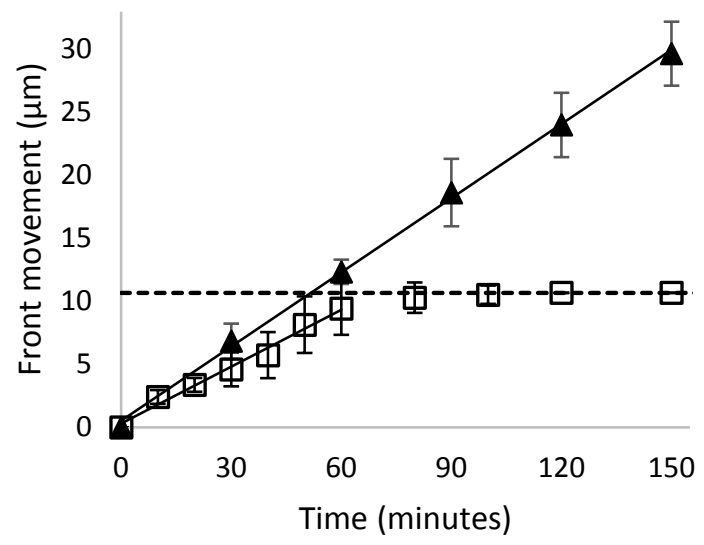

Figure 5.4: Front displacement of oil droplet digestion in macrobeads ( $\mathbf{\Delta})$ and microbeads () in a simulated intestinal system, as a function of time. The dotted line indicates the average diameter of the microbeads. 
For the macrobeads, the displacement of the front is linear in time, which corresponds to the release of FFA, which was also linear in time. After 2.5 hours, the front has moved approximately $30 \mu \mathrm{m}$ inwards. The amount of oil in this $30 \mu \mathrm{m}$ shell corresponds to approximately $9.7 \%$ of the total oil content. As shown in Figure 5.1, the release rate after 2.5 hours is approximately $9.0 \%$. This confirms that the breakdown of oil indeed proceeds from the outward in.

The displacement of the front in the microbeads is also linear in time. The oil of the beads with a diameter in the range of 9 to $12 \mu \mathrm{m}$ is mostly broken down within 80 minutes, which is in reasonable agreement with the FFA release data. The difference between these two measurements is the result of the polydispersity of the beads. For our image analysis we investigated mainly beads between 9 and $12 \mu \mathrm{m}$. There is however also a fraction of beads smaller than $9 \mu \mathrm{m}$ and another fraction of beads larger than $12 \mu \mathrm{m}$. Larger beads release their oil slowly, because of their lower specific surface area. After 2.5 hours there were still several bigger microbeads, of approximately $50 \mu \mathrm{m}$, that still had not released all their oil, and this is why in the FFA release graph only $80 \%$ of the oil of the microbeads is released. The rate of front displacement in the macrobeads is approximately $0.20( \pm 0.02) \mu \mathrm{m}$ per minute, while for the microbeads this is approximately $0.15( \pm 0.04) \mu \mathrm{m}$ per minute (calculated from the average bead size of $10.7 \mu \mathrm{m})$.

Both Li et al. and Corstens et al. have developed models for the diffusion of lipase through alginate microbeads $[5,6]$. The model of $\mathrm{Li}$ et al. did not fit the experimental results very well, for which they give several possible explanations. The pore size they assumed is most likely much smaller than the actual pore size, as found by Corstens et al., which dramatically reduces the diffusion coefficient. They also suggest that lipase may interact with the gel network, where we assume that lipase in fact interacts with the oil droplets, thereby also hindering diffusion.

Corstens et al. have used Fick's law to calculate the concentration of enzyme at a certain position in their beads. For the large beads we will assume the effects of curvature are negligible, and we will describe the diffusion process as a one-dimensional diffusion problem in a Cartesian coordinate system $(x, y, z)$. According to Fick's law the mass flux of lipase in the $x$-direction is given by: 


$$
J_{x}=-D \frac{\partial C}{\partial x}
$$

Where $J_{x}$ is the flux in mol m $\mathrm{m}^{-2} \mathrm{~s}^{-1}, \mathrm{D}$ is the diffusion coefficient in $\mathrm{m}^{2} \mathrm{~s}^{-1}$, and $\mathrm{c}$ is the concentration in $\mathrm{mol} \mathrm{m}^{-3}$.

A drawback of this model is that when combined with the mass balance for lipase, we obtain a parabolic partial differential equation, which predicts an unbounded speed of propagation of concentration perturbations. In our case however we have seen a clear front moving through the bead at a finite speed. To alleviate this problem we replace Eq. (1) by a Maxwell-Cattaneo type equation for the mass flux. The Maxwell-Cattaneo equation is an adaption of Fourier's law for heat conduction, where a relaxation time is introduced to avoid an unbounded speed of propagation of thermal perturbations [27]. For mass diffusion this equation is formulated as:

$$
\tau \frac{\partial J_{x}}{\partial t}+J_{x}=-D \frac{\partial C}{\partial x}
$$

Here $t$ is time, and $\tau$ is the relaxation time, or for mass transfer the retardation time, in s. Combining this expression for the mass flux with the differential mass balance for lipase, we obtain (see Appendix):

$$
\frac{\partial^{2} C}{\partial t^{2}}+\frac{1}{\tau} \frac{\partial C}{\partial t}-\frac{D}{\tau} \frac{\partial^{2} C}{\partial x^{2}}=0
$$

This is a telegraph equation, a hyperbolic partial differential equation which predicts a finite speed of propagation for concentration perturbations, $v$, given by:

$$
v=\sqrt{\frac{D}{\tau}}
$$

When $v$ is constant, (3) predicts a front displacement $L$ for the large beads, which is linear in time, i.e.

$$
L \sim\left(\sqrt{\frac{D}{\tau}}\right) t
$$


For the small beads, following along the same lines, we also find a relative front displacement which is linear in time. Both scalings are confirmed by our experimental results (see Figure 5.4).

In systems with smaller pores the retardation time will be longer, which will give a slower propagation speed. In systems with bigger pores the retardation time will be shorter, thereby increasing the propagation speed and more closely resembling the diffusion according to Fick's second law. Corstens et al. have used Fick's law to describe their systems [6]. An important difference between the two systems however is that the beads described by Corstens et al. have very large oil droplets $\left(D_{32}=21 \pm 4 \mu \mathrm{m}\right)$, whereas ours are relatively small (approximately $1 \mu \mathrm{m}$ ). The surface to volume ratio is smaller in larger droplets therefore there is less surface for lipase entrapment. Additionally, the droplets will need longer to completely digest because of this different ratio and therefore lipase can diffuse on without the previous oil droplet being entirely digested, which makes it difficult for a front, as we had, to be visible. The model of Corstens et al. has proven to be adequate for several alginate macrobead systems. In our system however, where a clear, linear front was visible over a prolonged length of time, Fick's law proves inadequate. 


\subsection{Conclusions}

Lipid digestion was slowed by encapsulating oil droplets into an alginate matrix, because the alginate creates a barrier that lipase first has to diffuse through before it is able to attach to the interface of the oil droplets. Once lipase is bound at the interface it is trapped until the droplet is digested, which retards lipase diffusion. The breakdown of oil droplets in the alginate beads proceeded from the outside of the bead to the centre, where a clear front was present during digestion. The progression of the front was linear and could be described by a Maxwell-Cattaneo type equation for the mass flux instead of the normally used Fick's law. For microbeads this front seemed to move slightly slower at $0.15( \pm 0.04) \mu \mathrm{m}$ per minute than for macrobeads, 0.20 $( \pm 0.02) \mu \mathrm{m}$ per minute. Despite the similar front speed, the oil in the microbeads digested much faster than the oil in microbeads because of the larger amount of surface area available.

\section{Acknowledgements}

The research presented in this paper was financially supported by the Graduate School VLAG, of Wageningen University. 


\section{References}

1. Alleleyn, A., et al., Gastrointestinal Nutrient Infusion Site and Eating Behavior: Evidence for A Proximal to Distal Gradient within the Small Intestine? Nutrients, 2016. 8(3): p. 117.

2. Welch, I., K. Saunders, and N.W. Read, Effect of ileal and intravenous infusions of fat emulsions on feeding and satiety in human volunteers. Gastroenterology, 1985. 89(6): p. 1293-1297.

3. Maljaars, P., et al., Length and site of the small intestine exposed to fat influences hunger and food intake. British journal of nutrition, 2011. 106(10): p. 1609-1615.

4. Spiller, R., et al., The ileal brake--inhibition of jejunal motility after ileal fat perfusion in man. Gut, 1984. 25(4): p. 365-374.

5. Li, Y., et al., Control of lipase digestibility of emulsified lipids by encapsulation within calcium alginate beads. Food Hydrocolloids, 2011. 25(1): p. 122-130.

6. Corstens, M.N., et al., Emulsion-alginate beads designed to control in vitro intestinal lipolysis: Towards appetite control. Journal of Functional Foods, 2017. 34(Supplement C): p. 319-328.

7. Lim, F. and A.M. Sun, Microencapsulated islets as bioartificial endocrine pancreas. Science, 1980. 210(4472): p. 908-910.

8. Covarrubias, S.A., et al., Alginate beads provide a beneficial physical barrier against native microorganisms in wastewater treated with immobilized bacteria and microalgae. Applied Microbiology and Biotechnology, 2012.93(6): p. 2669-2680.

9. Sultana, K., et al., Encapsulation of probiotic bacteria with alginate-starch and evaluation of survival in simulated gastrointestinal conditions and in yoghurt. International Journal of Food Microbiology, 2000. 62(1-2): p. 47-55.

10. Lee, K.-Y. and T.-R. Heo, Survival of Bifidobacterium longumImmobilized in calcium alginate beads in simulated gastric juices and bile salt solution. Applied and Environmental Microbiology, 2000. 66(2): p. 869-873.

11. Pasparakis, G. and N. Bouropoulos, Swelling studies and in vitro release of verapamil from calcium alginate and calcium alginate-chitosan beads. International Journal of Pharmaceutics, 2006. 323(1-2): p. 34-42.

12. Liu, J., et al., Magnetically sensitive alginate-templated polyelectrolyte multilayer microcapsules for controlled release of doxorubicin. The Journal of Physical Chemistry C, 2010. 114(17): p. 7673-7679.

13. Paques, J.P., et al., Food-Grade Submicrometer Particles from Salts Prepared Using Ethanol-in-Oil Mixtures. Journal of Agricultural and Food Chemistry, 2012. 60(34): p. 8501-8509.

14. van Leusden, P., et al., Permeation of probe molecules into alginate microbeads: Effect of salt and processing. Food Hydrocolloids, 2017. 73(Supplement C): p. 255261.

15. Tyle, P., Tactile Pattern RecognitionEffect of size, shape and hardness of particles in suspension on oral texture and palatability. Acta Psychologica, 1993. 84(1): p. 111118.

16. Martinsen, A., I. Storrø, and G. Skjårk-Bræk, Alginate as immobilization material: III. Diffusional properties. Biotechnology and Bioengineering, 1992. 39(2): p. 186194.

17. Liu, X.C., et al., Characterization of structure and diffusion behaviour of Ca-alginate beads prepared with external or internal calcium sources. Journal of microencapsulation, 2002. 19(6): p. 775-782. 
18. Stewart, W.W. and H.E. Swaisgood, Characterization of calcium alginate pore diameter by size-exclusion chromatography using protein standards. Enzyme and microbial technology, 1993. 15(11): p. 922-927.

19. Pluen, A., et al., Diffusion of Macromolecules in Agarose Gels: Comparison of Linear and Globular Configurations. Biophysical Journal, 1999. 77(1): p. 542-552.

20. Huguet, M.L. and E. Dellacherie, Calcium alginate beads coated with chitosan: Effect of the structure of encapsulated materials on their release. Process Biochemistry, 1996. 31(8): p. 745-751.

21. Paques, J.P., et al., Alginate submicron beads prepared through w/o emulsification and gelation with CaCl2 nanoparticles. Food Hydrocolloids, 2012. 31(2): p. 428434.

22. Minekus, M., et al., A standardised static in vitro digestion method suitable for foodan international consensus. Food \& function, 2014. 5(6): p. 1113-1124.

23. Korn, E.D., The fatty acid and positional specificities of lipoprotein lipase. Journal of Biological Chemistry, 1961. 236(6): p. 1638-1642.

24. Mattson, F. and L. Beck, The specificity of pancreatic lipase for the primary hydroxyl groups of glycerides. Journal of Biological Chemistry, 1956. 219(2): p. 735-740.

25. Borgström, B., Influence of bile salt, $\mathrm{pH}$, and time on the action of pancreatic lipase; physiological implications. Journal of lipid research, 1964. 5(4): p. 522-531.

26. Pignol, D., et al., Critical role of micelles in pancreatic lipase activation revealed by small angle neutron scattering. Journal of Biological Chemistry, 2000. 275(6): p. $4220-4224$.

27. Jou, D., J. Casas-Vázquez, and G. Lebon, Extended Irreversible Thermodynamics: Evolution Equations, in Extended Irreversible Thermodynamics. 2010, Springer Netherlands: Dordrecht. p. 42-58. 


\section{Appendix}

Derivation of equation (3)

We start by rewriting (2) as:

$$
\frac{\partial J_{x}}{\partial t}=-\frac{D}{\tau} \frac{\partial C}{\partial x}-\frac{1}{\tau} J_{x}
$$

In a Cartesian coordinate system the mass balance for the lipase is given by:

$$
\frac{\partial C}{\partial t}=-\frac{\partial J_{x}}{\partial x}
$$

Taking the derivative with respect to time of this equation, we obtain:

$$
\frac{\partial^{2} C}{\partial t^{2}}=-\frac{\partial}{\partial x}\left(\frac{\partial J_{x}}{\partial t}\right)
$$

Here we have used the fact that $x$ and $t$ are independent variables, and exchanged the order of derivation in the term on the right hand side. When combining equations A.1 and A.3 we find:

$$
\frac{\partial^{2} C}{\partial t^{2}}=\frac{\partial}{\partial x}\left(\frac{D}{\tau} \frac{\partial C}{\partial x}+\frac{1}{\tau} J_{x}\right)
$$

Eliminating the second term on the right hand side, using A.2, we obtain:

$$
\frac{\partial^{2} C}{\partial t^{2}}+\frac{1}{\tau} \frac{\partial C}{\partial t}-\frac{D}{\tau} \frac{\partial^{2} C}{\partial x^{2}}=0
$$




\section{Chapter 6}

General discussion 


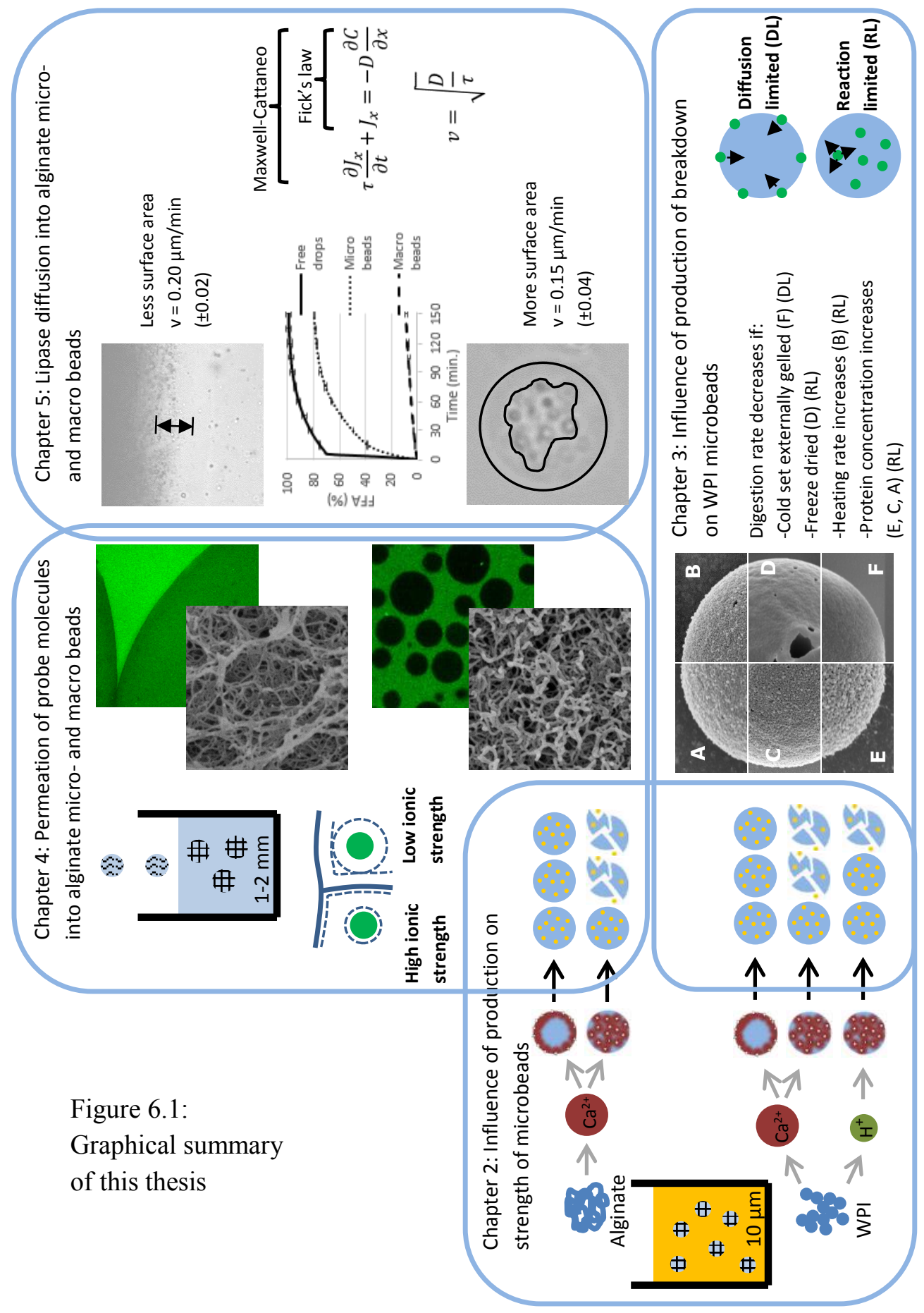


Hydrogel microbeads are capable of trapping, protecting and delivering components, such as living cells, oil droplets, vesicles and chemicals. In this thesis 'Effects of structure on hydrogel microbead function' we investigated the influence of different production parameters on hydrogel microbead formation, its resulting microstructure, and how that in turn affects the functionality of the microbeads in their function as encapsulation systems. The main findings are summarised in Figure 6.1.

Encapsulation systems must be specifically tailored for the purpose and for the environment in which they will be used. First we looked at the strength of the microbeads, because they have to be able to withstand shear, mostly during the production process, if they are ever to be applied in actual systems. Secondly we looked at the diffusion of molecules in beads. In the case of hydrogel microbeads the diffusivity of molecules into or out of the beads is key. This factor determines the encapsulation efficiency, release profile and breakdown rate. In chapter 1 we identified several factors important to the diffusivity. We divided the factors into characteristics of the gel, the diffusing component and the environment. In this thesis we have considered several of the factors mentioned. For the gel bead we looked at the hydrocolloid type, the production method, the hydrocolloid density and the size of the beads. For the diffusing component we looked at the size and the charge. For the environment we looked at the ionic strength. For the probe we now also consider another factor: the function of the probe molecule. These factors are summarised in Figure 6.2. These factors are interconnected and vary in importance based on the entire system. 
Environment

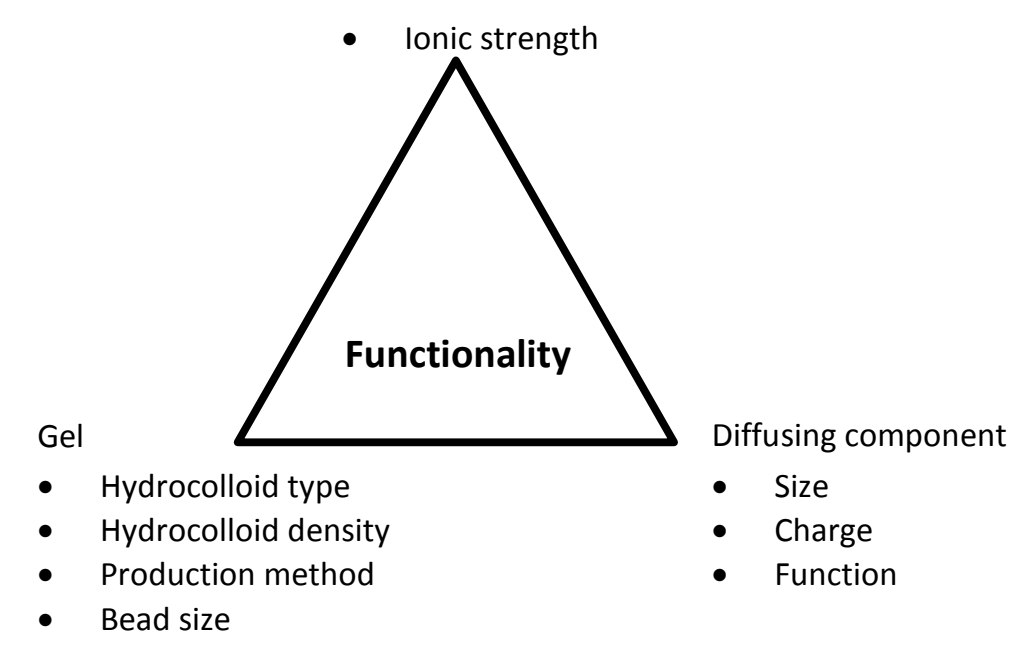

Figure 6.2: Schematic overview of factors important to hydrogel microbead functionality.

In chapter 2 we investigated the influence of the hydrocolloid, gelling agent and the method of gelation on the strength of hydrogel microbeads. The ability to withstand shear is critical during production processes. We tested WPI versus alginate, external versus internal calcium gelation, and calcium versus acid gelation. Here we found that the way in which the beads were gelled was the deciding factor in microbead strength.

In chapter 3 we investigated the breakdown behaviour of WPI beads produced by different methodologies in a simulated gastric system. The stomach is the main system in the digestive tract where protein is broken down by pepsin. Here, again, we found that the production process had a significant effect on the time and mechanism by which the beads break down. Cold-set beads broke down in a diffusion limited manner, while all other beads broke down in a reaction limited manner. Factors delaying digestion were: increasing the protein concentration, increasing the heating rate during gelation, freeze drying, and using cold-set gelation.

In chapter 4 we compared diffusion in microbeads with diffusion in alginate macrobeads, which are 1 to $2 \mathrm{~mm}$ in diameter, and made by dripping an alginate solution into a calcium salt bath. Here we found that the confined 
environment of the emulsified alginate solution during gelation of the microbeads created a tighter network with smaller pores, and allowed less access to probe molecules than the macrobeads, which swell in the calcium salt bath during gelation. The ionic strength of the environment affects the diffusion by affecting the Debye length, which determines the range over which the electrostatic interactions, attraction and repulsion, are effective. Even FITC (389 Da), which is much smaller than the pore size, can be excluded from the beads when the ionic strength is very low and the Debye length is thus very large.

In chapter 5 we investigated the rate of diffusion of lipase into oil-filled, alginate micro- and macrobeads, in a simulated intestinal tract, which is the main location for oil digestion. Encapsulation delayed oil digestion and we saw a visible front of oil droplet digestion moving inward, from the outside of the beads. Because of the clear front movement, we described the oil digestion and movement of the enzyme with a Maxwell-Cattaneo equation, adjusted for mass transfer.

In the following sections we discuss the findings and connections of the previous chapters, discuss additional research in the development and applications of the microbeads, and give the conclusions and outlook.

\subsection{Discussion}

\subsubsection{Effects of gel characteristics}

In the introduction we mentioned the hydrocolloid type and density, production method, and bead size as factors which are important to characteristics of the hydrogel microbeads. It is however very difficult to separate these factors in practice. The gelation method and hydrocolloid density depend on the hydrocolloid used. Furthermore it is not possible to create the micro- and macrobeads of this thesis with the same method. The dripping method is impossible to use for producing microbeads, because it cannot produce such small droplets. The emulsification method is inappropriate for production of macrobeads because the emulsion does not remain stable during gelation of the larger beads. 
In this thesis we have investigated two hydrocolloids: WPI and alginate. An important difference between the hydrocolloids is that WPI is digestible in the intestinal tract, whereas alginate is not. Where for the alginate systems we looked at the diffusion of probe molecules into the matrix, for WPI systems we also considered what the probe molecule, pepsin, does to the matrix itself. In chapter 2 we looked at the influence of hydrocolloid type and gelling agent and method on the strength of microbeads. The strongest beads were the externally gelled WPI and alginate beads, which produced beads with a smooth microstructure. This smooth surface is most likely created because of the gradual release of calcium from the calcium crystals which diffuse to the interface, where they dissolve. This slow release of calcium allows for diffusion of non-gelled alginate (or WPI aggregates) to the interface where as a result a denser shell is created. This dense shell, reflected in the smooth surface as shown by the SEM images, is what increases the resistance of the beads to shear. Since this effect was observed both for the externally gelled alginate and cold-set WPI beads, we concluded that the method of gelation was a more important factor for their mechanical strength, than the hydrocolloid type.

In chapter 3, where we considered the influence of gelation method and hydrocolloid density on the digestion of WPI microbeads, we found that both factors influenced the digestion time. For heat set beads the digestion time increased with increasing protein concentration, going from $12(15 \%)$ to 48 minutes $(25 \%)$. This is as expected because a higher protein content means that more protein needs to be hydrolysed before the bead disintegrates. Diffusion of pepsin throughout the bead occurred within 1.5 minutes, and breakdown of the heat-set beads occurred in a reaction limited manner. Digestion of $10 \%$ cold-set protein beads was however slower than that of the heat-set $15 \%$ beads. The delay in breakdown was caused by the fact that the breakdown was diffusion limited instead of reaction limited. The smoother, tighter microstructure at the interface, which as discussed in the previous section also caused them to be stronger, delayed access of pepsin to the bead interior. This shell needed to be broken down before the interior could be reached. The diffusion of pepsin into the beads was delayed up to 12 minutes. Bead breakdown could also be slowed by increasing the heating rate during gelation, and by freeze drying, with neither type of bead being completely digested after 2 hours. Freeze dried beads needed to be rehydrated before 
enzymes could diffuse into the bead. Increasing the heating rate had an immense effect on the ease with which the enzyme hydrolysed the proteins, though little effect of the heating rate was seen in SEM images of the microstructure.

In chapters 4 and 5 we investigated the diffusion behaviour of various proteins in alginate beads. The amount of component able to diffuse into the alginate bead increased with lower hydrocolloid density. This lower density gave bigger pores and less internal repulsion, thereby allowing more component to diffuse in. Here we also found influences of gelation method. Where in chapter 4 the protein probes (18.4-66.5 $\mathrm{kDa})$ diffused into alginate beads within several minutes, pepsin $(35 \mathrm{kDa})$ was not able to freely diffuse into cold-set protein microbeads, even though SEM pictures showed a similar smooth microstructure on the surface of both alginate and WPI microbeads. This difference is either caused by the higher density on the surface of the WPI microbead ( $10 \%$ vs. $2 \%)$ which blocked the pepsin, or by the fact that the pepsin is attracted to the WPI matrix. We also found that the macrobeads made by the dripping method swelled during gelation, thereby also giving a lower relative alginate density which allowed for more component to diffuse in. These results are reflected in chapter 5 where lipase diffused more quickly into macrobeads than into microbeads. When looking at the difference in amount of oil digested in micro- and macrobeads however, the delay is negated by the enormous difference in surface area between the micro- and macrobeads.

For the gel characteristics which influenced microbead functionality we have investigated hydrocolloid type and density, gelation method, and bead size. In conclusion, the hydrocolloid type is very important when the diffusing component has an interaction with the matrix itself. Otherwise the hydrocolloid type does not greatly affect the bead strength or the rate of diffusion. The hydrocolloid density influences the amount of component able to diffuse into the beads, but does not significantly influence the rate of diffusion. The gelation method influences both the final uptake and the rate of diffusion. Gelation method is however especially important to the strength of the microstructure. Bead size is a very important factor. Not because it greatly influences the final uptake or rate of diffusion, but because it has an enormous influence on the specific surface of the beads. 


\subsubsection{Effects of size and functionality of the diffusing component}

For the characteristics of the diffusing component we investigated the influence of the size and the function of the diffusing component. In chapter 4 we considered the diffusion of different sized probe molecules into alginate beads. The probe molecules, globular proteins labelled with FITC, diffused quickly, and equilibrium was established within several minutes. The final uptake of probe molecule in the beads decreased with increasing component size.

We added another factor which is important to diffusion that has not been previously considered in other literature: the function of the diffusing component. We have investigated 3 different systems: (1) systems with no interaction between the matrix (protein probes and alginate, chapter 4) and the diffusing component (other than excluded volume or electrostatic repulsive interactions), (2) systems without interaction between the component and the matrix, but with interactions between the component and a component encapsulated within the matrix (lipase and oil droplets within alginate, chapter 5), (3) systems with an interaction between the component and the matrix (pepsin and WPI, chapter 3). When there is no interaction (1) the diffusion occurred within several minutes throughout the beads, for both micro- and macrobeads. For enzymes interacting with (a component in) the matrix also the enzymatic activity must be considered. For the heat set beads in chapter 3 the breakdown of the matrix by pepsin was reaction limited, and final uptake was reached within minutes. However for the cold-set beads the breakdown was diffusion limited, and the rate of diffusion of pepsin was much lower than in the heat set beads. The thicker shell around the cold-set beads apparently slowed the rate of diffusion to such an extent that it was slower than the rate of hydrolysis. In the oil-filled alginate beads of chapter 5, produced in the same way as in chapter 4 , lipase which is of similar size as the probe molecules of chapter 4, diffused much more slowly into the beads. The lipase diffused into the beads, but upon encountering an oil droplet, the lipase attached to the oil water interface, and was trapped there until the oil droplet was digested, after which the lipase could diffuse on. The lipase reached the centre of the microbeads after approximately one hour, as opposed to several minutes, and breakdown of the oil-droplets clearly occurred in a diffusion limited manner. When performing diffusion studies the activity of the diffusion component needs to be considered. 


\subsubsection{Effects of environmental conditions on diffusion in hydrogel beads}

Ionic strength of the environment is an important factor for the diffusion of components into microbeads, if both the component and the matrix carry a charge, which is in practice often the case. Microbeads are often made of proteins or polysaccharides, and important diffusing components are often protein based. Notable exception are components made of sugar molecules such as sucrose, starch and cellulose. As explained, the ionic strength influences the Debye length. In the simulated gastric system of chapter 3 the protein beads carry a positive charge and the pepsin a slightly negative charge $[1,2]$. In chapter 4 and 5 the alginate beads carry a negative charge and the FITC-protein probes and lipase also a negative charge [3-5]. The final uptake of pepsin inside and the rate of diffusion of pepsin into the heat set WPI microbeads was therefore facilitated by their attractive charges and the high salt content of the environment. This also confirms that the shell of the coldset beads was particularly dense. If pepsin was able to diffuse into the beads in substantial amounts, this would have resulted in swelling of the beads. Despite the attractive interactions and short Debye length, the beads were broken down from the outside in, which means that the pepsin concentration at the interface was much higher than inside the beads. In chapter 4 and 5, the diffusion of the component was hindered by the repulsion between the alginate matrix and diffusing component. The final uptake of component in the beads was reduced by the negative charges and, in chapter 4, the large Debye layer caused by the low ionic strength. An environment with a very low ionic strength (demineralised water) was able to completely exclude components from the interior of all types of beads, independent of gelation method, the hydrocolloid content, or the diffusing component size.

In conclusion, hydrogel microbeads are essentially very porous systems, in which small colloidal particles such as oil droplets can be trapped, but proteins are freely able to diffuse into or out of the beads. A low ionic strength and similar charges are the only factors able to completely exclude a component from the interior of the bead. The diffusion of a component into the bead can be severely delayed if the component has a reaction to facilitate within the bead. Production method, hydrocolloid type and density and size of the component have a limited influence on the final uptake and rate of diffusion within the beads. The size of the bead does not slow diffusion but may slow the digestion of a component caught within the bead. The gelation method is 
the most important factor contributing to bead strength. The gelation method may also have an influence on the digestion rate if the matrix itself is digestible.

\subsection{Research into increasing microbead functionality}

In the previous chapters we have found that the hydrogel beads can successfully encapsulate small colloids such as oil droplets, but are otherwise very permeable to smaller compounds. The latter can be a problem when the encapsulated component has a relatively high water solubility, or is susceptible to degradation by small molecules in the continuous phase. Here we will discuss a number of possible applications of these microbeads. We will also discuss strategies to resolve the issue of the high permeability of the hydrogel microbeads, and discuss some additional experiments and suggestions for further research.

To reduce the high permeability of the beads we have done investigations into application of a coating around the beads. An extra shell reduces or even stops diffusion of components into or out of the structure and it gives extra protection to the component carried within. These coatings may also be activated under certain environmental circumstances, such as the application of ultrasound, or a change in $\mathrm{pH}$, creating a triggered release system.

As a potential application of the microbeads we have investigated coencapsulation of multiple (synergistic) components. Usually in encapsulation systems there is a single core in which a single component is present. The ability of our microbeads to encapsulate small colloids, such as oil droplets, can be exploited to encapsulate multiple types of small colloidal particles within a single microbead, in which different, sometimes incompatible, components can be encapsulated. As an example, we co-encapsulated an oil soluble component in oil droplets, and a water soluble component in vesicles, within single protein or alginate microbeads. 


\subsubsection{Coating of hydrogel microbeads}

\section{Coatings for ultrasound active microcapsules}

We first discuss the application of a shell around the oil-filled, hydrogel beads to create an ultrasound active delivery system. Ultrasound mediated drug delivery is the targeted release of medication, located in or on a microbubble, by the application of ultrasound. The bubble starts resonating upon application of ultrasound waves, because of the density contrast between the gas inside the bubble and the surrounding liquid. The bubble ruptures with application of enough energy, thereby releasing the medicine. One such system is the acoustically active liposphere, a system with a gas core stabilized by an oil and phospholipid layer (Figure 6.3, left). The oil layer in the vesicle wall must be of sufficient thickness to obtain an effective load of the liposome. But this viscous oil layer has a severe dampening effect on the ultrasound, and this means that the liposome needs high levels of energy to rupture [6]. The application of high intensity ultrasonic waves may however damage the surrounding tissue, which limits the application potential of such devices [7].
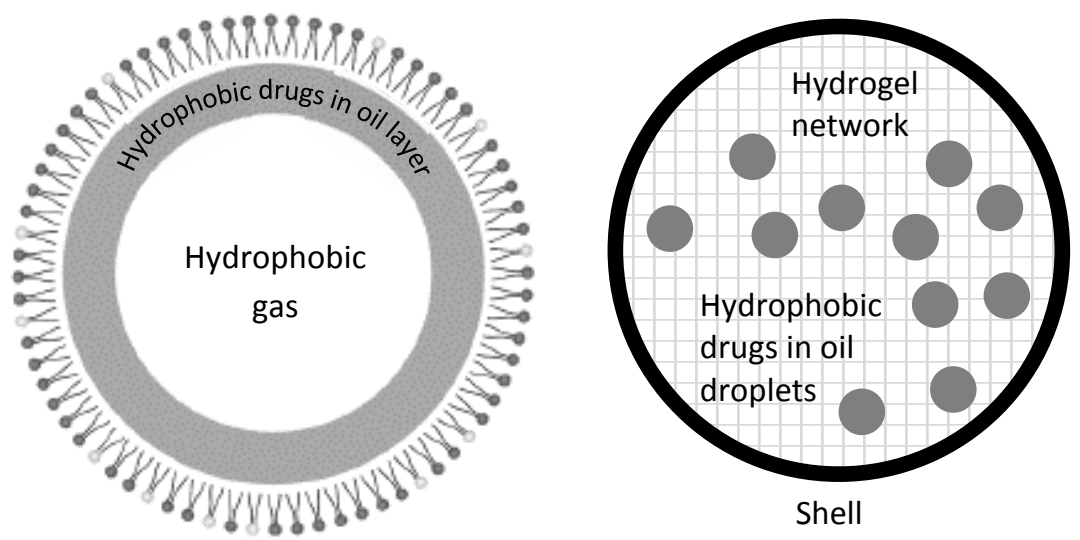

Figure 6.3: Schematic presentation of: Acoustically active liposphere [8] (left) and gas filled hydrogel matrix with shell and captured oil droplets (right).

Based on our microbeads, we attempted to construct an alternative to such systems: an air bubble with an internal structure with individual oil droplets (which contain the active component), captured in a network. We first created a hydrogel microbead with small oil droplets incorporated in its interior 
network, and then applied a coating to the surface of the microbead. We subsequently attempted to displace the aqueous phase from the hydrogel matrix, and replace it with a gas (Figure 6.3, right). The shell is necessary to retain the gas because the matrix is very permeable, even to molecules as large as proteins (18.4-66.5 $\mathrm{kDa}$ ), as we have found in chapters 3 and 4 . Adding an extra shell will reduce permeability.

Coatings can be applied in various ways, including but not limited to the emulsion-solvent evaporation, emulsion-coacervation, precipitation coating, layer by layer deposition (LbL) and spray drying [9-12]. All these systems can be used with a template, often emulsion droplets, in a solution of coating material, where the coating material deposits on the surface of the template. This is generally done in either of two ways. 1) Reducing the solubility of the polymer after which it precipitates on the template, for example by evaporating the solvent (spray drying and emulsion-solvent evaporation) or by changing environmental aspects such as $\mathrm{pH}$ or ionic strength (precipitation coating). 2) By binding the polymer to the surface of the bead through attractive interactions between the template and the coating material (emulsion-coacervation and $\mathrm{LbL}$ )

We applied a shell made by LbL deposition. LbL is a method where components of an opposite charge are deposited on a charged surface. By repeating this process structures with multiple layers can be made [12-19]. Alginate beads are negatively charged, so layer-by-layer deposition can be used for application of a shell. We applied LbL coatings on alginate microbeads using combinations of pectin, ovalbumin fibrils [20, 21], lysozyme fibrils [22] and vesicles [23] to create up to eight layers.

To make these structures ultrasound active, the water phase inside the bead needed to be replaced with gas to create the necessary density difference inside and outside the bead. We have attempted this by two different methods. Firstly by freeze drying the beads and removing all water. However the capsules were unable to keep out liquid upon resuspension in an aqueous phase. This is either because the structure was damaged during freeze drying (Figure 6.4), or because the LbL structure is not impermeable enough to keep out liquid. Even with the addition of a vesicle layer instead of only fibril layers, the shell might have still been too porous to keep out water molecules (18 Da) for an extended time. 


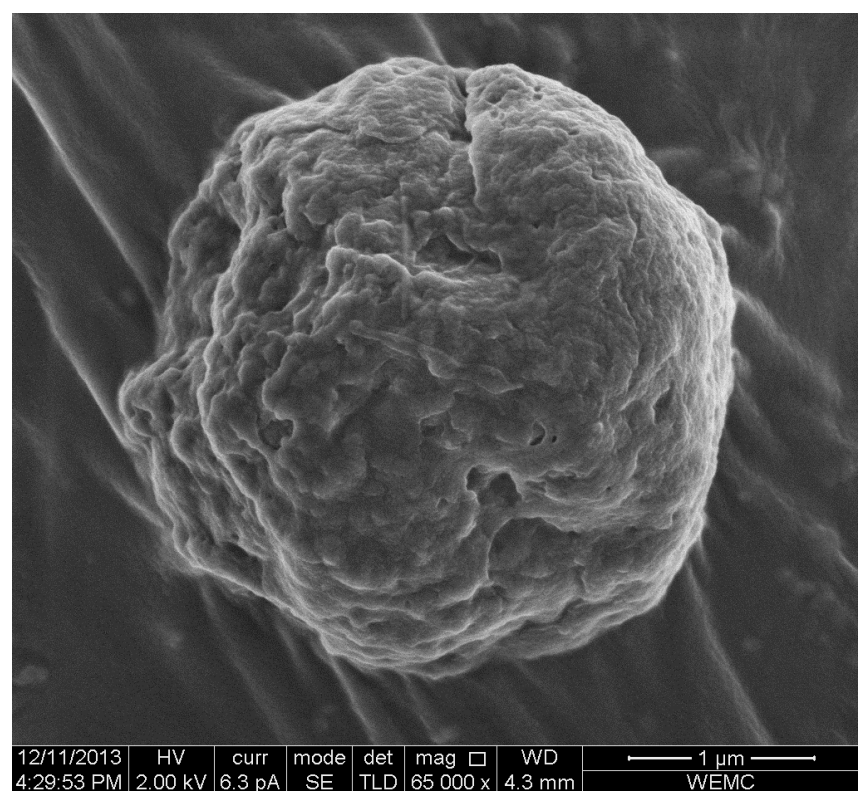

Figure 6.4: SEM image of a freeze dried alginate bead with 7 layers (vesicles and lysozyme and ovalbumin fibrils)

To avoid the freeze drying step we have also attempted to fill these capsules from the inside by using perfluoropentane $\left(\mathrm{C}_{5} \mathrm{~F}_{12}\right)$. This liquid is more often used in ultrasound active microbubbles [24-26]. $\mathrm{C}_{5} \mathrm{~F}_{12}$ is a liquid at room temperature $\left(20^{\circ} \mathrm{C}\right)$ and a gas at body temperature $\left(37^{\circ} \mathrm{C}\right)$. By co-encapsulating both the medicine and $\mathrm{C}_{5} \mathrm{~F}_{12}$, and then raising the temperature to $37^{\circ} \mathrm{C}$, the $\mathrm{C}_{5} \mathrm{~F}_{12}$ was expected to undergo a phase transition, displace the aqueous phase, and fill the capsule with gas. We found however that the liquid $\mathrm{C}_{5} \mathrm{~F}_{12}$ droplets were unable to undergo a phase transition into a gas state, even upon an increase of temperature to $80^{\circ} \mathrm{C}$. Part of that is explained by the small size of the $\mathrm{C}_{5} \mathrm{~F}_{12}$ droplets and the increase in Laplace pressure which prevents the expansion [27]. At $80^{\circ} \mathrm{C}$ some evaporation was however expected. It is likely that the gel structure did not allow for expansion or evaporation. In future studies, $\mathrm{C}_{5} \mathrm{~F}_{12}$ could be replaced with $\mathrm{C}_{4} \mathrm{~F}_{10}$, which has a lower boiling point, or ultrasound could be applied, which also aids evaporation, and may allow for evaporation and filling of the structure with gas. Also, the gel strength could be reduced by reducing the alginate or calcium concentration, thereby allowing for the expansion necessary during evaporation. 


\section{pH triggered LbL coating}

Coatings can also be activated by a change of $\mathrm{pH}$ in the environment. Many biological systems exhibit changes of $\mathrm{pH}$, such as the changes of $\mathrm{pH}$ which occur when food moves from the stomach to the intestine, or the decrease of the $\mathrm{pH}$ in sites of inflammation. The LbL method can create a shell which detaches upon a change of $\mathrm{pH}$. The shell is built of layers which attract each other, but when one of the layer materials can undergo a reversal in charge induced by a change in $\mathrm{pH}$, the layers will repel each other and detach from the surface of the bead. In our research we have chemically altered chitosan into carboxymethyl chitosan ( $\mathrm{CMCh})$. Chitosan is a molecule which is positively charged and soluble below $\mathrm{pH}$ 6.5, while neutral and insoluble above. When chemically adding carboxyl groups a polyampholyte is formed [28]. Three consecutive layers were deposited upon alginate microbeads. The layers were applied in a $50 \mathrm{mM}$ MOPS buffer at $\mathrm{pH} 7.5$, with the then negatively charged $\mathrm{CMCh}$ and positively charged polyallylamine hydrochloride (PAH). The third layer (PAH) was bound with FITC for observation with CLSM (Figure 6.5). At pH 7.5 (left) the entire beads were green, but there was a clear line around the beads. This means that the FITCPAH layer was able to coat the bead but that the FITC-PAH was also present inside the bead, thereby altering the characteristics of the beads. When the $\mathrm{pH}$ is lowered to where both $\mathrm{PAH}$ and $\mathrm{CMCh}$ are positive the coating is released (right). The inside of the beads remains green and small aggregates, presumably the coating material, were seen in the surrounding liquid. This means that the coating is only partly removed from the bead and that the coating is able to diffuse into the bead, thereby altering the characteristics of the encapsulation system. To prevent the diffusion of coating material into the beads one may use bigger, less flexible or branched coating materials, or decrease the porosity of the hydrogel, for example by increasing the hydrocolloid concentration. 

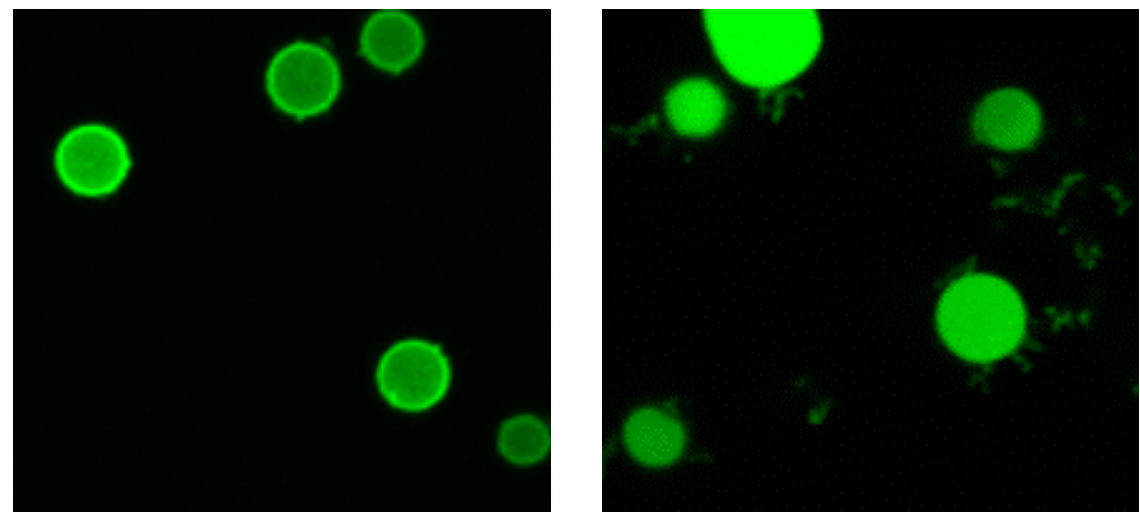

Figure 6.5: Alginate beads with 3 layers: $P A H-C M C h-P A H-F I T C$, at $p H$ 7.5 (left) and $\mathrm{pH} 4.9$ (right)

\section{pH triggered coating by precipitation-deposition}

Another attempt at creating a $\mathrm{pH}$ sensitive coating was made by precipitationdeposition instead of LbL. Here, a layer is made by making a soluble compound insoluble, which then precipitates onto the beads, forming a shell. Eudragit E PO (EE) is such a compound which has been more often used to coat tablets [29-32]. The EE was dissolved $\mathrm{pH} 3.5$, the alginate beads were added and then the $\mathrm{pH}$ was raised, dropwise, to $\mathrm{pH}$ 7.7. The coating was made visible in CLSM by adding quercetin. We see a green bead with a bright layer on the outside of the bead, which means that a coating was successfully applied but that the coating material, as with $\mathrm{PAH}$, diffused into the interior of the bead (Figure 6.6, left). There was also a significant degree of aggregation due to the neutral charge of the eudragit at this $\mathrm{pH}$. When decreasing the $\mathrm{pH}$ to remove the coating, we see that the bright layer disappears but the bead is still coloured and that the EE was thus not completely removed (Figure 6.6, right).

To summarize, coating of the beads has thus far been partly successful. The natural charge of the alginate bead allows for application of oppositely charged molecules thereby allowing shells to be made by both the LbL and deposition method. The application of the shell will reduce the porosity of the systems, though the exact degree of reduction has not been determined, and depends on the number of layers and the components the shells are made of. For the ultrasound active microbead the shell could not be made impermeable to water, but filling the bead from the inside with the highly insoluble 
perfluorocarbons remains an option. Another difficulty is the diffusion of coating material into the bead, thereby affecting the bead and possibly affecting the encapsulated material. Again, to prevent this bigger or less flexible coating materials should be used, or the porosity of the hydrogel should be decreased.
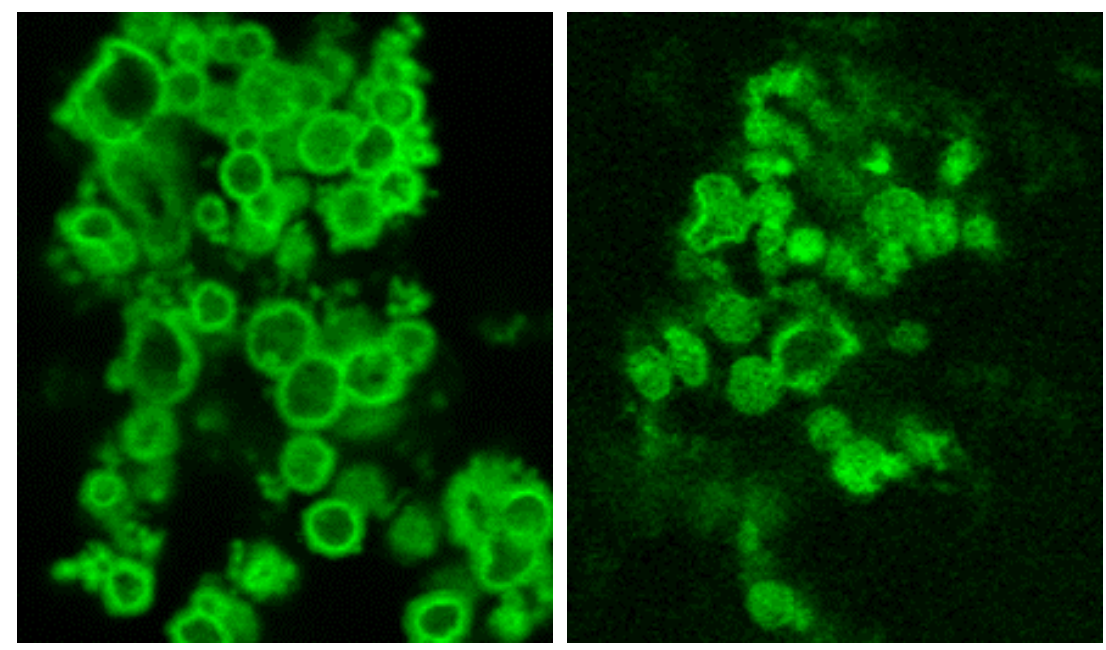

Figure 6.6: Alginate beads with deposited EE coatings at $\mathrm{pH} 7.7$ (left) and $\mathrm{pH}$ 5.5 (right)

\subsubsection{Co-encapsulation}

Another application we have investigated is co-encapsulation. Hydrogel beads allow for the encapsulation of multiple components simultaneously. This is advantageous when the components do not mix or have a synergistic effect. Vitamin $\mathrm{E}$ and $\mathrm{C}$ are examples of this. Vitamin $\mathrm{E}$ is an oil soluble component and can quench harmful radicals by donating a hydrogen atom. Vitamin $\mathrm{C}$ is water soluble and is able to convert the vitamin $\mathrm{E}$ radical back to its scavenging form. The combination of vitamin $\mathrm{E}$ and $\mathrm{C}$ lowered the oxidation rate of lipids more than the sum of the individual components [33, 34]. Both vitamin $\mathrm{E}$ and $\mathrm{C}$ are quite unstable and have been shown to be more stable when encapsulated [35-41]. These two compounds can be encapsulated together in protein microbeads.

Both curcumin and catechin can prevent several types of cancer [42-46]. Curcumin is a lipophilic component and catechin a hydrophilic component. 
Research suggest that a combination of both compounds is more effective in preventing colon cancer in rats than one compound alone [47, 48]. These two compounds can also be encapsulated simultaneously in the alginate microbeads we have developed.

The hydrophilic and hydrophobic compounds were encapsulated by enclosing them first within their own colloidal sub-system, respectively liposomes and MCT nanodroplets, which were then embedded into the microbeads during gelation (Figure 6.7). Liposomes were made of cholesterol, Epikuron 200 and Tween 80. The mixture was dissolved in chloroform, dried in a rotary evaporator, redispersed in a solution with the respective component, and sonicated. The nanodroplets were made by mixing the hydrophobic component with MCT and emulsifying it into nanodroplets. The liposomes, nanodroplets and hydrocolloid were mixed and made into hydrogel microbeads by methods similar to what is described in chapters 3 and 5 .

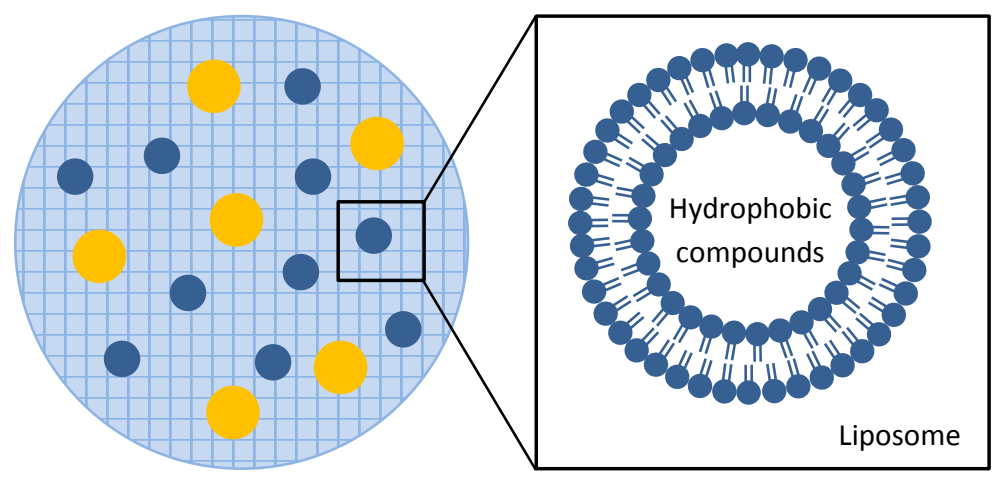

Figure 6.7: Schematic representation of co-encapsulation of oil droplets and liposomes (enlarged) in a hydrogel microbead

CLSM images strongly suggest that liposomes and oil droplets can successfully and simultaneously be encapsulated in protein microbeads. Figure 6.8 shows CSLM images of the beads from the normal light channel, which shows the oil droplets and alginate beads, and a channel with specifically the light emitted by sulforhodamin B, which shows the presence of the liposomes. In sample A only liposomes were encapsulated and Figure 6.8 A1 shows liposomes but A2 shows there are no visible structures present within the beads. In sample B only oil droplets are encapsulated and those 
structures are visible within the beads. In sample $\mathrm{C}$ both oil droplets and liposomes were encapsulated. Figure $\mathrm{C} 1$ shows that the liposomes are present and $\mathrm{C} 2$ shows that the oil droplets are present within the same sample.
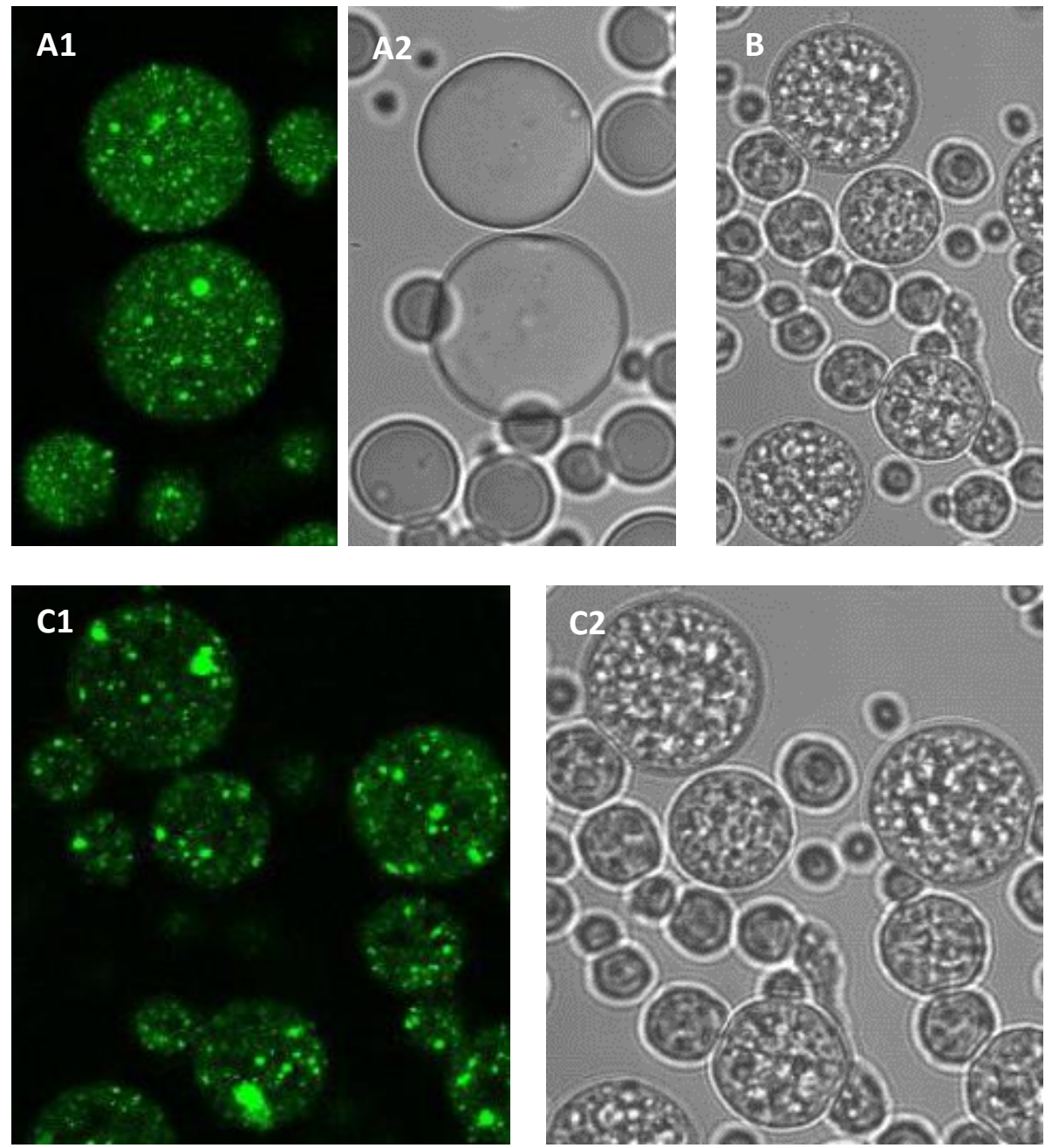

Figure 6.8: WPI as encapsulation devices for liposomes and oil droplets. A1 and A2: liposomes, B: oil droplets, $C$ both liposomes (1) and oil droplets (2) 
We attempted to determine the encapsulation efficiency of the beads. Analysis found that vitamin $\mathrm{E}$ is present in the oil droplets, though the encapsulation efficiency could not be reliably determined. The presence of vitamin $C$ could not be proven because we were unable to successfully extract the liposomes from the protein microbeads. Liposomes and oil droplets were also successfully co-encapsulated in alginate microbeads. Catechin was detected in the beads after encapsulation, though again, the amount could not be reliably determined. Curcumin was only found in very low concentrations, most likely because, though curcumin is known as a hydrophobic compound, it remains very slightly water soluble. The amount of water far supersedes the amount of oil present in the samples, mostly during the washing of the beads during production, thereby most likely washing the curcumin from the system.

Liposomes and emulsion droplets can thus be co-encapsulated in both protein and alginate microbeads but the presence of the encapsulated components was difficult to quantify, mostly due to inadequate extraction methods. Possibly the effectiveness of the encapsulation systems, rather than the concentration of the components, can be more easily proven.

\subsection{Concluding remarks and outlook}

In this thesis we investigated hydrogel microbeads as encapsulation systems and the relation between their production methods, microstructure and characteristics. Hydrogel microbeads can be made from a variation of hydrocolloids which can be gelled with various methods. The strength and breakdown profile is important for the applicability of the microbeads, because the beads offer the most protection if they remain intact. The diffusivity of molecules in the bead determines the release profile of the encapsulated compound and the protection from outside influences.

Factors which showed the largest influence on the rate of diffusion of compounds into the beads were the ionic strength of the environment, and the function of the diffusing component. A low ionic strength can increase the Debye length to such an extent that the component can be completely excluded from the matrix. The diffusion time could be increased from several minutes up to an hour, if the diffusing component was enzymatically active inside the 
bead. The size of the bead does not slow diffusion but may slow the digestion of a component caught within the bead, because of the different surface to volume ratio of micro- and macrobeads. Production method, hydrocolloid type and density, and size of the component seem to have a limited influence on the amount of component able to diffuse into the bead, and the rate of diffusion. Cold-set gelation does delay diffusion of components slightly because of the high hydrocolloid density at the interface, especially of the WPI beads. The process of cold-set gelation is however especially important to the bead strength; more important than the hydrocolloid type. The gelation method was also especially important to the breakdown rate of WPI microbeads. Not because they significantly altered the visible microstructure of the beads (except for the cold-set beads), but more likely because it made it harder for the pepsin to hydrolyse the protein strands of the matrix.

A partly reversible coating may be applied using the opposing charges of the bead and the coating material. The diffusion of components into the beads may be reduced by the extra coating but the extent depends on the methods and materials used. The coating material is however also able to diffuse into the bead, due to the opposing charges of the matrix and the coating material and the high ionic strength usually present during the coating process. This will irreversibly change the characteristics of the beads.

Both alginate and protein microbeads are capable of encapsulating several different smaller systems, such as oil droplets and vesicle, at the same time. These smaller systems may be used to encapsulated their own hydrophobic and hydrophilic components.

An important step to the applicability of these encapsulation devices is size control. The current process uses emulsification with a mixer, which gives a wide size distribution in microcapsules. If the microbeads are too large in food products the food will acquire negative sensorial aspects such as graininess. In the future these beads may also be used for biomedical applications. For intravenous use a tight control of the bead size is imperative, because if beads are too large they may block blood vessels which can lead to tissue death.

Another recommendation is to look further into the application of a coating. Current beads are able to retain microsystems of approximately $50 \mathrm{~nm}$ to several $\mu \mathrm{m}$. No proteins were completely excluded from the microbeads, 
though the amount that could diffuse in could be reduced. The application of a coating could reduce the amount of outside compounds diffusing in and thereby increase the degree of protection. We successfully applied coatings but have primarily looked into coating with fibrillar structures, which were also able to diffuse into the beads thereby irreversibly changing the beads. To exclude the coating material from the bead interior larger, less flexible or branched coating materials may offer a solution or reducing the porosity of the hydrogel bead by increasing the hydrocolloid concentration.

Beads described as in this thesis are already applicable as encapsulation devices, especially for encapsulation of oil soluble materials in food products. The release profile has however only been investigated in vitro. The actual effect and uptake of the encapsulated materials in vivo is unknown and needs to be explored to assess the usefulness of the hydrogel microbeads in actual food products.

In conclusion, the hydrogel microbeads investigated in this thesis have shown different strengths, breakdown behaviours and diffusivity profiles. The functionality of these hydrogel microbeads was not dependent on individual factors, such as gelation method or the hydrocolloid type. Instead the functionality depends on a complicated system in which the matrix, the diffusing component and the environment all play varying but important roles in the final system. In this thesis we have built a framework on how to balance the importance of these factors based on the entire system. Additionally, we have continued research into increasing the microbead functionality and considered future applications. The microbeads are already a viable encapsulation device, but they may also form a basis for more complicated encapsulation and triggered release systems. 


\section{References}

1. Bryant, C.M. and D.J. McClements, Molecular basis of protein functionality with special consideration of cold-set gels derived from heat-denatured whey. Trends in Food Science \& Technology, 1998. 9(4): p. 143-151.

2. Malamud, D. and J.W. Drysdale, Isoelectric points of proteins: A table. Analytical Biochemistry, 1978. 86(2): p. 620-647.

3. Draget, K.I., G. Skjåk Bræk, and O. Smidsrød, Alginic acid gels: the effect of alginate chemical composition and molecular weight. Carbohydrate Polymers, 1994. 25(1): p. 31-38.

4. van Leusden, P., et al., Permeation of probe molecules into alginate microbeads: Effect of salt and processing. Food Hydrocolloids, 2017. 73(Supplement C): p. 255261.

5. Donner, J., Preparation of porcine pancreatic lipase free of co-lipase activity. Acta chem. scand. B, 1976. 30(5).

6. Shortencarier, M.J., et al., A method for radiation-force localized drug delivery using gas-filled lipospheres. IEEE transactions on ultrasonics, ferroelectrics, and frequency control, 2004. 51(7): p. 822-831.

7. Unger, E.C., et al., Acoustically active lipospheres containing paclitaxel: A new therapeutic ultrasound contrast agent Investigative Radiology, 1998. 33(12): p. 886892.

8. Lentacker, I., S.C. De Smedt, and N.N. Sanders, Drug loaded microbubble design for ultrasound triggered delivery. Soft Matter, 2009. 5(11): p. 2161-2170.

9. Rosca, I.D., F. Watari, and M. Uo, Microparticle formation and its mechanism in single and double emulsion solvent evaporation. Journal of controlled release, 2004. 99(2): p. 271-280.

10. Lertsutthiwong, P., P. Rojsitthisak, and U. Nimmannit, Preparation of turmeric oilloaded chitosan-alginate biopolymeric nanocapsules. Materials Science and Engineering: C, 2009. 29(3): p. 856-860.

11. Tirpude, R.N. and P.K. Puranik, Rabeprazole sodium delayed-release multiparticulates: Effect of enteric coating layers on product performance. Journal of advanced pharmaceutical technology \& research, 2011. 2(3): p. 184.

12. Johnston, A.P.R., et al., Layer-by-layer engineered capsules and their applications. Current Opinion in Colloid \&amp; Interface Science, 2006. 11(4): p. 203-209.

13. Ghosh, S.K., Functional coatings: by polymer microencapsulation. 2006: John Wiley \& Sons.

14. Rossier-Miranda, F.J., K. Schroën, and R. Boom, Mechanical Characterization and pH Response of Fibril-Reinforced Microcapsules Prepared by Layer-by-Layer Adsorption. Langmuir, 2010. 26(24): p. 19106-19113.

15. Borden, M.A., et al., DNA and Polylysine Adsorption and Multilayer Construction onto Cationic Lipid-Coated Microbubbles. Langmuir, 2007. 23(18): p. 9401-9408.

16. De Geest, B.G., et al., Ultrasound-Triggered Release from Multilayered Capsules. Small, 2007. 3(5): p. 804-808.

17. Decher, G., J.D. Hong, and J. Schmitt, Buildup of ultrathin multilayer films by a selfassembly process: III. Consecutively alternating adsorption of anionic and cationic polyelectrolytes on charged surfaces. Thin Solid Films, 1992. 210-211, Part 2(0): p. 831-835.

18. Liu, J., et al., Magnetically sensitive alginate-templated polyelectrolyte multilayer microcapsules for controlled release of doxorubicin. The Journal of Physical Chemistry C, 2010. 114(17): p. 7673-7679. 
19. Skirtach, A.G., et al., Ultrasound stimulated release and catalysis using polyelectrolyte multilayer capsules. Journal of Materials Chemistry, 2007. 17(11): p. 1050-1054.

20. Humblet-Hua, K.N.P., et al., Encapsulation systems based on ovalbumin fibrils and high methoxyl pectin. Food Hydrocolloids, 2011. 25(4): p. 569-576.

21. Veerman, C., et al., Irreversible self-assembly of ovalbumin into fibrils and the resulting network rheology. International Journal of Biological Macromolecules, 2003. 33(1-3): p. 121-127.

22. Humblet-Hua, N.-P.K., E. van der Linden, and L.M.C. Sagis, Microcapsules with Protein Fibril Reinforced Shells: Effect of Fibril Properties on Mechanical Strength of the Shell. Journal of Agricultural and Food Chemistry, 2012. 60(37): p. 9502-9511.

23. Michel, M., et al., Layer by Layer Self-Assembled Polyelectrolyte Multilayers with Embedded Phospholipid Vesicles. Langmuir, 2004. 20(12): p. 4835-4839.

24. Grayburn, P., Perflenapent emulsion (echogen $\AA$ ): A new long-acting phase-shift agent for contrast echocardiography. Clinical cardiology, 1997. 20(S1): p. 12-18.

25. Fabiilli, M.L., et al., Delivery of Chlorambucil Using an Acoustically-Triggered Perfluoropentane Emulsion. Ultrasound in Medicine \& Biology, 2010. 36(8): p. 1364-1375.

26. Fabiilli, M.L., et al., Acoustic droplet-hydrogel composites for spatial and temporal control of growth factor delivery and scaffold stiffness. Acta Biomaterialia, 2013. 9(7): p. 7399-7409.

27. Rapoport, N.Y., et al., Controlled and targeted tumor chemotherapy by ultrasoundactivated nanoemulsions/microbubbles. Journal of Controlled Release, 2009. 138(3): p. 268-276.

28. Chen, X.-G. and H.-J. Park, Chemical characteristics of O-carboxymethyl chitosans related to the preparation conditions. Carbohydrate Polymers, 2003. 53(4): p. 355359.

29. Li, J., et al., Curcumin-Eudragit ${ }^{\circledR}$ E PO solid dispersion: A simple and potent method to solve the problems of curcumin. European Journal of Pharmaceutics and Biopharmaceutics, 2015. 94: p. 322-332.

30. Cerea, M., et al., A novel powder coating process for attaining taste masking and moisture protective films applied to tablets. International Journal of Pharmaceutics, 2004. 279(1-2): p. 127-139.

31. Li, J., et al., In vitro evaluation of dissolution behavior for a colon-specific drug delivery system (CODES ${ }^{\mathrm{TM}}$ ) in multi-pH media using United States Pharmacopeia apparatus II and III. AAPS PharmSciTech, 2002. 3(4): p. 59.

32. Yang, L., et al., Effect of Colonic Lactulose Availability on the Timing of Drug Release Onset in Vivo from a Unique Colon-Specific Drug Delivery System (CODESTM). Pharmaceutical Research, 2003. 20(3): p. 429-434.

33. Niki, E., Interaction of Ascorbate and $\alpha$-Tocopherol. Annals of the New York Academy of Sciences, 1987. 498(1): p. 186-199.

34. Yeum, K.-J., et al., Synergistic interactions of antioxidant nutrients in a biological model system. Nutrition, 2009. 25(7): p. 839-846.

35. de Lourdes Samaniego-Vaesken, M., E. Alonso-Aperte, and G. Varela-Moreiras, Vitamin food fortification today. Food \& nutrition research, 2012. 56(1): p. 5459.

36. Yang, S., et al., Characterization and bioavailability of vitamin $C$ nanoliposomes prepared by film evaporation-dynamic high pressure microfluidization. Journal of Dispersion Science and Technology, 2012. 33(11): p. 1608-1614.

37. Alishahi, A., et al., Shelf life and delivery enhancement of vitamin C using chitosan nanoparticles. Food Chemistry, 2011. 126(3): p. 935-940.

38. Kirby, C., et al., Stabilization of ascorbic acid by microencapsulation in liposomes. International journal of food science \& technology, 1991. 26(5): p. 437-449. 


\section{Chapter 6}

39. Yang, Y. and D.J. McClements, Encapsulation of vitamin E in edible emulsions fabricated using a natural surfactant. Food Hydrocolloids, 2013. 30(2): p. 712-720.

40. Marsanasco, M., et al., Liposomes as vehicles for vitamins $E$ and $C$ : An alternative to fortify orange juice and offer vitamin $C$ protection after heat treatment. Food research international, 2011. 44(9): p. 3039-3046.

41. Chiu, Y. and W. Yang, Preparation of vitamin E microemulsion possessing high resistance to oxidation in air. Colloids and surfaces, 1992. 63(3-4): p. 311-322.

42. Anand, P., et al., Curcumin and cancer: an "old-age" disease with an "age-old" solution. Cancer letters, 2008. 267(1): p. 133-164.

43. Aggarwal, B.B., A. Kumar, and A.C. Bharti, Anticancer potential of curcumin: preclinical and clinical studies. Anticancer research, 2003. 23(1/A): p. 363-398.

44. Johnson, J.J. and H. Mukhtar, Curcumin for chemoprevention of colon cancer. Cancer letters, 2007. 255(2): p. 170-181.

45. Shukla, Y. and J. George, Combinatorial strategies employing nutraceuticals for cancer development. Annals of the New York Academy of Sciences, 2011. 1229(1): p. $162-175$.

46. Yang, C.S., P. Maliakal, and X. Meng, Inhibition of carcinogenesis by tea. Annual review of pharmacology and toxicology, 2002. 42(1): p. 25-54.

47. $\mathrm{Xu}, \mathrm{G}$. , et al., Combination of curcumin and green tea catechins prevents dimethylhydrazine-induced colon carcinogenesis. Food and chemical toxicology, 2010. 48(1): p. 390-395.

48. Li, Y., et al., Control of lipase digestibility of emulsified lipids by encapsulation within calcium alginate beads. Food Hydrocolloids, 2011. 25(1): p. 122-130. 
Summary 
Encapsulation is the process in which a component is enclosed within a larger system to protect the component from outside influences and, if necessary, to release the component at the optimal time and location. Hydrogel microbeads are such systems and have successfully encapsulated components such as cells, oil droplets, vesicles, drugs and other compounds. The degree of protection the hydrogel beads offer to encapsulated components depends on their strength, their breakdown rate and the diffusivity of components into the beads. In this thesis, 'Effects of structure on hydrogel microbead function', we related hydrogel microbead production to their microstructure and resulting functionality as encapsulation devices.

In chapter 2 the influence of the production method on the strength of microbeads was studied. We varied the hydrocolloid type (alginate vs WPI), gelling agent (acid vs calcium) and gelling mechanism (internal vs external) and looked at the integrity of the microbeads after application of shear. We found that both alginate and WPI beads made with external calcium gelation had a very smooth microstructure and were strong enough to stay intact after the shear applied by the homogeniser. This means that the gelling agent and method of gelation were more important than the hydrocolloid from which the beads were made.

In chapter 3 , the relation between production method and the breakdown rate of WPI microbeads was investigated. Oil droplets were caught in the WPI network and the beads were gelled in various ways after which the release of the oil droplets was followed in a simulated gastric system. Pepsin diffused quickly into the heat-set beads where the standard, $25 \%$ heat-set beads broke down in 48 minutes. Decreasing the protein content of the beads increased breakdown rate. Freeze drying delayed the breakdown rate because the beads needed to be rehydrated before the pepsin could access the interior of the bead. Increasing the heating rate delayed the breakdown rate because the protein strands were more resistant to hydrolysis. Producing the beads with cold-set gelation slightly delayed the breakdown of the beads, because the finer microstructure slowed the diffusion of pepsin into the bead.

In chapter 4 we investigated the uptake of FITC-labelled, protein probe in alginate micro- and macrobeads at equilibrium. The microbeads (approximately $10 \mu \mathrm{m}$ ) were made by emulsification and macrobeads (approximately $1 \mathrm{~mm}$ ) were made by dripping an alginate solution into a 
calcium salt bath. Diffusion of the probes into the beads was fast and equilibrium set in within several minutes. The uptake of probe in the beads increased with decreasing alginate concentration and lower amounts of cross linking by calcium. Macrobeads had higher concentrations of probe in their interior than the microbeads, because of the different gelation methods. The ionic strength of the environment was found to be important to the internal concentration of probe molecules because it strongly influences the Debye length. When decreasing the salt concentration the effective radius of the alginate matrix pores decrease and the effective radius of the diffusing components increase.

In chapter 5, the diffusion of lipase into the same networks as in chapter 4, but filled with oil droplets, in a simulated intestinal system was followed. Encapsulation of the oil droplets delayed the digestion of the oil when compared to free oil droplets. The oil in microbeads was digested much faster than in macrobeads because of the higher surface to volume ratio. When investigating the diffusion of lipase into the beads microscopically, it could be seen that there was a clear front of oil droplet digestion moving from the bead interface to the centre. The displacement of the front scaled linear with time. The movement was described by a Maxwell-Cattaneo type equation for the mass flux, instead of the normally used Fick's law.

In chapter 6 we integrate the results from the previous chapters. In this thesis we specifically investigated the influence of the production of the gelled matrix, the characteristics of the diffusing component and the ionic strength of the environment on the strength, breakdown rate and diffusion of components into hydrogel microbeads. We concluded that the production method is the most important factor that determines bead strength and may also influence the digestion rate of the matrix. Microbeads are porous systems where small systems, such as oil droplets, can be retained but diffusion of smaller components, such as proteins, is fast. Production method, hydrocolloid type and density, and size of the component have limited influence on the final uptake and rate of diffusion within the beads. Only a low ionic strength is able to completely exclude components from the bead interior. The diffusion of a component into the bead can be delayed if the component is trapped by facilitating a reaction. The size of the bead does not 
slow the diffusion rate but slows the digestion of a component caught within the matrix, because of the different surface to volume ratios.

In chapter 6 we also discuss methods to increase the functionality of the hydrogel microbeads as encapsulation devices and we discuss several applications. Because we found that hydrogel microbeads are porous systems, we applied shells around the beads to reduce the diffusion of molecules into the beads. Shells could be applied around the bead, but because the coating material also diffused and deposited inside the bead the shell was not reversible and altered the nature of the beads. These beads could not be made ultrasound active by replacing the liquid in the interior by gas, because the capsules could not be filled with or retain the gas adequately. Coencapsulation by retaining vesicles, with hydrophobic components, and oil droplets, with hydrophilic components, within the gelled matrix was successful, though exact concentrations of the encapsulated materials could not be determined.

To conclude, we have shown that hydrogel microbead functionality is not dependent on individual factors, but on an integrated system in which the matrix, diffusing components and microbead environment play varying but important roles. We have also shown that the hydrogel microbeads discussed here are already an applicable encapsulation system and may also form a starting point for more complicated encapsulation systems. 




\section{Acknowledgements}

Many people have contributed to the completion of this thesis. I hereby would like to, shortly, take the opportunity to thank you all. (Besides, you all know who you are!)

First I would like to thank my Wageningen supervisors, Leonard and Erik, for your support, enthusiasm, patience (and chocolate!) during this project. I would also like to thank my external supervisors, Gertjan, Michiel and Aalt, for their contribution and support throughout my thesis. Additionally, I would like to thank all the students who did their thesis projects on my subject and thereby contributed to this thesis.

Then there are many people, friends and colleagues, old and new, who have made my work so much more enjoyable. I, possibly, could have done it without you guys, but not so easily nor with so much fun.

Stefan, I want to thank you for still standing beside me, supporting me and loving me. It cannot have been easy, but I am so happy that you are here.

Most of all I want to thank my family, the people who have nurtured, supported and shaped me throughout my life. I love you very, very much and I am extremely grateful that you are here, and that you are mine. 

About the author 


\section{Curriculum Vitae}

Pauline van Leusden was born on the $17^{\text {th }}$ of May, 1988, in Eindhoven. She attended the Eckart college in Eindhoven, where she received her VWO diploma in 2006.

She started her study Food Technology at Wageningen University in the same year, where she received her BSc degree in 2009. She continued studying Food Technology with the specialisation Ingredient Functionality.

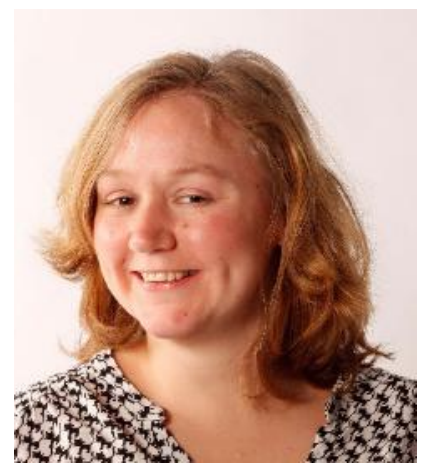
During her MSc thesis she looked at physical instability in hypoallergenic, ready-to-feed baby food in collaboration with Royal FrieslandCampina. For her internship she went to Melbourne, Australia, where she worked at CSIRO and investigated the effect of pulsed electric field processing and kiwi juice on the stability and quality of orange juice.

After graduating in 2012, she started working as a $\mathrm{PhD}$ researcher at Wageningen University in the department of Physics and Physical Chemistry of Foods. The results of her research are presented in this thesis.

Email: paulinevanleusden@gmail.com 


\section{List of publications}

P. van Leusden, G.J.M. den Hartog, A. Bast, M. Postema, E. van der Linden, L.M.C. Sagis (2016) Strength of microbeads for the encapsulation of heat sensitive, hydrophobic components, Food Hydrocolloids, 56, 318-324

P. van Leusden, G.J.M. den Hartog, A. Bast, M. Postema, E. van der Linden, L.M.C. Sagis (2016) Structure engineering of filled protein microbeads to tailor release of oil droplets in gastric digestion, Food \& Function, 7, 35393547

P. van Leusden, G.J.M. den Hartog, A. Bast, M. Postema, E. van der Linden, L.M.C. Sagis (2017) Permeation of probe molecules into alginate microbeads: Effect of salt and processing, Food Hydrocolloids, 73, 255-261

P. van Leusden, G.J.M. den Hartog, A. Bast, M. Postema, E. van der Linden, L.M.C. Sagis. Lipase diffusion in oil-filled, alginate micro- and macrobeads. Submitted 


\section{Overview of completed training activities}

\section{Discipline specific activities}

International symposium on food rheology and structure, Zurich, CH, 2012 COST meeting, Lunteren, NL, 2012

School on surface and technology, Geneva, CH, 2013

European student colloid conference, Potsdam, DE, 2013

Rheology school, Leuven, BE, 2013

Food Colloids, Karlsruhe, DE, 2014

International symposium on food rheology and structure, Zurich, CH, 2015 Mini-symposium ETH, Zurich, CH 2015

Food colloids, Wageningen, NL, 2016

\section{General courses}

Competence assessment, VLAG, Wageningen, NL, 2012

VLAG PhD week, VLAG, Baarlo, NL, 2012

Project and time management, WGS, Wageningen, NL, 2012

Teaching and supervising a master thesis, ESD, Wageningen, NL, 2012

Interpersonal communication for PhD students, WGS, Wageningen, NL, 2012

Scientific writing, WGS, Wageningen, NL, 2014

Techniques for writing and presenting a Scientific paper, WGS, Wageningen, NL, 2014

Mobilising your scientific network, WGS, Wageningen, NL, 2015

Voice matters, WGS, Wageningen, NL, 2015

Career orientation, WGS, Wageningen, NL, 2015

\section{Optional activities}

Preparation of research proposal, Wageningen, NL, 2012 FPH-group theme meetings, Wageningen, NL, 2012-2017 VLAG PhD council, Wageningen, NL, 2013-2014

PhD study tour, US and CA, 2014 
The research described in this thesis was financially supported by the Graduate School VLAG

Cover pictures: Ed van Leusden

Printed by: ProefschriftMaken, 75 copies 


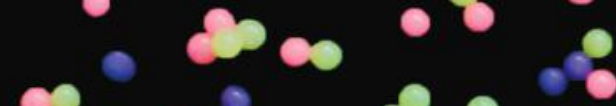

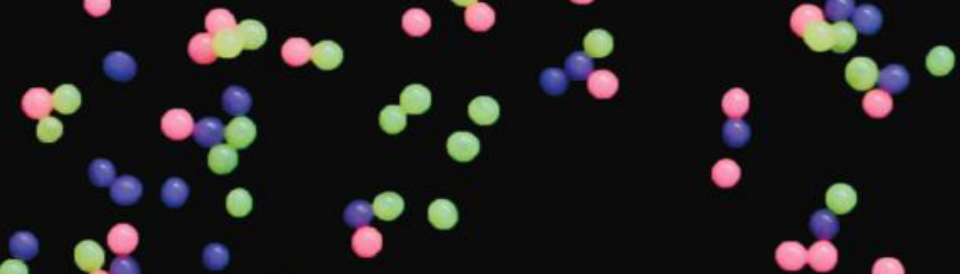
$88: 8 \%$

$\bullet$

$\bullet$

-

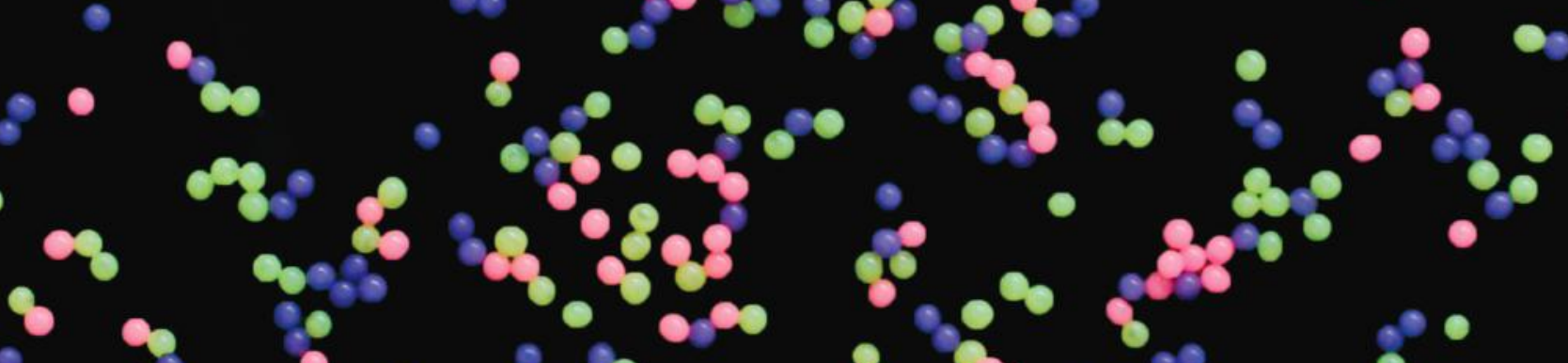

$\circ$

$\circ$ -

-

9

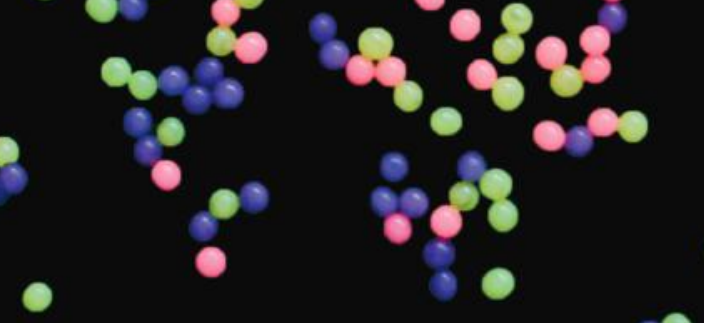

- 8.80

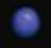

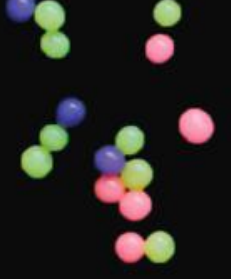

- \&

8

$3^{\circ} 83$

$\bullet$

-

$83^{3} \cdot 8^{8}$

$\therefore \circ-80$

$-6$

$\because \bullet$

$\bullet$

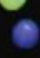

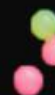

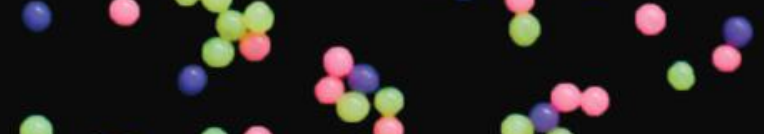

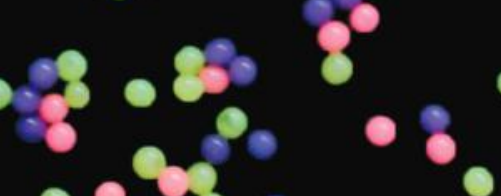

- 2000

$-8+30$ $\int_{0}^{\infty} 8_{0}^{\infty}$

0

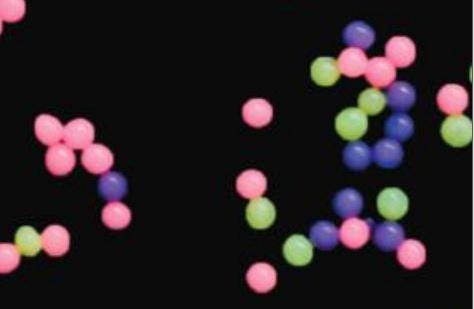

